\title{
THE ASSOCIATION BETWEEN MEDICAL EDUCATION ACCREDITATION AND THE EXAMINATION PERFORMANCE OF INTERNATIONALLY EDUCATED PHYSICIANS SEEKING CERTIFICATION IN THE UNITED STATES
}

A Dissertation
Submitted to
the Temple University Graduate Board
in Partial Fulfillment
of the Requirements for the Degree
DOCTOR OF PHILOSOPHY
barta van Zanten
May 2012

Examining Committee Members:

Ian A. Greaves, M.D., Chair, Temple University College of Health Professions and Social Work Eugene Komaroff, Ph.D., Associate Professor, Temple University College of Health Professions and Social Work

Gerald H. Sterling, M.D., Senior Associate Dean for Education, Temple University School of Medicine

Carol A. Aschenbrener, M.D., External Member, Chief Medical Education Officer, Association of American Medical Colleges 


\begin{abstract}
Background

Physicians do not always provide appropriate patient care, due in part to inadequacy in their education and training. Performance outcomes, such as individuals' examination scores have been linked to future performance as physicians, accentuating the need for high-quality educational institutions. While the medical school accreditation process in the United States assures a uniform standard of quality, approximately one quarter of physicians in training and in practice in the United States graduated from medical schools located outside of the United States or Canada. These graduates of international medical schools (IMGs) have been more likely than domestically educated doctors to practice primary care and treat underserved and minority populations. An increasing proportion of IMGs who seek to enter post-graduate training programs and subsequent licensure in the United States graduated from medical schools located in the Caribbean. The quality of medical education at some of these schools has been questioned.
\end{abstract}

Accreditation systems are frequently viewed as a way to ensure the quality of medical education, although currently there is limited data linking an educational oversight mechanism to better performance of the graduates. In addition, accreditation systems vary in the methodology, standards, and procedures used to evaluate educational programs. The purpose of the first phase of the present research was to examine medical education accreditation practices around the world, with special focus on the Caribbean region, to determine the association of accreditation of medical schools with student/graduate performance on examinations. The aim of the second 
phase of this research was to evaluate the quality of a select group of accrediting agencies and the association of quality with student/graduate outcomes.

Methods

All IMGs seeking to enter graduate training positions in the United States must first be certified by the Educational Commission for Foreign Medical Graduates (ECFMG). In addition to other requirements, ECFMG certification includes passing scores on the United States Medical Licensing Examination (USMLE) Step 1 (basic science), Step 2 Clinical Knowledge (CK), and Step 2 Clinical Skills (CS).

In the first phase, all IMGs taking one or more examinations leading to ECFMG certification during the five-year study period (January 1, 2006 through December 31, 2010), and who graduated from, or attended at the time of testing, a school located in a country that met the accreditation inclusion criteria, were included in the study population. First-attempt pass rates for each examination were calculated based on personal variables (gender, years elapsed since graduation at the time the individual took an examination $[<3$ years versus $\geq 3$ years], native language [English versus all others]), and on accreditation status of an individual's medical school. Next, separately for each examination, a generalized estimating equations model was used to investigate the effect of accreditation after controlling for the personal variables. Following the assessment of accreditation on test performance at the global level, the same analyses were conducted separately on the data from students/graduates who attended medical schools located in the Caribbean, and on the data from students/graduates who attended medical school not located in the Caribbean.

In the second phase, the quality of a select group of accrediting agencies was evaluated according to the criteria determined by a panel of experts to be the most salient features of an 
accreditation system. Accreditation systems that used $80 \%$ or more of the criteria were given a quality grade of A, and systems using less than $80 \%$ of the criteria were given a grade of B. The association between the quality of an accreditation system and student performance, as measured by first-attempt pass rates on USMLE, was investigated in this second phase.

The Temple University Office for Human Subject Protections Institutional Review Board determined by expedited review that this study qualified for exemption status.

Results

As of January 2011, there were 173 countries with medical schools listed in the International Medical Education Directory (IMED), of which 118 met the inclusion criteria. During the study period approximately 67,000 students/graduates took Step 1 for the first time, 55,600 took Step 2 CK, and 58,200 took Step 2 CS. Over one quarter of the test takers graduated from, or were students at, schools located in the Caribbean.

For the global population, better performance on Step 1 was associated with the male gender, testing within three years of graduation, non-native English-speaking status, and attending a school located in a country with a system of accreditation. For the Caribbean population on Step 1, results were similar, except native English speakers outperformed nonnative English speakers. After controlling for covariates, the odds of passing Step 1 for those from accredited schools were 1.8 times greater for the global group and 4.9 times greater for the Caribbean group as compared to the odds of passing the examination on the first attempt for individuals from nonaccredited schools. In contrast, in the non-Caribbean group accreditation was not associated with examination performance.

Increased performance on Step $2 \mathrm{CK}$ for the global group was associated with the female gender, testing within three years of graduation, non-native English-speaking status, and 
attending a school located in a country with a system of accreditation. For the Caribbean population on Step $2 \mathrm{CK}$, females, those testing closer to graduation, and native English speakers outperformed their counterparts. After controlling for covariates, the odds of passing Step 2 CK for those from accredited schools were 1.3 times greater for the global group and 2.3 times greater for the Caribbean group as compared to individuals from nonaccredited schools. Accreditation was not associated with examination performance for the non-Caribbean group.

For all three groups (global, Caribbean, and non-Caribbean), better performance on Step 2 CS was associated with the female gender, testing within three years of graduation, native English- speaking status, and attending a school located in a country with a system of accreditation. After controlling for covariates, the odds of passing Step 2 CS for those from accredited schools were 1.3 times greater for the global group, 2.4 times greater for the Caribbean group, and 1.1 times greater for the non-Caribbean group compared to individuals from nonaccredited schools.

In phase two, the expert panel unanimously agreed on 14 essential standards that should be required by accrediting agencies to ensure the quality of physicians. Of the accreditation systems in 18 countries that were analyzed for inclusion of the criteria, four systems, used in 10 countries, were given a grade of A (included $80 \%$ or more of the essential standards), and eight systems, used in eight countries, were given a grade of B (included less than $80 \%$ of the essential standards). The IMGs attending medical schools accredited by a system that received a grade of A performed better on Step 1 and Step 2 CS as compared to IMGs attending medical schools that are accredited by a system receiving a grade of B. For Step 2 CK, the results were reversed. Certain essential standards were associated with better performance for all three examinations. 


\section{Discussion}

The purpose of this study was to investigate the USMLE performance of graduates of international medical schools who voluntarily seek ECFMG certification based on variables related to the accreditation of their medical education programs. In this study, for the selfselected population who took examinations during the study period, accreditation was associated with better performance in specific regions and for some examinations.

Of the three examinations, the existence of a system of accreditation had the strongest association with Step 1 performance for the global and Caribbean groups. Many accreditation criteria are directly related to aspects of the preclinical phase of education. The association between accreditation and Step 2 CS was positive for all three groups of students/graduates, although systems of accreditation may have less direct impact on student performance on clinical examinations as students' experiences in the clinical phase are likely more varied. Of the three groups, the existence of accreditation systems had the greatest associated with examination performance in the Caribbean, an important finding considering the large numbers of IMGs educated in this region seeking ECFMG certification and ultimately treating U.S. patients.

The quality of accrediting agencies, as determined by the number of essential elements utilized in the systems, was positively associated with performance for Step 1 and Step 2 CS, but not Step 2 CK. The finding supporting the importance of a high-quality accreditation system on Step 2 CS performance is important due to the purpose of this examination in evaluating a physician's skills in a real world setting.

This study lends some support to the value of accreditation. Due to the substantial resources needed to design and implement accreditation processes, these results provide some positive evidence beyond face validity, especially in the Caribbean region, that quality assurance 
oversight of educational programs is associated with the production of more highly skilled physicians, which in turn should improve the health care of patients in the United States and around the world. 


\section{ACKNOWLEDGMENTS}

I would like to begin by thanking my Chair, Dr. Ian Greaves for his very thoughtful and helpful direction in assisting me to finish this research. Dr. Greaves graciously agreed to take me on as a doctoral student when I was mid-way through planning my dissertation, and I am very thankful for his all of his guidance and support during this most difficult stage of the journey. My search for a new Chair was easy once I learned of Dr. Greaves' impressive research achievements, and the fact that he is an Australian international medical graduate sealed the deal. I contacted Dr. Greaves even before he arrived at Temple in the hopes that if I managed to be the first adrift doctoral student at his new institution to contact him, his only option would be to agree to be my Chair!

To the rest of my committee, Drs. Komaroff, Sterling and Aschenbrener, thank you as well for your helpful guidance over the past years. You probably almost forgot who I was in the long time intervals that went by in between hearing from me, but I hadn't forgotten about you. I might not have leaned on you as much as some of your previous doctoral students, but I always appreciated your help and the notable credibility you lent to my research.

Thanks to my previous Chair, Dr. Johanna Maselko, who provided me with very useful guidance and insight during my early stages of research planning. I was sorry when Dr. Maselko left Temple to pursue new opportunities, and I owe a great deal of thanks to her in helping shape the early phases of my study.

My colleagues here at FAIMER deserve very special thanks for their assistance in this endeavor. Jack Boulet, my boss, was invaluable in encouraging me to stay on track and in completing the statistical analysis. His critical eye for details, refreshingly direct insights and 
intelligent humor contributed to making this research enjoyable and interesting. John Norcini, thank you so much for all of your support and mentorship over the years. You are a wonderful role model for scholarship and for treading the sometimes tricky political waters that result. So many of my other colleagues here at FAIMER, ECFMG, and NBME have been incredibly helpful and supportive throughout this long process. Thanks for all the lunches, happy hours, and times spent together while travelling when you listened to my ideas and also shared your wisdom. I am truly lucky to have so many wonderful and intelligent colleagues who I also consider close friends!

I have had the privilege while working for the past 15 years for ECFMG and FAIMER to travel to numerous international conferences and meet many of the global experts in the field of accreditation. Thank you to all of my contacts who gratefully answered my questions, provided data, and completed my survey. Your assistance was invaluable.

To my parents, Paul Longacre and Nancy Heisey, thank you for being supportive and encouraging of this endeavor. Nancy, you were such an inspiration to me when you earned your PH.D. in your 40's. I'm honored to follow in your footsteps!

In an abstract sense, I would be missing a very important group if I didn't extend my thanks to all of the international medical graduates in the world who have the dream to come to the United States for graduate medical education. To the thousands of U.S. citizens who went abroad for medical school, and doctors from India, Pakistan, Philippines, China, Nigeria, etc., who decided to come here, thank you for being in my data, even though you don't know it.

I have been a student at Temple University off and on since 1993. It is about time that I stopped paying tuition and fees and thinking of myself as an eternal student. I took the full seven 
years to earn this doctorate, so I feel I got my money's worth. I will miss the “Temple Challenge", but it is time to finally say goodbye.

Lastly, and most importantly, to my husband, Erwin, and daughter, Ruby, thank you for all of your encouragement and sacrifices over the years. Thank you for being proud of me and my accomplishments. Your support, love, and overall day-to-day kindness were my main sources of inspiration to continue to pursue this degree. I couldn't have done it without you. 


\section{TABLE OF CONTENTS}

Page

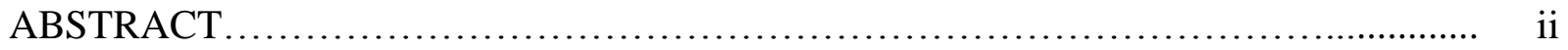

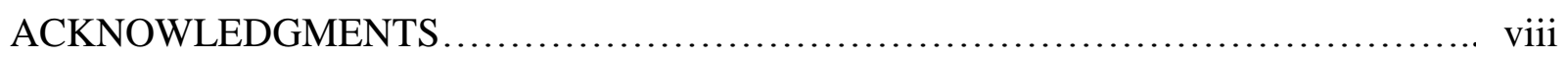

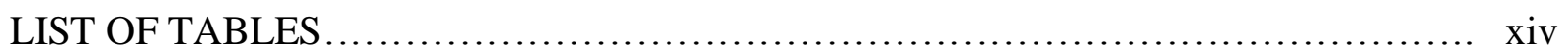

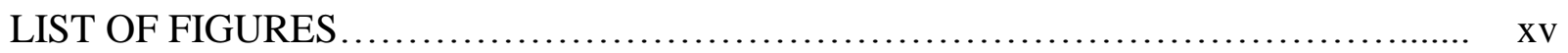

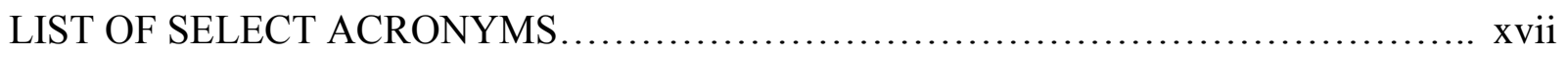

CHAPTER

1. BACKGROUND AND SIGNIFICANCE $\ldots \ldots \ldots \ldots \ldots \ldots \ldots \ldots \ldots \ldots \ldots \ldots \ldots \ldots \ldots \ldots \ldots \ldots \ldots$

Physician Quality....................................................... 1

Variables that Predict Physician Quality................................... 2

Assessments...................................................... 2

Medical School Variables and Examination Performance.................. 3

Medical School Variables and Future Adverse Actions.................... 4

Medical School Variables and Quality of Care.......................... 5

International Medical Graduates (IMGs) Practicing in the United States.............. 5

Contribution of IMGs in Providing Care to Underserved Patients............... 6

IMGs Certified by ECFMG.............................................. 8

Medical Education of IMGs............................................. 9

Caribbean-Educated IMGs............................................ 11

Accreditation............................................................ 15

Theoretical Basis for Accreditation...................................... 16

General Higher Education Accreditation in the United States................... 19

Accreditation of Medical Education..................................... 20

Accreditation of Medical Education in the United States.................. 20

Accreditation of Graduate Medical Education in the United States.......... 23

Accreditation of Medical Education Globally.......................... 24

Accreditation of Medical Education in the Caribbean..................... 25

Accreditation in Health Professions and Other Educational Fields.............. 32

Quality of Accreditation.............................................. 35

2. RESEARCH DESIGN AND METHODS .................................... 37

Phase 1 (Existence of Accreditation) ...................................... 37

Study Population.................................................... 37

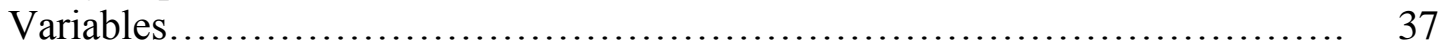

Student/Graduate (Individual) Variables........................... 37

Examination Variables........................................ 38 
Medical Schools....................................................... 39

Medical School / Country Variable: Accreditation....................... 39

Analyses............................................................ 41

Statistical Methods.................................................. 42

Phase 2 (Quality of Accreditation) ......................................... 43

Development of Accreditation System Quality Rating...................... 44

Survey Design.................................................... 45

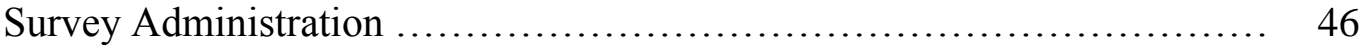

Ethical Approval.................................................... 47

Survey Analyses......................................................... 47

Study Population..................................................... 48

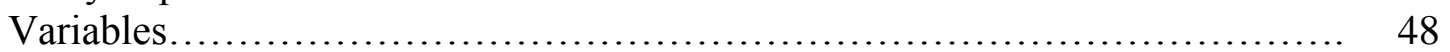

Student/Graduate (Individual) Variables............................ 48

Examination Variables................................................ 48

Medical Schools.................................................... 48

Medical School / Country Variable: Accreditation......................... 48

Analyses........................................................ 49

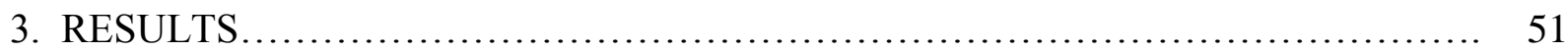

Phase 1 (Existence of Accreditation) ....................................... 51

Countries (Global).................................................... 51

Countries (Caribbean) ................................................ 51

Countries (Non-Caribbean).......................................... 52

Sample Size (Students/Graduates) ................................... 52

Step 1 (Global) ................................................... 53

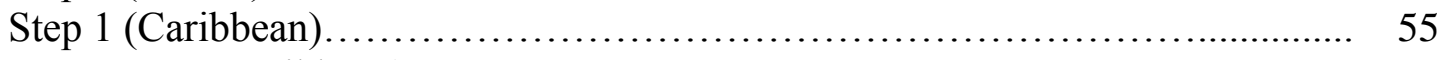

Step 1 (Non-Caribbean).......................................... 57

Step 2 Clinical Knowledge (CK) (Global).............................. 58

Step 2 Clinical Knowledge (CK) (Caribbean)............................. 60

Step 2 Clinical Knowledge (CK) (Non-Caribbean)......................... 63

Step 2 Clinical Skills (CS) (Global) .................................. 65

Step 2 Clinical Skills (CS) (Caribbean)................................... 67

Step 2 Clinical Skills (CS) (Non-Caribbean)............................. 68

Accreditation Data Summary................................................ 70

Phase 2 (Quality of Accreditation) ...................................... 72

Survey to Determine Essential Standards............................... 72

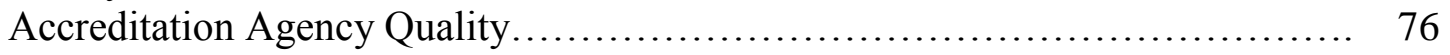

Specific Essential Standards................................................ 84

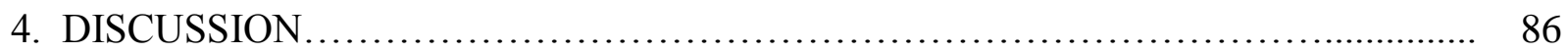

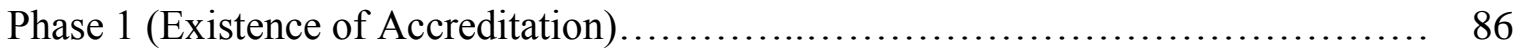

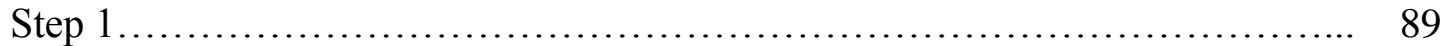

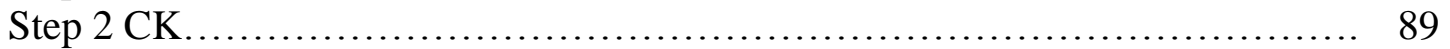

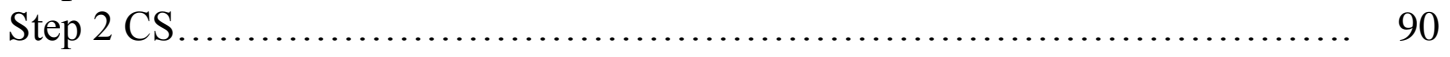

Global Versus Caribbean Group Versus Non-Caribbean Group.................... 91 
Variables Associated with USMLE Performance................................ 92

Gender................................................................... 92

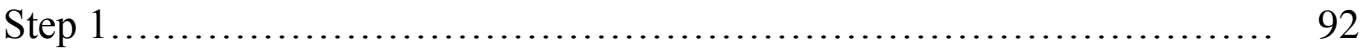

Step 2 CK..................................................... 93

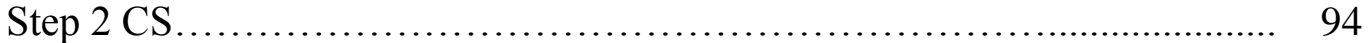

Years Elapsed Since Graduation at Time of Testing......................... 95

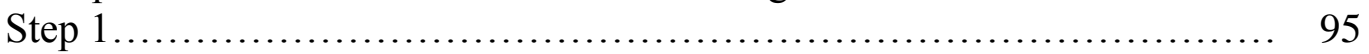

Step 2 CK................................................... 96

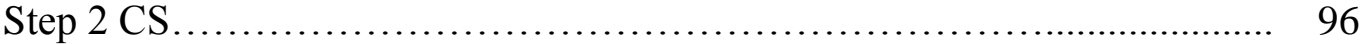

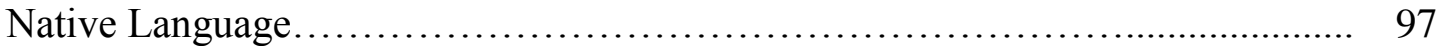

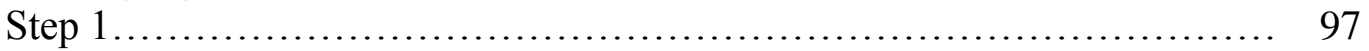

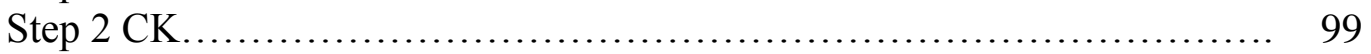

Step 2 CS............................................................ 99

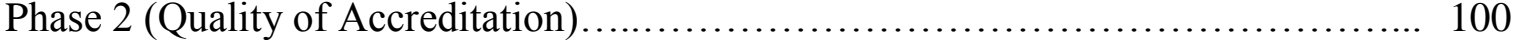

Accreditation Agency Quality............................................. 104

Accreditation Agency Quality (Grade A Versus Grade B)........................ 105

Specific Essential Standards......................................................... 106

Limitations............................................................ 107

Conclusions............................................................ 111

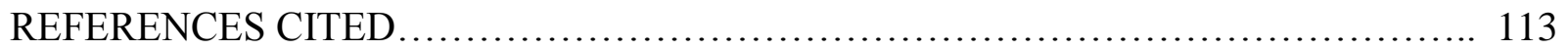

APPENDICES............................................................. 121

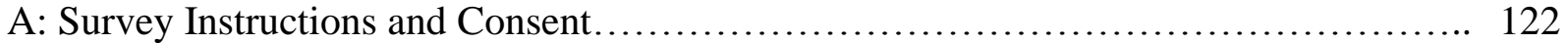

B: Survey.................................................................. 127

C: Essential Standards Used by Accrediting Agencies............................. 140 


\section{LIST OF TABLES}

Table

1 Countries and Territories in the Caribbean That Have Open Medical Schools

Page

Listed in the International Medical Education Directory (IMED) (as of January 1,

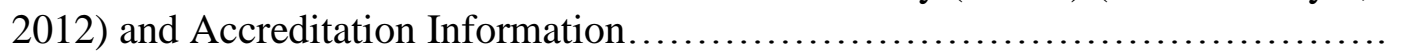

2 Numbers of Test Takers for Step 1, Step 2 CK, and Step 2 CS During the Period 2006 - 2010, by Gender, Years Since Graduation, Native Language, School Accreditation.

3 Summary of the Association Between Accreditation and USMLE First-Attempt Pass Rates

4 Number of Ratings Provided and Mean (SD) for Each of the 13 Expert Raters......

5 Standards that Received Unanimous Agreement as Being Essential, Standards That Received Mean Ratings Equal to or Less than 2.00, and Standards With Variances Equal or Greater Than 0.50 .

6 Number and Percent of the 14 Essential Standards used by Accrediting Agencies and the Country(ies) where the Agencies have Accredited Medical Schools...

7 The Presence or Absence of "Essential" Accreditation Standards in Relation to Pass Rates on First Attempt for Step 1, Step 2 CK, and Step 2 CS...............

8 Essential Standards Used by Accrediting Agencies 


\section{LIST OF FIGURES}

Figure

1 The top 10 countries of medical education of IMGs certified by ECFMG in

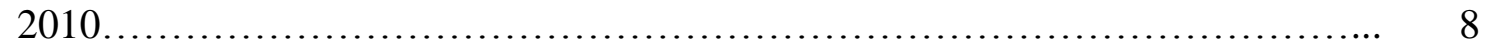

2 The top 10 countries of citizenship of IMGs certified by ECFMG in 2010....... 9

3 Step 1 first-attempt pass rates by gender, years since graduation, native language, and school accreditation status for the entire study population .....................

4 Step 1 first-attempt pass rates by gender, years since graduation, native language, and school accreditation status for students/graduates of Caribbean medical schools

5 Step 1 first-attempt pass rates by gender, years since graduation, native language, and school accreditation status for students/graduates of non-Caribbean medical schools

6 Step 2 CK first-attempt pass rates by gender, years since graduation, native language, and school accreditation status for the entire study population......

7 Step 2 CK first-attempt pass rates by gender, years since graduation, native language, and school accreditation status for students/graduates of Caribbean medical schools

8 Step 2 CK first-attempt pass rates by gender, years since graduation, native language, and school accreditation status for students/graduates of non-Caribbean medical schools

9 Step 2 CS first-attempt pass rates by gender, years since graduation, native language, and school accreditation status for the entire study population...

10 Step 2 CS first-attempt pass rates by gender, years since graduation, native language, and school accreditation status for students/graduates of Caribbean medical schools

11 Step 2 CS first-attempt pass rates by gender, years since graduation, native language, and school accreditation status for students/graduates of non-Caribbean medical schools.

12 First-attempt pass rates for Step 1 by number of essential standards used by the accrediting agencies. 


\section{LIST OF FIGURES (Continued)}

Figure Page

13 First-attempt pass rates for Step 2 Clinical Knowledge (CK) by number of essential standards used by the accrediting agencies......................... 80

14 First-attempt pass rates for Step 2 Clinical Skills (CS) by number of essential standards used by the accrediting agencies.................................. 81

15 First-attempt pass rates for Step 1, Step 2 CK and Step 2 CS by number of essential standards used by the accrediting agencies...............................

16 First-attempt pass rates for Step 1, Step 2 CK, and Step 2 CS by quality grade given to the accrediting agencies that accredited the schools attended by the test

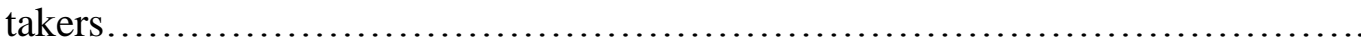




\section{LIST OF SELECT ACRONYMS}

ECFMG Educational Commission for Foreign Medical Graduates

www.ecfmg.org

FAIMER Foundation for Advancement of International Medical Education and Research

www.faimer.org

IMED International Medical Education Directory

www.faimer.org/resources/imed.html

IMG International Medical Graduate

LCME Liaison Committee on Medical Education

www.lcme.org

NBME National Board of Medical Examiners

www.nbme.org

USMG United States Medical Graduate

USIMG United States International Medical Graduate

USMLE United States Medical Licensing Examination

www.usmle.org

WFME World Federation for Medical Education

www.wfme.org 


\title{
CHAPTER 1
}

\section{BACKGROUND AND SIGNIFICANCE}

\author{
Physician Quality
}

Physicians are an integral part of the health care team providing care to patients, yet it has been documented that American patients receive care according to published guidelines only about 55\% of the time (McGlynn et al., 2003). Whether these discrepancies are due to resource constraints, a physician's lack of expertise and training, or another reason is difficult to determine.

The art of caring for the sick and preventing disease is complex and multidimensional. A physician must possess the knowledge and skills to elicit pertinent information from a patient, perform an appropriate physical examination, diagnose disease, make clinical decisions, and effectively counsel patients regarding treatment options, behavior modifications, and compliance issues. In addition, a physician must exhibit appropriate interpersonal skills to develop rapport with patients and make them feel at ease during discussion of difficult or sensitive issues. A physician should also be flexible and intuitive, modifying his or her behaviors appropriately to optimize care with patients with diverse cultural backgrounds and health beliefs, and in various working environments.

This complexity makes it somewhat challenging to effectively assess physicians' skills in practice. Donabedian (1980) provides a framework for organizing studies on analyzing the quality of physicians. The outline consists of three variables: structure, which includes observing test scores and other achievement data such as rates of specialty board certification; 
process, which measures procedures and guidelines followed (or not adhered to) while treating patients; and outcome, which includes measures of results of health care measures performed, such as mortality rates, complication rates, patient complaints, and so on.

This section will provide an overview of the literature related to measuring physician quality and present evidence that educational variables can be a predictor of future measures. These educational variables include higher scores on standardized examinations, which are in turn linked to improved physician performance on patient care indices. In addition, the association between medical school variables and outcomes such as examination scores is described.

\section{Variables That Predict Physician Quality}

\section{Assessments}

During medical training, a student is evaluated throughout his or her education and grades obtained are assumed to have a strong influence in predicting later performance as a physician. The purpose of assessments, such as the United States Medical Licensing Examination (USMLE) series, is to ensure that graduates from diverse medical schools and countries have achieved a standard level of competence. Ideally, these assessments demonstrate that an individual possesses the minimal knowledge and expertise necessary to practice medicine commensurate with the individual's level of training. Throughout all assessments, including written examinations and observation of a physician performing a task, the assumption is made that the knowledge demonstrated to answer the question, or the skills necessary to perform the observed behaviors, extend beyond the task at hand to the real world and to other similar situations. 
A 2006 meta-analysis focused on evaluating the predictive validity of a variety of assessments of student performance in medical schools (predictors) and the students' future performance as physicians (practice outcomes) (Hamdy et al., 2006). The authors were specifically interested in investigating the extent to which scores obtained by students in medical school predicted outcomes by these same physicians in clinical practice. There was a wide range of outcomes described in these studies, ranging from residency supervisor ratings to measures of actual clinical performance. Correlations between predictors and outcomes were, in general, moderate, validating the use of examinations as one predictor of quality.

Examination performance of physicians has been directly linked to patient outcomes, although due to numerous methodological challenges, studies of this type are not frequently conducted. In one study of physicians practicing in Quebec, higher scores achieved on certification and licensure examinations taken at the end of medical school showed a sustained relationship with indices of preventive care and acute and chronic disease management in primary care practice, including mammography screening rate, continuity of care index, diseasespecific and symptom-relief prescribing rate, contraindicated prescribing rate, and consultation rate (Tamblyn et al., 2002). For example, for every standard deviation increase in examination score, the mammography screening rate increased by 13.3 women per 1,000 in physicians' first two years of practice, 21.7 by the third and fourth years of practice, and by 19.2 in years five through seven.

\section{Medical School Variables and Examination Performance}

In addition to evidence demonstrating assessment scores predicting future performance as a physician and patient outcomes, a limited number of studies have also investigated the linkage 
between differences in medical school variables and student performance on examinations. In one study of USMLE Step 1 (basic science), Step 2 Clinical Knowledge (CK), and Step 3 performances of students from 116 U.S. and Canadian medical schools, the mean unadjusted school variance for the three examinations ranged from $10.50 \%$ to $14.74 \%$. When student covariates were included, the between-school variation was decreased to less than $5 \%$ for all three examinations. The potential contribution of various curriculum and educational policies at the schools was determined to have a small effect on the students' examination performance (Hecker \& Violato, 2008). In a similar study of United Kingdom medical school graduates’ performance on various standardized examinations, there was wide contrast by school.

Pre-admission variables accounted for the majority of the variance, leaving approximately $40 \%$ of the school-level variance the result of other factors. The authors concluded that the betweenschool differences are likely the result of variation in criteria such as teaching focus, approaches, and curriculum content (McManus et al., 2008). Despite the somewhat limited school-related influences found in these specific studies, it is important to note that in both investigations the schools were subject to the same accreditation practices, and therefore the programs were potentially relatively homogeneous in terms of educational quality.

\section{Medical School Variables and Future Adverse Actions}

As another measure of the association between education and outcomes, medical school attended as a predictor of future adverse actions has been investigated to a limited degree. In a study of malpractice claims filed against graduates of U.S. medical schools, results showed that graduating from a medical school whose graduates are often sued significantly increased an individual physician's likelihood of being sued (Waters et al., 2003). The authors speculate that 
malpractice claims might be related to medical school attended because of differences in quality of education, training in interpersonal skills, likelihood of a school's graduates to enter specialties more likely to be sued, student selection factors, and the institutional culture of the various schools. In a study of Canadian physicians practicing in Ontario and Quebec, lower scores on the patient-physician communication and clinical decision-making components of the required national licensing examination predicted an increase in later patient complaints to medical regulatory authorities (Tamblyn et al., 2007).

\section{Medical School Variables and Quality of Care}

A 2010 study investigated the quality of care provided by physicians based on location of medical school (graduates of international medical schools [IMGs] compared to graduates of U.S. medical schools [USMGs]), and within IMGs, those individuals who are U.S. citizens compared to citizens of all other countries. Quality of care indicators were mortality rates for congestive heart failure or acute myocardial infarction. The authors found no significant mortality difference when comparing all IMGs with USMGs, although within IMGs, there were fewer in-hospital deaths among the patients of IMGs who were not U.S. citizens compared to patients of U.S. citizen IMGs (Norcini et al., 2010).

International Medical Graduates (IMGs) Practicing in the United States

Investigating a potential linkage between physicians' education and future performance is crucial because of the variability in the medical education of physicians practicing in the United States. This section will describe the current population of physicians in the United States and 
provide evidence regarding the importance of internationally educated doctors in providing patient care to underserved patient populations and in under-resourced geographic areas. If a system of accreditation of medical education can be positively associated with increased quality of the graduates, this finding will be useful in enhancing the care provided to all patients in this country.

Currently about three quarters of doctors in residency training and in practice are graduates of U.S. medical schools (USMGs), and one quarter are graduates of international medical schools (IMGs) (Brotherton \& Etzel, 2011). The Educational Commission for Foreign Medical Graduates (ECFMG) certification process ensures the readiness of IMGs to enter Accreditation Council for Graduate Medical Education (ACGME) accredited training programs in the United States, a prerequisite for unrestricted practice and licensure.

\section{Contribution of IMGs in Providing Care to Underserved Patients}

In the United States, IMGs play a very important role in the provision of patient care because they are more likely than USMGs to fill positions in underserved areas. In a study of the distribution of practicing IMGs as compared to USMGs in U.S. cities, IMGs were found in disproportionate numbers in poverty areas in a number of cities, especially the largest ones (Mick \& Lee, 1999a). In a similar study of the difference in proportions between USMGs and IMGs in rural areas characterized by need (high infant mortality, low socioeconomic status, high proportion of nonwhite population, high proportion of population 65 years and older, and low physician-to-population ratio), results showed a larger proportion of IMGs located in needy rural counties as compared to USMGs (Mick \& Lee, 1999b). In a study of office-based visits from 
2005 to 2006, IMGs were more likely to practice in nonurban primary care shortage areas (67.8\%) as compared to USMGs (39.8\%) (Hing \& Lin, 2009).

In addition to practicing in underserved areas, IMGs are more likely than USMGs to specialize in primary care disciplines. A study of IMGs entering residency training between 1995 and 2003 indicated that they were most likely to be selected into primary care programs. For some disciplines, such as family medicine, the number and proportion of IMGs has been growing steadily over the past decades. In 1995, 6.3\% of all IMGs accepted training positions in family medicine; by 2003 this proportion had increased to 15.8\%. (Boulet et al., 2006a).

Patients who seek care from IMGs also tend to differ from patients of USMGs. In a study of office-based visits from 2005 to 2006, consultations with IMGs were less likely to be made by white patients $(63.8 \%)$ compared to $77.8 \%$ for USMGs. IMGs' patients were also more likely to be Hispanic, Latino, Asian, or of Pacific Islander descent (24.9\%), as compared to patients who visited USMGs (12.4\%). Visits to IMGs were more likely to be made by patients who lived in neighborhoods with lower median household incomes (12.6\%) compared to USMGs (10.6\%), and a higher percentage of individuals who did not speak English well (5.6\% for IMG and 3.0\% for USMG visits) (Hing \& Lin, 2009).

It has also been demonstrated that IMGs are more likely to treat patients who rely on government funding for their health care. In the same study of office-based visits from 2005 to 2006, visits to IMGs were more likely to consist of patients using Medicaid or other governmentally funded sources as their payment (17.6\%) as compared to the sources of funding used by patients seeking care from USMGs (10.2\%) (Hing \& Lin, 2009). A study specifically of IMG psychiatrists revealed that they received a higher percentage of their income from Medicaid and Medicare (38.1\%), as compared to USMGs (25.1\%) (Blanco et al., 1999). 


\section{IMGs Certified by ECFMG}

In 2010, ECFMG issued 9,399 certificates to IMGs, and the top 10 countries of IMGs' medical education were (in descending order): India (19.0\%; $\mathrm{n}=1,789)$, Dominica (7.5\%; $\mathrm{n}=702)$, Grenada (6.4\%; $\mathrm{n}=606)$, Pakistan (5.9\%; $\mathrm{n}=553)$, China (3.3\%; $\mathrm{n}=310)$, Philippines (2.6\%; $\mathrm{n}=242)$, Sint Maarten (2.4\%; $\mathrm{n}=229)$, Israel (2.4\%; $\mathrm{n}=228)$, Egypt $(2.4 \% ; \mathrm{n}=223)$, and Cayman Islands (2.1\%; n=199) (ECFMG, 2011). These data are presented in Figure 1.

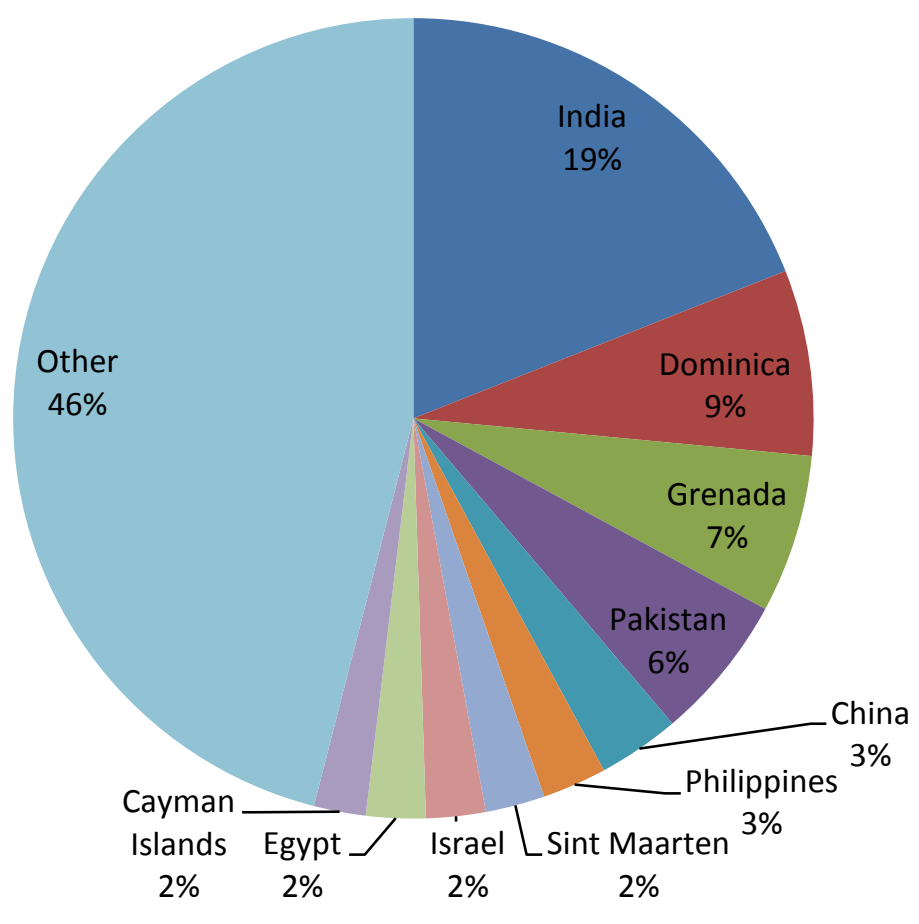

Figure 1. The top 10 countries of medical education of IMGs certified by ECFMG in 2010

The top 10 countries of IMGs' citizenship of IMGs certified by ECFMG in 2010 are (in descending order): United States (24.3\%; $n=2,287)$, India (19.7\%; $n=1,848)$, Pakistan (5.6\%; $\mathrm{n}=526)$, Canada (4.4\%; $\mathrm{n}=410)$, China (3.2\%; $\mathrm{n}=304)$, Nigeria (2.3\%, $\mathrm{n}=215)$, Philippines $(2.2 \%$; 
n=211), Egypt (2.2\%; n=209), Iran (1.8\%; n=171), and Syria $(1.5 \% ; n=142)($ ECFMG, 2011). These data are presented in Figure 2.

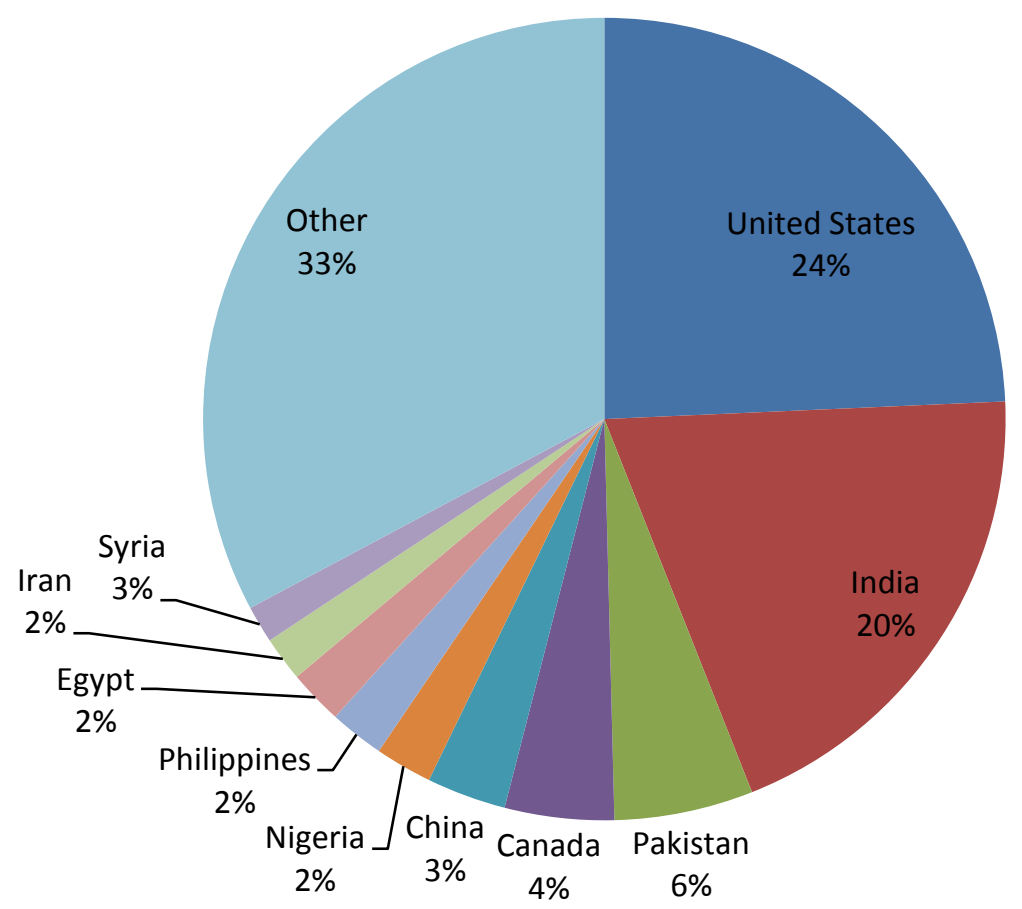

Figure 2. The top 10 countries of citizenship of IMGs certified by ECFMG in 2010

\section{Medical Education of IMGs}

IMGs who achieve ECFMG certification, participate in graduate medical education (GME) in the United States, and are licensed for unrestricted practice in this country are educated at medical schools located all over the world. Globally, there are more than 2,200 medical schools currently educating medical students in more than 170 countries/territories. Aspects of medical education varies across countries and regions, including teaching traditions, 
available resources, cultural conditions, the health and disease spectrum of the region, and the national organization of the health care delivery system (Karle, 2004).

IMGs who seek to enter residency or fellowship programs in the United States that are accredited by the Accreditation Council for Graduate Medical Education (ACGME) must first be certified by the ECFMG. Participation in GME is a prerequisite for licensure and the unrestricted practice of medicine in the United States for all physicians. The ECFMG program ensures that IMGs, regardless of country of origin, current citizenship, medical school attended, years of practice, specialty choice, etc., are all subject to the same certification standards.

To be eligible for certification by ECFMG, IMGs must meet numerous requirements. The physician's medical school must be listed in the International Medical Education Directory (IMED), maintained by the Foundation for Advancement of International Medical Education and Research (FAIMER). IMGs must have been awarded credit for at least four credit years (academic years for which credit has been given toward completion of the medical curriculum) by a medical school that is listed in IMED. The information available through IMED is derived from current and historical data collected by ECFMG throughout its history of evaluating the medical education credentials of IMGs. A medical school is added to IMED after FAIMER receives confirmation from the Ministry of Health, Ministry of Education, or other appropriate agency that the ministry or agency has recognized that school for award of the M.D. degree or equivalent, and that the graduates of the medical school are eligible to practice medicine in the country where the school is located.

ECFMG applicants must document the completion of all requirements for, and receipt of, the final medical diploma. ECFMG verifies every applicant's medical school diploma with the 
appropriate officials of the medical school that issued the diploma and ensures that the medical school provides the final medical school transcript.

\section{Caribbean-Educated IMGs}

While IMGs are educated at medical schools located all over the world, many who seek ECFMG certification attended medical schools located in the Caribbean. This section will describe the educational structure and history of medical education in the Caribbean and provide a summary of the performance of students/graduates from these schools on various outcome measures.

The Caribbean is composed of 24 island countries and territories in which approximately 38 million inhabitants speak English, Spanish, French, Dutch, and a variety of indigenous languages. Approximately 60 medical schools in the Caribbean are currently listed in IMED. This region has a higher density of medical schools per capita, with 1.42 medical schools per one million inhabitants (Boulet et al., 2007), more than any other region of the world. In contrast, Western Europe has 0.60 and North America has 0.50 medical schools per one million inhabitants. Despite this high concentration of medical schools in the Caribbean, the density of practicing physicians in the region is comparable to that in the United States and Canada (Boulet et al., 2007), which indicates that many physicians are training in the Caribbean and practicing elsewhere.

Caribbean schools attracting mainly international students differ in educational structure from U.S. medical schools and Caribbean schools educating a domestic student population. In general, schools that attract a large portion of international students offer the first two years of basic science medical education in the Caribbean country where the school is located, and the 
second two years of clinical science education (clinical clerkships) at affiliated hospitals, predominantly located in the United States (Eckhert, 2010). Despite the U.S. citizen status of the majority of the students and the fact that part of their education took place in the United States, students who graduate from these Caribbean schools are designated as IMGs, and, therefore, are required to obtain ECFMG certification prior to seeking residency positions in the United States.

Large numbers of U.S. students have been seeking medical education opportunities in the Caribbean since the 1970s. Fifty years ago there were only a small number of medical schools in the region, including the University of the West Indies (UWI) in Jamaica, then part of the University of London, and a limited number of national schools in Cuba, the Dominican Republic, and Haiti. The student population at these established schools has been primarily comprised of nationals from the respective countries who complete physician training and remain in their country to practice. The second half of the twentieth century saw a slow but steady increase in the creation of medical education institutions in the region, including the opening of a small number of schools aimed primarily for a U.S. student population.

St. George's University, located in Grenada; the American University of the Caribbean School of Medicine, originally in Montserrat and now in Sint Maarten; and Ross University in Dominica all opened their doors in the late 1970s.

The most prolific growth has occurred most recently, with a $40 \%$ increase in the number of medical schools opened since 2000 (Boulet et al., 2007), and this growth is expected to continue. For example, plans are currently underway to establish additional medical schools in Montserrat, Saint Vincent and the Grenadines, and Turks and Caicos Islands (Caribbean Accreditation Authority for Education in Medicine and other Health Professions, 2012). Unlike the domestic student body at some of the more established educational institutions, these 
newly created schools recruit, almost exclusively, an international population of students, including a large number of U.S. citizens who intend to seek residency positions and ultimately practice in the United States.

Due to a lack of uniform oversight processes in the region and the rapid growth in the number of new schools being created, there have been continuing concerns regarding the quality of the educational experiences offered at Caribbean institutions (Busari et al., 2001; Ceaser, 2005; Croasdale, 2006). Thirty years ago, studies indicated that U.S. citizens who completed part or all of their studies abroad (USIMGs) did not perform as well on knowledge assessments as did USMGs (Relman, 1978; Weinberg \& Bell, 1978). More recently, a study of performance of physicians who attended one of 12 medical schools in the Caribbean that produced more than 200 USIMGs from 1980 to 2000 showed considerable variation in quality indicators. ECFMG certification rates varied by school from $28 \%$ to $86 \%$. Specialty Board certification rates were also analyzed, with $63 \%$ of USIMGs (compared to the historical $88 \%$ for USMGs) ultimately achieving this marker of quality (Norcini et al., 2006b). In a study of students' transcripts and survey responses from the 10 schools that supplied the most USIMGs seeking ECFMG certification between 2001 and 2004, there were significant differences in educational experiences and examination performance of USIMGs from Caribbean schools as compared to a representative sample of USMGs (Norcini et al., 2006a). Students from Caribbean institutions were less likely to have received formal instruction in various topics, including epidemiology, communication skills, and cultural competence. The clinical clerkships were also different, with fewer USIMGs reporting a requirement to complete clerkships in emergency medicine, family practice, neurology, geriatrics, and radiology. Comparison of performance of this study 
population on the USMLE Step1 and Step 2 CK examinations also showed remarkable variation, with USMGs performing the best, followed by non-USIMGs and lastly USIMGs.

In a study of almost 30,000 students who attended a medical school in the Caribbean and applied for an examination leading to ECFMG certification between the years 1993 and 2007, there was wide variability of first-attempt pass rates by country of medical school. The firstattempt Step 1 pass rate ranged, by country, from $19.4 \%$ to $84.4 \%$. On Step 2 Clinical Knowledge, there was a $26.3 \%-79.7 \%$ first-attempt pass rate range, and on Step 2 Clinical Skills the first-attempt pass rate ranged from 60.6\% - 97.2\% (van Zanten \& Boulet, 2008). A follow-up study investigated USMLE attempts and ECFMG certification rates of 20,000 Caribbean-educated students/graduates who applied for an ECFMG examination between 1996 and 2009. The average number of examination attempts for those individuals who eventually achieved certification ranged, by country of medical schools, from 1.19 to 2.84 for Step 1, from 1.20 to 2.13 for Step 2 CK, and from 1.01 to 1.42 for Step 2 CS. While certification success ranged by country of medical school from $19.1 \%$ to $91.5 \%$, overall, approximately $14,000(74.2 \%)$ of the study participants eventually achieved certification. In addition, this study documented the increase in females and non-U.S. citizens attending medical schools in the Caribbean (van Zanten \& Boulet, 2009).

The third paper in the series investigated trends in performance of Caribbean-educated physicians focused on individuals who registered for examinations between 2000 and 2009. The numbers of students increased every year and overall USMLE Step 1 and Step 2 CK firstattempt pass rates increased over the study period. Performance trends by country of medical education varied widely (van Zanten \& Boulet, 2011). 
The numbers of graduates of Caribbean medical schools seeking ECFMG certification has been increasing over the past decade. In 2000, there were 1,510 registrants for ECFMG certification, and that number has increased in subsequent years to 4,000 in 2009 (van Zanten \& Boulet, 2011). This increase in graduates educated in the Caribbean region seeking to enter the U.S. health care system, together with the questions regarding the merit of some of these institutions and the potential role accreditation systems can have in enhancing their quality, are important reasons for the special focus of this research in the region.

\section{Accreditation}

Taking into consideration the sizable number of medical schools in the world, significant variations in medical education globally, and the large numbers of IMGs seeking entry to GME in the United States, the presence of systems of accreditation is often viewed as an effective mechanism for ensuring the quality of international medical schools. Accreditation for the purposes of this study is defined as a process by which a designated authority reviews and evaluates an educational program and/or institution using clearly specified criteria and procedures.

In the next section a theoretical basis for accreditation will be given, drawing on evidence from the field of economics. A case will be made that accreditation is valuable because it can be directly linked to a school's ability to attract higher quality students. This linkage is important because measures of individual ability prior to entry at medical school (e.g., grade point average, preadmission examination scores) were not available for this study, and the assumption is made that a positive accreditation status is a marker of quality, leading to the recruitment of 
high-ability students. Therefore, the need to account for preadmission ability levels of the students is minimized.

The following section describes higher education accreditation within the U.S. context, including accreditation of general higher education, undergraduate medical education (allopathic and osteopathic), and graduate medical education. Next, the prevalence of systems of accreditation for medical education around the world is outlined, including a detailed description of the systems of medical education accreditation extant in Caribbean countries. The section concludes with a rationale for research to be conducted on the impact of accreditation in the medical education field and background evidence regarding the association between accreditation and performance in other educational disciplines.

\section{Theoretical Basis for Accreditation}

The field of economics provides literature describing a theoretical basis for the value of accreditation. In this theoretical structure, third-party certifiers, such as an accreditation authority, provide market signals to the public concerning product value. Third-party certifiers are defined as external, independent entities that assess, evaluate, and certify quality claims (Deaton, 2004). A third-party certifier acquires authority and credibility in the market place if it is perceived by the public as being objective and independent of influence from both the buyer and seller of a product.

Economics theory has also demonstrated that the costs of receiving independent thirdparty certification are inversely related to the product's quality. A low-quality product would necessitate an expensive series of improvements in order to qualify for the accreditation status. Conversely, a high-quality product would likely already meet most, if not all, of the standards, 
requiring the spending of minimal monetary and time resources to achieve accreditation (Deaton, 2004).

In a study of factors influencing decisions of Health Management Organizations (HMOs) to become accredited, the authors demonstrate how an accredited status can be used as a signal to the public of the quality of the organization (Gohmann, 2006). The findings of this study can be used to draw parallels to the educational realm. Similar to the circumstance with HMOs, schools will acquire the accreditation signal if the benefits of obtaining the signal outweigh the costs of undergoing the accreditation. These costs include not only the costs of the accreditation process, but most importantly the costs of the quality improvements necessary to meet the standards. Benefits to an educational institution in acquiring the signal include the ability to attract higher quality students, increased student enrollment, and better retention of current students. An accredited institution also may potentially be able to charge a higher fee if demand outweighs supply and the market is willing to pay more for the perception of a higher quality product.

Health Management Organizations can be either for-profit or not-for-profit, and obtaining an accredited status has been demonstrated to be of particular value for the for-profit organizations (Gohmann, 2006). Similar comparisons can be made in the educational field. Through accreditation, for-profit entities can more easily respond to adverse perceptions regarding their quality. Additionally, for-profit organizations can argue that their accredited status precludes the need for governmental oversight and regulation to ensure quality. Overall, for-profit entities, such as private schools, HMOs, private hospitals, etc., have a greater need to signal their quality to the public, and, therefore, have an increased need to achieve an accredited status from an independent third-party certifier. 
An accreditation signal has the most value when some organizations, but not all, achieve an accredited status. If accreditation is perceived as a signal of quality, then a mandatory requirement for accreditation diminishes the value of that signal. For example, prospective students evaluating various U.S. medical schools would not likely consider a particular school's accreditation status to be of value in distinguishing schools from each other, as all are accredited. Conversely, the accreditation status of a medical school in Mexico may be of more perceived value to the public. In Mexico, the independently run Consejo Mexicano para la Acreditación de la Educación Medica, A.C. (COMAEM) (the Mexican Board for the Accreditation of Medical Education) reports that not all of the eligible medical schools have achieved an accredited status (National Committee on Foreign Medical Education and Accreditation, 2007a, 2011a). Similarly, in the Philippines, the Philippine Accrediting Association of Schools, Colleges and Universities (PAASCU) voluntarily accredits medical schools in the country, and only a minority of schools has achieved a positive accreditation status (van Zanten et al., in press).

This framework from the field of economics also demonstrates a key relationship between accreditation authorities and the existence of international and national standardization bodies (Deaton, 2004). Third-party certifiers emerge in various fields based on a number of factors, including the presence of applicable national or international standards. Standards authorities provide sampling and testing protocols that can be used by third-party certifiers in their review process. International entities can also provide structure and guidance for thirdparty certifiers on which to base their protocols and standards. In the field of oversight of medical education quality, organizations such as the World Federation for Medical Education (WFME) fulfill this role. WFME has developed a Trilogy of Global Standards for Quality Improvement, including resources that are aimed at assessing the quality of medical schools 
leading to an undergraduate allopathic degree: Standards in Basic Medical Education.

This document is not designed to be used restrictively, but instead is intended to function as a template for national agencies interested in developing accreditation procedures (Karle, 2006; Karle, 2008). The WFME standards are being used in a number of countries throughout the world as a model for establishing national and regional accreditation procedures, although their use is not universal.

\section{General Higher Education Accreditation in the United States}

In the United States, accreditation activities have been around for more than a century. At the end of the 1800 s, there was virtually no oversight of higher education, and quality and curriculum content varied significantly between institutions. Among the professions, such as medicine, knowledge and learning were becoming more specialized and numerous educational institutions were operating with wide variation in quality. Additionally, the population was becoming increasingly mobile and institutions needed a mechanism for evaluating the education of transfer students. Three unique phenomenon led up to the development of accreditation in the United States: (a) activities were begun voluntarily, not as a result of a governmental law, (b) the process was begun simultaneously from professions outside of the educational arena and from within the educational institutions themselves, and (c) accreditation from both types of entities was the result of a need to respond to serious problems of the times (Pinkham, 1955).

Accreditation organizations can be classified as one of two types: entities that accredit educational institutions as a whole, or entities that accredit specific programs, i.e., law, business, medicine, etc. It is important to note that in the United States, the government did not establish its own accrediting organization, but rather developed quality standards which are used to 
recognize and appoint private agencies to fulfill this role (Schray, 2005). Beginning in the 1950s the federal government formed a linkage with accreditation organizations as a way to determine educational institutions qualifying for federal grants and loans. Currently the U.S. Department of Education and the Council for Higher Education Accreditation recognize accrediting agencies (Council for Higher Education Accreditation, 2012). In contrast, in many other countries around the world, the government is directly responsible for designing and implementing a process of educational institution quality review.

\section{Accreditation of Medical Education}

\section{Accreditation of Medical Education in the United States}

There is a relatively long history of allopathic (training leading to an M.D. degree) medical accreditation practices in United States and Canada (Kassebaum, 1992). A description of the history of the development of accreditation in this field is important because it was arguably the most important catalyst for influencing the movement for accreditation across a wide range of educational disciplines. In the twentieth century the profession of medicine was transformed from an unorganized group consisting of both charlatans and skilled clinicians, indistinguishable from each other to most of the American public, into one of the most influential and respected professions in the country. This transformation was accomplished by changing the education and training of medical students and, in conjunction, the creation of a standardized system for quality control oversight of the institutions providing the education.

The impetus for this change was a 1908 report, commissioned by the Carnegie Foundation, which described the state of the practice of medicine in the country (Flexner, 1910; Starr, 1982). This report was based on an investigation of medical education programs 
conducted by Abraham Flexner, a nonphysician educational theorist. The Flexner Report outlined an alarming range in the quality of care provided to patients, from the continued use of treatments already widely considered to be irrational at the time, such as bleeding and purging, to the modern use of scientifically sound practices such as vaccinations and sterilization techniques. The cause for this extreme variation in patient care was determined to be due to a lack of standardization in the educational system for new physicians. Medical education at the time was delivered in three distinct modes: an apprenticeship system, a proprietary (for-profit) system, and a university system. Abraham Flexner visited all 155 medical schools that were in existence at the time and assessed their quality using five quality indicators. These standards on which the schools were judged were: a) entrance requirements, b) faculty, c) financial strength, d) clinical facilities, and e) classrooms and laboratories. Flexner's report was widely endorsed by both the public and policy makers, and resulted in the closure of about half of the medical schools.

The American Medical Association (AMA) and the Association of American Medical Colleges (AAMC) continued the work of Flexner. In 1942 the two organizations consolidated their efforts, resulting in the formation of the Liaison Committee on Medical Education (LCME), which is the nationally recognized accrediting authority for medical education programs leading to the M.D. degree in U.S. and Canadian medical schools (www.lcme.org). The LCME document, Functions and Structure of a Medical School, is used in determining compliance (LCME, 2011). The LCME model has been used as a framework for the development of additional accrediting systems in other regions of the world.

The LCME standards include five sections, each of which addresses a major component of the medical school and education program. The five sections are institutional setting, 
educational program, medical students, faculty, and educational resources. Criteria measured under institutional setting include governance and administration and the academic environment. The educational program and medical students sections of the LCME standards are generally the most intense focus of the evaluation. The educational program standards include measuring the educational objectives and the general design and content of the curriculum, teaching and evaluation, curriculum management, and evaluation of program effectiveness. Issues surrounding medical students are scrutinized through and evaluation of admissions, student services, and the learning environment. Faculty are assessed by consideration of the number, qualifications and functions, personnel policies, and governance. Finally, educational resources are addressed through an evaluation of a school's finances, general facilities, clinical teaching facilities, and information resources and library services.

The LCME accreditation process is designed as a quality-improvement exercise. Approximately a year and a half before an accreditation review, a medical school begins compiling a database where each standard for accreditation is linked directly to the school's documentation of compliance. After the data have been collected, the school undertakes a selfstudy of the materials. Concurrently, a team of experts independently analyzes the medical program, student services, and educational resources. Following the self-review, a survey team of outside individuals experienced in medical education performs a site visit to the school to validate and assess how accurately the institution is achieving its mission, goals, and objectives. The survey team reviews the institution's materials and collects additional information through interviews with faculty, students, and staff. At the conclusion of the site visit, the survey team presents a verbal review of the teams' finding to the dean of the medical school and president of the university. Next the survey team writes a detailed report documenting the evidence that 
supports the conclusions of the team. At the next LCME meeting, the report is reviewed and the LCME makes a final decision regarding accreditation of the program. If a program does not meet all criteria, evidence must be provided in a timely manner indicating that deficiencies have been addressed. The standard cycle for accreditation and re-accreditation is eight years, more frequently if the school reports substantial changes that would affect how the school meets the accreditation standards.

While the LCME accredits allopathic medical schools, another organization, the Commission on Osteopathic College Accreditation (COCA), accredits schools granting the osteopathic (D.O.) degree. In the United States, osteopathic physicians have the same licensing and practice rights as allopathic physicians. The basic structure of the LCME and the COCA are functionally similar, although the LCME accreditation standards are more expansive. A comparative analysis across the two sets of standards was conducted to determine if differences could affect educational quality of M.D. versus D.O. education (Wood \& Hahn, 2009). The authors found some variations, although they concluded that accreditation is likely not a factor in any quality issues across the two professional degrees.

\section{Accreditation of Graduate Medical Education in the United States}

Graduate medical education (GME) is an essential part of the continuum of medical education in the United States. Upon graduation from medical school, physicians are eligible to apply for GME positions. GME is frequently referred to as residency training, generally lasts three or four years, depending on the area of specialization, and is a requirement to obtain a license to practice medicine. The Accreditation Council for Graduate Medical Education (ACGME) is the oversight body responsible for quality assurance of GME in the United States. 
The ACGME has identified six general competencies deemed essential for residency training: patient care, medical knowledge, practice-based learning and improvement, interpersonal and communication skills, professionalism, and systems-based practice.

Since the implementation of these competencies, numerous investigations have attempted to measure their effectiveness in enhancing the training of physicians. A meta-analysis of 56 studies reported mixed results (Lurie et al., 2009), with the authors concluding that there was little evidence that current measurement tools validly assessed the competencies independently from one another. The exception to the equivocal findings was competency of medical knowledge, which has been demonstrated to be an important predictor of later clinical behaviors.

\section{Accreditation of Medical Education Globally}

Due to regional and cultural differences regarding medical education traditions and theories, disease preponderance, clinical guidelines, available resources, doctor-patient relations, etc., variations exist in medical education experiences offered in institutions around the world (Karle, 2004). Questions continue to be raised regarding the most appropriate way to assess the quality of education provided at a particular institution in relation to standards appropriate for that particular country or region of the world. Challenges exist in creating a meaningful and defensible system that is not prescriptive and allows for necessary flexibility due to local situations, resources, and needs. Despite the recent focus on the need for accreditation of medical education programs and the increasing globalization of the medical profession and migration of health care workers, there is little published research regarding medical education quality assurance oversight from an international perspective. A report based on a 1996 World Health Organization (WHO) survey of ministries of health and deans of medical schools 
indicated that almost two thirds of medical schools were accredited by an external body, although the report did not provide detailed data depicting the various processes (Boelen \& Boyer, 2001). A global study of medical education accreditation found that while over half of all countries with medical schools have a national system of accreditation, the nature of the various authorities and levels of enforcement varied considerably (van Zanten et al., 2008). A study comparing medical education accreditation systems in nine developing countries located throughout the world concluded that the trend towards instituting robust quality assurance procedures was spreading to some developing countries, where protocols similar to those used in the United States have been developed and implemented (Cueto, Jr. et al., 2006).

\section{Accreditation of Medical Education in the Caribbean}

There is a variety of oversight and formal accreditation practices in the Caribbean region. In the past, review of the educational quality of medical programs was conducted sporadically by various organizations depending on the country and the affiliations of the schools in question. The following section describes the current state of medical education accreditation in the Caribbean.

There are several incentives for a school in the region to undergo an accreditation review. For example, in order for students who are U.S. citizens to be eligible to receive federally funded student loans while studying medicine at schools outside of the United States, the schools need to meet certain requirements, including being accredited by an agency that has met a comparability determination of the accreditation process. The purpose of the U.S. Department of Education National Committee on Foreign Medical Education and Accreditation (NCFMEA) is to review the standards used by foreign countries to accredit medical schools and determine whether those 
standards are comparable to standards used to accredit medical schools in the United States

(NCFMEA, 2012). Thus medical schools located outside of the United States that seek to attract

U.S. citizen students are incentivized to seek accreditation by an agency that has been deemed

comparable by the NCFMEA.

Table 1 displays the countries/territories in the Caribbean, the number of medical schools, the extant accrediting agency(ies), and a description of the accrediting agencies' scope and availability of information to the public.

Table 1. Countries and Territories in the Caribbean That Have Open Medical Schools Listed in the International Medical Education Directory (IMED) (as of January 1, 2012) and Accreditation Information

\begin{tabular}{|c|c|c|c|c|c|}
\hline $\begin{array}{l}\text { Country / } \\
\text { Territory }\end{array}$ & $\begin{array}{l}\text { Number } \\
\text { of open } \\
\text { medical } \\
\text { schools } \\
\text { listed in } \\
\text { IMED }\end{array}$ & $\begin{array}{c}\text { Accrediting } \\
\operatorname{organization}(s)\end{array}$ & $\begin{array}{c}\text { Number of } \\
\text { medical schools } \\
\text { accredited }\end{array}$ & $\begin{array}{c}\text { Scope of } \\
\text { accrediting } \\
\text { organization }\end{array}$ & $\begin{array}{c}\text { Public } \\
\text { availability of } \\
\text { accreditation } \\
\text { process and } \\
\text { standards used } \\
\text { (if school(s) are } \\
\text { accredited) }\end{array}$ \\
\hline Anguilla* & 1 & CAAM-HP & 1 (provisional) & Voluntary & Yes \\
\hline $\begin{array}{l}\text { Antigua and } \\
\text { Barbuda }\end{array}$ & 2 & CAAM-HP & 0 & Voluntary & \\
\hline Aruba & 2 & No accrediting agency & 0 & & \\
\hline Barbados & 2 & CAAM-HP & $\begin{array}{l}1 \text { accredited } \\
1 \text { not accredited }\end{array}$ & Voluntary & Yes \\
\hline Bonaire & 1 & NVAO & 0 & Mandatory & \\
\hline $\begin{array}{l}\text { Cayman } \\
\text { Islands }\end{array}$ & 1 & ACCM & 1 & Voluntary & No \\
\hline Cuba & 14 & CEA-CU & 14 & Mandatory & No \\
\hline Curacao & 3 & No accrediting agency & 0 & & \\
\hline Dominica & 2 & MBD & $\begin{array}{l}1 \text { accredited } \\
1 \text { not accredited }\end{array}$ & Mandatory & No \\
\hline & & CAAM-HP & 1 & Voluntary & Yes \\
\hline $\begin{array}{l}\text { Dominican } \\
\text { Republic } \\
\end{array}$ & 10 & SEESCYT & 10 & Mandatory & No \\
\hline Grenada & 1 & $\begin{array}{l}\text { GMHSS } \\
\text { CAAM-HP }\end{array}$ & $\begin{array}{l}1 \\
1\end{array}$ & $\begin{array}{l}\text { Mandatory } \\
\text { Voluntary }\end{array}$ & $\begin{array}{l}\text { No } \\
\text { Yes }\end{array}$ \\
\hline Haiti & 4 & CAAM-HP & 0 & Voluntary & \\
\hline
\end{tabular}


Table 1. (Continued)

\begin{tabular}{|c|c|c|c|c|c|}
\hline $\begin{array}{l}\text { Country / } \\
\text { Territory }\end{array}$ & $\begin{array}{l}\text { Number } \\
\text { of open } \\
\text { medical } \\
\text { schools } \\
\text { listed in } \\
\text { IMED }\end{array}$ & $\begin{array}{c}\text { Accrediting } \\
\text { organization(s) }\end{array}$ & $\begin{array}{c}\text { Number of } \\
\text { medical schools } \\
\text { accredited }\end{array}$ & $\begin{array}{c}\text { Scope of } \\
\text { accrediting } \\
\text { organization }\end{array}$ & $\begin{array}{c}\text { Public } \\
\text { availability of } \\
\text { accreditation } \\
\text { process and } \\
\text { standards used } \\
\text { (if school(s) are } \\
\text { accredited) } \\
\end{array}$ \\
\hline Jamaica & 2 & CAAM-HP & $\begin{array}{l}1 \text { accredited } \\
1 \text { provisionally } \\
\text { accredited }\end{array}$ & Voluntary & Yes \\
\hline Montserrat & 1 & CAAM-HP & $\begin{array}{l}\text { Denied } \\
\text { accreditation }\end{array}$ & Voluntary & \\
\hline Puerto Rico & 4 & LCME & $\begin{array}{l}3 \text { accredited } \\
1 \text { on probation }\end{array}$ & $\begin{array}{l}\text { Voluntary } \\
\text { (Required GME } \\
\text { in the U.S.) }\end{array}$ & Yes \\
\hline Saba & 1 & $\begin{array}{l}\text { ACCM } \\
\text { NVAO }\end{array}$ & $\begin{array}{l}1 \\
0\end{array}$ & $\begin{array}{l}\text { Voluntary } \\
\text { Mandatory }\end{array}$ & No \\
\hline $\begin{array}{l}\text { Saint Kitts and } \\
\text { Nevis }\end{array}$ & 4 & $\begin{array}{l}\text { Accreditation Board of } \\
\text { St. Kitts and Nevis } \\
\text { CAAM-HP }\end{array}$ & 0 & $\begin{array}{l}\text { Unknown } \\
\text { Voluntary }\end{array}$ & \\
\hline Saint Lucia & 5 & $\begin{array}{l}\text { Medical School } \\
\text { Accreditation, Approval } \\
\text { and Monitoring } \\
\text { Committee } \\
\text { CAAM-HP } \\
\end{array}$ & 0 & Unknown & No \\
\hline $\begin{array}{l}\text { Saint Vincent } \\
\text { and the } \\
\text { Grenadines* }\end{array}$ & 2 & $\begin{array}{l}\text { National Accreditation } \\
\text { Board of St. Vincent } \\
\text { and the Grenadines } \\
\text { CAAM-HP }\end{array}$ & 0 & Unknown & No \\
\hline Sint Eustatius & 1 & NVAO & 0 & Mandatory & \\
\hline Sint Maarten & 1 & ACCM & 1 & Voluntary & No \\
\hline $\begin{array}{l}\text { Trinidad and } \\
\text { Tobago }\end{array}$ & 1 & CAAM-HP & 1 & Voluntary & Yes \\
\hline
\end{tabular}

Caribbean Community (CARICOM) Countries. In Barbados, Jamaica, and Trinidad and Tobago, up until 2003 accreditation from the General Medical Council (GMC) of the United Kingdom allowed graduates of the three campuses of the University of the West Indies medical education programs to register and practice in the United Kingdom and most other Commonwealth nations without further examinations. After this practice was discontinued, the Caribbean Accreditation Authority for Education in Medicine and Other Health Professions 
(CAAM-HP) was established in 2004 under the auspices of the Caribbean Community (CARICOM) to fulfill this role (van Zanten et al., 2009). CARICOM is a political and economic affiliation of 15 member states, and it includes most of the English-speaking islands and some Central and South American nations. Member countries are Antigua and Barbuda, the Bahamas, Barbados, Belize, Dominica, Grenada, Guyana, Haiti, Jamaica, Montserrat, Saint Kitts and Nevis, Saint Lucia, Saint Vincent and the Grenadines, Suriname, and Trinidad and Tobago. Associate members of CARICOM include Anguilla, Bermuda, the British Virgin Islands, the Cayman Islands, and the Turks and Caicos Islands.

As of January 2012, CAAM-HP-accredited medical education programs include the UWI's campuses in Barbados, Jamaica and Trinidad and Tobago, St. George's University School of Medicine in Grenada, Ross University School of Medicine in Dominica, and the University of Guyana. Saint James School of Medicine in Anguilla and the All American Institute of Medical Sciences in Jamaica both received provisional accreditation for development. The British International University in Montserrat had its provisional accreditation status withdrawn, and the University of Science, Arts and Technology in Montserrat was denied provisional accreditation status.

In some CARICOM countries, additional accreditation organizations have reviewed medical schools in the country. In Dominica, the Medical Board of Dominica (MBD) is the agency designated by the Dominican Ministry of Health and Social Security to conduct mandatory reviews of medical schools located in the country (MBD, 2006). Two schools are located in Dominica, both providing education mostly to international students from the United States and Canada. The MBD assesses a school in terms of its stated objectives, governance, administration, faculty, educational program, admissions standards, and facilities and other 
resources. Ross University has been accredited by the MBD, while All Saints University, School of Medicine, Dominica, was denied accreditation.

There is only one medical school in Grenada, St. George's University, educating primarily U.S. and Canadian students. The Grenada Ministry of Health and Social Security (GMHSS) is responsible for mandatory review of this school, and the Ministry bases the review on the New York State Education Department (NYSED) standards that were developed for evaluating international schools seeking clerkship positions for their students in the state of New York (NCFMEA, 2012).

Medical schools located in the countries of Saint Kitts and Nevis, Saint Lucia, and Saint Vincent and the Grenadines have not been accredited by CAAM-HP. Limited information is available regarding governmental review of schools located on these islands.

Accreditation Commission on Colleges of Medicine (ACCM). The Accreditation Commission on Colleges of Medicine (ACCM) is an independent, not-for-profit organization located in the Republic of Ireland. The ACCM has accredited medical schools in various Caribbean countries, including Saint Mathew's University School of Medicine in the Cayman Islands, Saba University School of Medicine on the island territory of Saba, which is a special municipality of the Netherlands, American University of the Caribbean School of Medicine located on Sint Maarten, and Medical University of the Americas (Nevis), located in the country of Saint Kitts and Nevis. The ACCM reports to use the guidelines of the LCME. The standards used to evaluate medical schools and clinical sites consist of 11 elements, including an evaluation of educational goals, corporate organization, curriculum, evaluation, admissions, resources, faculty, and facilities. Accreditation, if granted, is given for periods ranging from one 
to six years. (National Committee on Foreign Medical Education and Accreditation, 2007b,c; 2009a,b; 2011b).

Special Caribbean Municipalities of the Netherlands. On October 10, 2010, the former country of the Netherlands Antilles, which had been comprised of the island territories of Bonaire, Curacao, Saba, Sint Eustatius and Sint Maarten, dissolved politically (Ministry of Constitutional and Interior Affairs and the Project Organisation Dismantling of the Country Netherlands Antilles (POLNA), 2009). Curacao and Sint Maarten each became autonomous countries, while Bonaire, Sint Eustatius, and Saba (BES islands) became special municipalities of the Netherlands. Each of the BES islands has one medical school: Saba University School of Medicine, located on Saba, the University of Sint Eustatius School of Medicine on the island of Sint Eustatius, and Saint James School of Medicine on Bonaire.

This political change impacts the current system of medical education on the islands. For example, in order for a school to be listed in IMED, among other requirements, the Ministry of Health or Education (or other appropriate body) in the country where the school is located must verify that the school is recognized in the country to grant the M.D. or equivalent degree, and that graduates of the school are eligible to practice medicine in the country where the school is located. The source of the recognition of these schools in the BES islands is now the Netherlands.

The Nederlands-Vlaamse Accreditatie Organisatie (NVAO) (Netherlands-Flemish Accrediting Organization) is an independent agency established in 2003 in The Hague, the Netherlands. The NVAO is responsible for ensuring the quality of higher education in the Netherlands and Flanders (the Flemish speaking part of Belgium). The organization makes accreditation recommendations which are submitted to the Ministry of Education, Culture and 
Science for final approval. Accreditation by NVAO is a prerequisite for recognition of the educational program by the Ministry of Education. In 2008 the NVAO conducted a pilot study to determine the feasibility of accrediting these schools using the Dutch-Flemish framework and standards. The BES island schools are currently in a transition period, and have been given until December 31, 2012 to achieve NVAO accreditation and subsequent recognition by the Netherlands Ministry of Education (NVAO, 2012).

Aruba and Curacao. Aruba and Curacao are autonomous countries within the Kingdom of the Netherlands. Currently there is no nationally mandated accreditation process for the three medical schools located in Aruba and the three schools in Curacao, and none of the schools have achieved accreditation by an outside agency.

Cuba. There are 14 medical schools in Cuba currently listed as open in IMED. The La Comisión de Evaluación Y Acreditación de Carreras Universitarias (CEA-CU) (The Commission of Evaluation and Accreditation of University Programs) is the organization responsible for implementing the accreditation process for all programs of higher education in Cuba, including medical education. The CEA-CU process includes five quality variables: pertinence and social impact, faculty, students, infrastructure, and curriculum. Once the accreditation report is completed, it is submitted to the Junta de Acreditación Nacional (JAN) (National Accreditation Group) for final approval (CEA-CU, 2012).

Dominican Republic. The Secretaría de Estado de Educación Superior, Ciencia y Tecnología (SEESCYT) (Secretary of State for Higher Education, Science and Technology) is the organization in the Dominican Republic responsible for the accreditation of higher education science and technology institutions, which includes medical education programs. There are 10 medical programs listed in IMED, nine are affiliated with public universities and one with an 
autonomous Catholic university. The accreditation is conducted on a five-year schedule (SEESCYT, 2011).

Puerto Rico (Territory of the United States with Commonwealth Status). There are four medical schools located in Puerto Rico which are currently accredited by the LCME. Graduates from LCME-accredited Puerto Rican medical schools are not considered IMGs and are not required to be certified by the ECFMG.

\section{Accreditation in Health Professions and Other Educational Fields}

While trends of a worldwide focus on medical education quality assurance oversight have been increasing, there is a lack of published research demonstrating that accreditation activities are related to the ultimate goal: producing more highly skilled physicians and in turn, improving health care of populations. Recently there has been a call for the type of research linking undergraduate educational institution accreditation variables to the quality of health care professionals, including physicians, and evidence that standards and procedures are based on data which clearly demonstrate that schools which adhere to these protocols produce professionals who are more knowledgeable and skilled, and who are ultimately able to provide higher quality care to their patients (Davis \& Ringsted, 2006; Braithwaite et al., 2006; Joly et al., 2007; Asch et al., 2007).

Despite the increasing focus on accreditation as a mechanism to ensure minimum standards are met and to improve educational quality in various fields, limited published research was found in other educational fields investigating the impact of accreditation on outcomes (Stensaker et al., 2010). This section describes studies focused on the association between 
accreditation processes and a variety of measures, including institutional characteristics, educational program variables, and performance of graduates.

In nursing education, multiple indices of quality were investigated among accredited and nonaccredited schools located in one state. No differences were found in terms of their goals and objectives, distribution of curriculum hours, and student performances on licensure examinations. Accredited programs did show small positive differences in faculty preparation at the doctoral level and fewer graduates working outside of the nursing field (Gropper, 1996). In contrast, in the field of paramedical studies accreditation of educational programs was linked to better examination performance of students. Paramedic students who attended a nationally accredited paramedic education program were more likely to pass the national certification examination compared to students from unaccredited programs (Dickinson et al., 2006). In another study in this same field, predictors including high school class rank, highest level of education, gender, race, accreditation status of educational program, and instructor credentials, were investigated for influence on student performance. Attending an accredited program was the highest predictor of success on the national examination (Fernandez et al., 2008). In the field of marital and family therapy graduate education, students from schools accredited by one of the approved accrediting agencies were more successful on state examinations than students graduating from schools accredited by a different agency (Caldwell et al., 2011). A study on the influence of accreditation on undergraduate homeopathy education in Europe showed that accredited programs provided more extensive education and more teaching hours compared to nonaccredited programs (Viksveen \& Steinsbekk, 2011).

Outside of the health professions, some research on the association between accreditation and student outcomes has been conducted in a variety of educational fields. In a study 
measuring the impact of a change in accreditation standards used to evaluate engineering programs in the United States, findings revealed that engineering programs changed substantially as a result of implementation of the new standards. Programs increased their emphasis on required curriculum topics and active learning strategies. In addition, students graduating since the new accreditation standards took effect scored higher in all student learning outcomes specified in the new criteria (Volkwein et al., 2007). In comparing the academic engagement of students in accredited versus nonaccredited parks, recreation and leisure programs, Cole and Cole (2008) reported a small but consistent pattern of higher self-reported academic engagement for students in accredited programs compared to nonaccredited programs.

In the field of business education, the influence of accreditation by the Association to Advance Collegiate Schools of Business (AACSB) was investigated by comparing CEOs of companies who graduated from AACSB accredited versus nonaccredited schools (Jalbert et al., 2011). Findings indicated that while a larger percentage of CEOs graduated from accredited schools, the accredited school graduate CEOs did not outperform the CEOs who graduated from nonaccredited schools. An investigation of the perceived association between an accreditation process and organizational effectiveness revealed that European Quality Improvement System (EQUIS)-accredited business schools were viewed more positively by students and were more likely to attract qualified faculty and academic partners than nonaccredited schools, although students were equally satisfied with the curriculum regardless of accreditation status (Lejeune \& Vas, 2009).

In addition to evaluating the effect of accreditation on educational programs, the association between accreditation and the quality of health care services, such as the overall performance of hospitals, has been studied. In a 2011 meta-analysis investigating this field, 
general accreditation programs were found to significantly improve clinical outcomes and the quality of care of a wide spectrum of clinical conditions (Alkhenizan \& Shaw, 2011).

While many of these studies lend evidence to the value of accreditation, they are frequently limited in scope and are not in the field of undergraduate medical education. Therefore, beyond a face-validity perspective, the value of accreditation of medical education remains somewhat uncertain, with numerous unanswered legitimacy questions regarding the overall influence and demonstrated effectiveness of the process.

\section{Quality of Accreditation}

In addition to gathering data on the existence of accreditation systems and their effects, it is also important to investigate the components of accreditation, such as the specific standards used, that can be demonstrated to enhance the quality of the process. While previous investigations focused on describing the existence and some general characteristics of accreditation systems, few studies in the medical education field were found comparing or assessing the effectiveness or appropriateness of the specific standards used to make accreditation decisions. These data are necessary to support the perceived value of accreditation as a means of assuring educational program quality and fostering continued excellence.

A 1998 study conducted by the LCME, the agency that accredits medical education programs in the United States and Canada, focused on gathering evidence to validate the agency's standards. The researchers interviewed key stakeholders regarding their opinions of the perceived importance of the standards. In general, respondents believed that the accreditation standards were important, although some respondents noted confusion about meaning and measures of compliance (Kassebaum et al., 1998). A survey of stakeholders regarding standards 
used to accredit medical schools in South Korea revealed that all standards were deemed to have adequate content validity, although the level of importance of standards varied depending on the position and previous experience of the survey respondents (Yang, 2002).

The literature concerned with validating or evaluating accreditation standards in other fields is sparse. Hagerty and Stark (1989) emphasized educational outcomes and faculty's perceptions of the rigor of accreditation standards in ten professional fields (architecture, business administration, engineering, education, law, library science, nursing, pharmacy, journalism, and social work). Results showed that, overall, the standards used by the specialized accrediting agencies did not strongly emphasize student outcomes (e.g., professional competencies, such as technical or interpersonal competence, and professional attitudes, such as ethics and motivation for lifelong learning). Faculty in nursing, engineering, and social work perceived their accrediting agencies' standards as most rigorous, and overall faculty perceptions of rigor were not systematically associated with explicitly outcome-related standards.

In light of the increased emphasis on accreditation of medical education worldwide and the lack of recent data describing best practices in the development and use of specific accreditation standards, the purpose of the second phase of the present research was to use a globally diverse pool of medical education accreditation experts to evaluate the importance of a large set of standards commonly used by medical education accreditation agencies throughout the world (van Zanten, et al., 2012). These data are a critical component of evidence that can be used to validate the standards and associated accreditation systems and also for understanding and assessing the importance of the decisions made by various accrediting agencies who utilize these standards. Data from Phase 2 were used to create the rating scheme to quantify the quality of select accrediting agencies. 


\title{
CHAPTER 2
}

\section{RESEARCH DESIGN AND METHODS}

\author{
Phase 1 (Existence of Accreditation)
}

\section{Study Population}

ECFMG maintains a database of individuals who currently attend or who have graduated from a medical school located outside of the United States and Canada and who apply for ECFMG certification. The database contains each individual's demographic information, examination history status, medical school variables, and certification status. The ECFMG certifies approximately 10,000 physicians per year. All individuals who took one or more examinations (described below) leading to ECFMG certification during the five-year study period (January 1, 2006 through December 31, 2010) and who graduated from or attended at the time of testing a school located in a country that met the inclusion criteria (described below), are included in the study population.

\section{Variables}

\section{Student/ Graduate (Individual) Variables}

The following individual level data are included in the database and are used for this study: gender $($ male $=1$, female $=0)$, number of years that have elapsed since graduation from medical school when an individual took an examination (took examination prior to graduation or $<3$ years since graduation $=1$, took examination $\geq 3$ years since graduation $=0$ ), self-reported native language $($ English $=1$, all other languages $=0$ ), and medical school attended by the 
physician (or if the individual has not yet graduated, the medical school attended by the student at the time of examination).

\section{Examination Variables}

The database includes examination history for each individual, including examination performance on all attempts.

Step 1 (basic science) is a multiple-choice examination offered at test centers worldwide.

Step 1 assesses an examinee's ability to understand and apply important concepts of the sciences basic to the practice of medicine, with special emphasis on principles and mechanisms underlying health, disease, and modes of therapy (USMLE, 2012).

Step 2 Clinical Knowledge (CK) is also a multiple-choice examination offered at test centers worldwide. Step 2 CK assesses an examinee's ability to apply medical knowledge, skills, and understanding of clinical science essential for the provision of patient care under supervision (USMLE, 2012).

Step 2 Clinical Skills (CS) is a performance-based examination administered at five test centers in the United States. In the CS, standardized patients (lay persons trained to portray patients) are used to evaluate a physician's ability to gather information from patients, perform physical examinations, and communicate findings to patients and colleagues. The CS was implemented in 2004 (USMLE, 2012). From 1998 to 2004, a similar examination, the Clinical Skills Assessment (CSA), was a requirement for IMGs seeking ECFMG certification.

ECFMG certification requirements include, among other things, passing scores on Step 1, Step 2 CK, and Step 2 CS. The USMLE examination series can be taken in any order. In many international medical schools with educational programs oriented towards preparing students to enter U.S. residencies, such as many schools in the Caribbean, a passing score on Step 1 is 
required for students prior to entering the clinical training phase of education. Conversely, most IMGs who attend medical schools educating physicians mainly for the country's own domestic supply and who intend to seek a residency position in the United States wait until after they have graduated from medical school before taking the examinations leading to ECFMG certification.

The outcome measures used in this study are first-attempt pass rates on Step 1, Step 2 CK, and Step 2 CS.

\section{Medical Schools}

There are currently over 2,000 medical schools in more than 170 different countries or territories (hereafter described as "countries") listed in the International Medical Education Directory (IMED). To fulfill ECFMG certification requirements, an individual's medical school must be listed in IMED, and the year of graduation must be an acceptable year, defined as a year that the school was open and recognized by the appropriate entity, (i.e, Ministry of Education or Ministry of Health). In addition, IMGs must have been awarded credit for at least four credit years (academic years for which credit has been given toward completion of the medical curriculum) by a medical school that is listed in IMED.

\section{Medical School / Country Variable: Accreditation}

For the purposes of this study, an accreditation system is defined as a process by which an authority, either governmental or independently administered but accountable at a governmental level, reviews and evaluates an educational program and/or institution using

clearly specified criteria and procedures on a cyclical basis. Accreditation status was determined as of December 2009. For virtually all countries, determination of the existence (or nonexistence) of a system of accreditation was straightforward. The wide variety of sources used to make this determination included the FAIMER Directory of Organizations that 
Recognize/Accredit medical schools (FAIMER, 2012), the U.S. Department of Education National Committee on Foreign Medical Education and Accreditation (NCFMEA, 2012), accrediting agency websites, governmental websites, and published articles in peer-reviewed journals. For three countries, the information available to the public (e.g., websites) was conflicting regarding the existence of a system of accreditation. In these cases, the country was designated as having a system of accreditation only if confirmation was obtained from multiple individuals with knowledge of the situation in the country.

For each of the countries with medical schools listed in IMED, accreditation data (country level) were coded as follows:

- Did a system of accreditation specifically for medical schools or for all higher education institutions exist at the national level?

○ If yes, was the system mandatory or voluntary?

If yes, was the accreditation conducted by a government authority or independent organization?

- If no, was such a system under development?

- Was it known that such a system of accreditation does not exist?

- Was it unknown if such a system exists or does not exist?

For this study, countries are only included in the data set if

- For each of the three USMLE examinations (Step 1, Step 2 CK, and Step 2 CS), there were at least 10 individuals who took each examination during the study period $(2006-2010)$. 
- There was no system of accreditation specifically for medical schools or for all higher education institutions at the national level,

OR

- There was a system of accreditation specifically for medical schools or for all higher education institutions at the national level and it was mandatory, OR

- There was a system of accreditation specifically for medical schools or for all higher education institutions at the national level, and it was voluntary, and all schools were accredited.

Countries (and all schools within the country) were coded as follows: all schools in the country were accredited $=1$, all schools in the country were not accredited $=0$.

\section{Analyses}

In Phase 1, first-attempt pass rates for each examination (Step 1, Step 2 CK, and Step 2 CS) were calculated separately based on each of the variables of interest. At the individual level, the variables of interest were gender (male versus female), number of years elapsed since graduation at the time the individual took an examination ( $<3$ versus $\geq 3$ years), and self-reported native language (English versus all others). Based on literature described below, these personlevel variables have been demonstrated to be associated with examination performance. Therefore, to adequately investigate the association of accreditation and examination performance, it was necessary first to determine the effects of these person-level variables and account for them in subsequent analyses. 
At the school/country level, the variable of interest was accreditation status. Countries with voluntary accreditation resulting in some schools achieving accreditation and some not, were eliminated from the data set (i.e., Indonesia, Mexico, Philippines, and Turkey). Therefore all schools within the same country had the same accreditation status. Countries with fewer than 10 takers for each examination during the study period were also eliminated from the data set. Statistical Methods

In addition to first-attempt pass rates by each variable, unadjusted Odd Ratios (ORs), 95\% Confidence Intervals (CIs), and Pearson Chi-Square $\left(x^{2}\right)$ significance levels are reported for all three examinations (Step 1, Step 2 CK, and Step 2 CS) for each of the three person-level variables and for the accreditation variable. These statistics were used to depict the differences in first-attempt pass rates for each examination by each of the person-level variables.

Next, separately for each examination, the generalized estimating equations (GEE) method was used to investigate the association between accreditation status and first-attempt pass rates. This analysis, a generalization of ordinary linear regression that allows for response variables that have other than a normal distribution (i.e., accreditation status), was used to control for the person-level variables (gender, years elapsed since graduation at time of testing, selfreported native language) which have been demonstrated to be associated with examination performance, and takes into account the relatedness of individuals in the same cluster, or grouping (medical school/country). A model that predicts an $\mathrm{x}$ rate increase in pass rates based solely on medical school accreditation status is unlikely to generalize well over small schools and large schools because the odds of an individual passing examinations is not necessarily a linear function of medical school accreditation status. The GEE method, with the use logit link function, takes this differentiation into account. This model uses weighted combinations of 
observations (i.e., the number of students/graduates within each country who took a particular examination and the proportion of males versus females, etc.) to use the appropriate amount of information from each of the person-level data variables in determining the association between the actual variable of interest (accreditation) and the dependent variable (first-attempt pass rate) (Hanley et. al., 2003).

Following the investigation of the association between accreditation and examination performance at the global level, the same analyses were then conducted, by examination, on the data from students/graduates who attended medical schools located in the Caribbean, and then again on data from students/graduates who attended medical schools not located in the Caribbean. These analyses on the Caribbean data were conducted because approximately one quarter of the study sample of students/graduates seeking ECFMG certification attended schools located in this region, and the proportion of Caribbean-educated physicians has been increasing over the past decade.

Phase 2 (Quality of Accreditation)

There is wide variability in the specific standards and processes used around the world to accredit educational programs. Accreditation systems vary in the rigor and detail employed. The aim of Phase 2 was to evaluate the quality of a select group of accrediting agencies and the association between quality of the process and student/graduate outcomes. 


\section{Development of Accreditation System Quality Rating}

\section{Survey Design}

The World Federation for Medical Education (WFME) has developed a Trilogy of Global Standards for Quality Improvement. These resources include a document, Standards in Basic Medical Education, aimed at helping organizations assess the quality of medical schools leading to an undergraduate degree (WFME, 2003). This document is not designed to be used restrictively, but instead is intended to function as a template for national agencies interested in developing accreditation procedures and has been widely used in countries throughout the world as a model for establishing national and regional accreditation procedures (Karle, 2006).

A survey was developed that consisted of the entire set of WFME standards, supplemented with additional standards taken from numerous published documents describing the criteria used to accredit or evaluate undergraduate medical education programs around the world. The organizations that produced these additional standards included: the Accreditation Commission on Colleges of Medicine (ACCM), the Australian Medical Council (AMC), the Caribbean Accreditation Authority for Education in Medicine and other Health Professions (CAAM-HP), the Commission on Osteopathic College Accreditation (COCA), the Gulf Cooperation Council Medical Colleges Dean's Committee (GCCMCDC), the Liaison Committee on Medical Education (LCME), the Medical Council of India (MCI), and the Pakistan Medical and Dental Council (PMDC). Standards from these supplemental agencies describing concepts that were already covered in the WFME standards were not repeated in the survey. Thus the survey was designed to represent the universe of relevant standards used around the world. The large majority of standards in the survey were reproduced verbatim from the original sources, although some text was modified to ensure grammatical consistency within the survey. 
The survey (Appendix B) consisted of 150 standards organized into the nine WFME topic areas as follows:

1. Mission and Objectives (10 standards)

2. Educational Program (34 standards)

3. Assessment of Students (11 standards)

4. Students (30 standards)

5. Academic Staff / Faculty (12 standards)

6. Educational Resources (25 standards)

7. Program Evaluation (8 standards)

8. Governance and Administration (17 standards)

9. Continuous Renewal (3 standards)

The category Mission and Objectives consisted of standards that refer to the overall goals and purposes of the medical school and expected competencies of the graduates. Education Program standards pertained to the medical school's curriculum and other educational opportunities for students. Assessment of Students standards related to the testing and evaluation of students' knowledge, skills, and attitudes. The Students category referred to standards on admissions, selection criteria, size of the student body, and students' rights. Academic Staff / Faculty standards pertained to issues surrounding the individuals who deliver the curriculum to the students. The Educational Resources category referred to standards regarding the physical learning environment, the library, technology, assets for visiting / transferring students, and so on. Program Evaluation standards pertained to mechanisms for assessing and subsequent modification of the educational program. Governance and Administration standards related to 
the leadership and ongoing management of the school. Finally, the Continuous Renewal category consisted of standards ensuring that the medical education program remains relevant.

The survey instructions and consent form are included in Appendix A. Respondents were instructed to read each of the 150 standards and then rate the standard based on their expert opinions of the relative importance of the standard in determining and ensuring the quality of undergraduate medical education programs. Respondents were explicitly requested to base their ratings only on the appropriateness of the content or meaning of the standard, not on the level of written clarity of the standard or their opinion of the degree of attainability of the standard. The experts were provided with the following scale to rate each of the standards: Not important (The standard is not useful for determining quality.) Important but not essential (The standard is somewhat useful for determining quality but is not required.)

(N/R) Not able to rate (The meaning of the standard is not clear.)

The survey was piloted with a former president of a large national medical education accrediting organization, and a small number of edits were made to the survey instructions and formatting to ensure clarity of the task.

\section{Survey Administration}

Twenty-two experts in the field of medical education accreditation were contacted and provided with a description of the research project and a request to complete the survey anonymously. Many of these individuals were current or former senior staff of local, regional, or international accrediting agencies and have published extensively on the topic of accreditation or medical school quality. The experts' names and contact information were compiled from 
freely available sources. They were located in a wide geographic range of countries, including Australia, Bahrain, Brazil, Canada, Denmark, Dominica, Egypt, India, Jordan, Mexico, Nigeria, the Philippines, Poland, South Africa, Sweden, the United Arab Emirates, the United Kingdom, and the United States. Six of the contacted experts were women.

The experts were asked to return the completed survey in the included anonymous return envelope. They were also notified that their data would be coded under a random identifier that would not be linked to the respondent personally, and individual responses to the survey would not be identified in any way in the reports or subsequent publications.

\section{Ethical Approval}

Ethical approval was obtained by the Temple University Office for Human Subjects Protections Institutional Review Board. On January 25, 2010, this study (Phase 1 and Phase 2) was determined by expedited review to qualify for exemption. The exemption code for this study is 12936 .

\section{Survey Analyses}

Descriptive statistics were calculated by respondent. For each rater, the number of ratings provided (out of a possible total of 150) was determined. Next, the mean of all ratings provided and standard deviations were calculated. This was done to investigate the overall stringency or leniency and variability in ratings provided for each of the raters.

Following the analyses of the raters, descriptive statistics were calculated across individual standards. This was done to quantify the importance of individual standards and enable a relative ranking of their importance. For each standard, the mean rating received from all raters and the variance was determined. Standards that received a rating of 3 (essential) from 
all survey respondents were considered required criteria that should be incorporated by accrediting agencies.

\section{Study Population}

The Phase 2 population is a subset of the Phase 1 population. Phase 2 includes those individuals who met the inclusion criteria for Phase 1 and who graduated from /attended at the time of testing a school located in a country that met the accreditation inclusion criteria described below. These countries include the following: Australia, Barbados, Cayman Islands, Dominica, Grenada, India, Jamaica, New Zealand, Nigeria, Pakistan, Poland, Saba (Special Municipality of the Netherlands), Saudi Arabia, Sint Maarten, South Korea, Switzerland, Trinidad and Tobago, and the United Kingdom.

\section{Variables}

\section{Student /Graduate (Individual) Variables}

The student/graduate (individual) variables for Phase 2 were the same as the variables for Phase 1.

\section{Examination Variables}

The examination variables for Phase 2 were the same as the variables for Phase 1.

\section{Medical Schools}

The inclusion criteria for medical schools described above for Phase 1 were the same criteria for Phase 2.

Medical School / Country Variable: Accreditation

The definition of an accreditation system described in Phase 1 is the same as in Phase 2. The countries included in Phase 2 also met the following criteria: 
- There was a system of accreditation specifically for medical schools or for all higher education institutions at the national level, and

- the system was mandatory, or,

o the system was voluntary and all schools were accredited.

AND

- For each of the three USMLE examinations (Step 1, Step 2 CK, and Step 2 CS), there were at least 10 individuals who took each examination during the period $2006-2010$.

\section{AND}

- The accreditation standards used by the country to accredit the medical schools in the country were available in English.

AND

- The accreditation standards were available either on the accrediting agency's website or by written request.

\section{Analyses}

The specific standards used to accredit undergraduate medical education programs in the countries included in Phase 2 were analyzed for inclusion of the essential standards (i.e., standards that received a rating of 3 [Essential] by all accreditation experts).

Data from the accrediting agencies and associated countries that had the same number of the 14 essential standards incorporated into their standards were combined together into groups. First-attempt pass rates for each examination (Step 1, Step 2 CK, and Step 2 CS) were calculated separately for each of the groups. 
Next, the countries were given a quality grade. The Grade A group consisted of those countries that use an accreditation system with $80 \%$ or more of the essential standards. The Grade B group consisted of countries that use an accreditation system with less than $80 \%$ of the essential standards.

First-attempt pass rates for each examination (Step 1, Step 2 CK, and Step 2 CS) were first calculated separately for each country included in the Phase 2 population. Next, firstattempt pass rates for the three examinations were calculated for the Grade A group and the Grade B group. Finally, examination performance was analyzed based on each of the specific essential standards used by the agency accrediting the medical school attended by the students/graduates. For each of the 14 essential criteria, first-attempt pass rates were calculated for the students/graduates who attended medical schools that were accredited by agencies that used the essential criteria, and this percentage was compared to the first-attempt pass rates for the students/graduates that attended medical schools that were accredited by agencies that did not employ the essential criteria. 


\section{CHAPTER 3}

\section{RESULTS}

Phase 1 (Existence of Accreditation)

\section{Countries (Global)}

As of January 2011, there were 173 countries with medical schools listed in IMED. Of these 173 countries, there were 118 countries that had 10 or more USMLE test takers for each of the three examinations during the study period and information on extant accreditation systems. Of these 118 countries that met the threshold of test takers and accreditation information, 77 countries had a national system of accreditation, and 41 did not meet the criteria for having a system of accreditation. Of the 77 countries with a national system of accreditation, in 68 of the countries the system was mandatory, and in nine of the countries the system was technically voluntary, but all schools had undergone the process and were accredited.

\section{Countries (Caribbean)}

Nineteen countries in the Caribbean region met the study criteria for inclusion: Antigua and Barbuda, Aruba, Barbados, Bonaire (special municipality of the Netherlands), Cayman Islands, Cuba, Curacao, Dominica, Dominican Republic, Grenada, Haiti, Jamaica, Montserrat, Saba (special municipality of the Netherlands), Saint Kitts and Nevis, Saint Lucia, Sint Eustatius (special municipality of the Netherlands), Sint Maarten, and Trinidad and Tobago. Anguilla and Saint Vincent and the Grenadines did not meet the inclusion criteria of a minimum of 10 individuals taking each of the three examinations. Puerto Rico was not included in the analysis 
because graduates of Puerto Rican schools are considered graduates of U.S. medical schools, not IMGs. Of these Caribbean countries, 11 had a national system of accreditation or used a government appointed outside accreditor, and in eight countries there was no system of accreditation conducted by an organization that met the criteria to be considered an accrediting body.

\section{Countries (Non-Caribbean)}

The remaining 99 countries were used in the non-Caribbean analyses. (There were 118 countries in the global group, 19 countries in the Caribbean group, and 99 countries in the nonCaribbean group.)

\section{Sample Size (Students/Graduates)}

During the study period (January 1, 2006 - December 31, 2010), for Step 1 there were over 67,000 students/graduates who took the examination for the first time who graduated from, or were currently attending, a school in a country that met the inclusion criteria; approximately 55,600 took Step 2 CK and 58,300 took Step 2 CS. Of these individuals, for each of the three examinations, over one quarter of the test takers graduated from, or were students at the time of testing at, a school located in the Caribbean.

Data on the variables of interest were missing for a very small number of individuals. Table 2 displays the numbers of individuals, by examination, and by variable, for each of the three examinations. 
Table 2. Numbers of Test Takers for Step 1, Step 2 CK, and Step 2 CS During the Period 2006 2010, by Gender, Years Since Graduation, Native Language, School Accreditation Status

\begin{tabular}{llrrrr}
\hline & Gender & $\begin{array}{c}\text { Years since } \\
\text { graduation }\end{array}$ & $\begin{array}{c}\text { Native } \\
\text { language }\end{array}$ & $\begin{array}{c}\text { School } \\
\text { accreditation } \\
\text { status }\end{array}$ \\
\hline Step 1 & Global & 67,063 & 67,068 & 67,049 & 67,068 \\
& Caribbean & 18,326 & 18,330 & 18,327 & 18,330 \\
& Non-Caribbean & 48,737 & 48,738 & 48,722 & 48,738 \\
\hline Step 2 CK & Global & 55,600 & 55,602 & 55,594 & 55,602 \\
& Caribbean & 13,266 & 13,268 & 13,264 & 13,268 \\
& Non-Caribbean & 42,334 & 42,334 & 42,330 & 42,334 \\
\hline Step 2 CS & Global & 58,266 & 58,268 & 58,259 & 58,268 \\
& Caribbean & 14,223 & 14,225 & 14,221 & 14,225 \\
& Non-Caribbean & 44,043 & 44,043 & 44,038 & 44,043 \\
\hline
\end{tabular}

Many of the individuals took more than one examination during the study period and retook (an) examination(s) that they had previously failed. For this study, for each of the three examinations separately (Step 1, Step 2 CK, and Step 2 CS), only the individual's first attempt (pass versus fail) was used in the analyses. Overall, there were 94,741 unique individuals in the data set. These individuals were the total population of students/graduates attending or graduated from medical schools located in countries that met the inclusion criteria and who took one or more USMLE examinations leading to ECFMG certification during the study period.

Step 1 (Global)

The results for Step 1, for the entire population of test takers during the study period, are presented in Figure 3. Males were more likely to pass the examination on their first attempt $(76.1 \% ; \mathrm{n}=38,532)$ as compared to females $(69.8 \% ; \mathrm{n}=28,531)$, a difference of $6.3 \%$ (odds ratio $[\mathrm{OR}]=1.4$, confidence interval $\left.[\mathrm{CI}], 1.3-1.4, x^{2}=336.1, \mathrm{p}<.0001\right)$. Individuals who took Step 1 in a time period less than three years since graduation had a $4.2 \%$ higher first-attempt pass rate 
$(75.0 \% ; \mathrm{n}=42,217)$ compared to those individuals who took the examination in a time period equal to or greater than three years since their graduation from medical school (70.8\%;

$\mathrm{n}=24,851)\left(\mathrm{OR}=1.2, \mathrm{CI}, 1.2-1.3, x^{2}=140.3, \mathrm{p}<.0001\right)$. Native English speakers had a $3.1 \%$ lower first-attempt pass rate. Individuals who self-reported English as their native language had a first-attempt pass rate of $71.3 \%(\mathrm{n}=21,707)$. Those with a native language other than English had a first-attempt pass rate of $74.4 \%(\mathrm{n}=45,342)\left(\mathrm{OR}=0.9, \mathrm{CI}, 0.8-0.9, x^{2}=140.3, \mathrm{p}<.0001\right)$.

Accreditation was positively associated with Step 1 performance, with students/graduates of accredited schools having a first-attempt pass rate of $75.4 \%(\mathrm{n}=56,094)$ compared to a pass rate of $63.3 \%(n=10,974)$ for those individuals from nonaccredited schools. This represents a $12.1 \%$ increase associated with accreditation $\left(\mathrm{OR}=1.8, \mathrm{CI}, 1.7-1.9, x^{2}=681.3, \mathrm{p}<.0001\right)$.

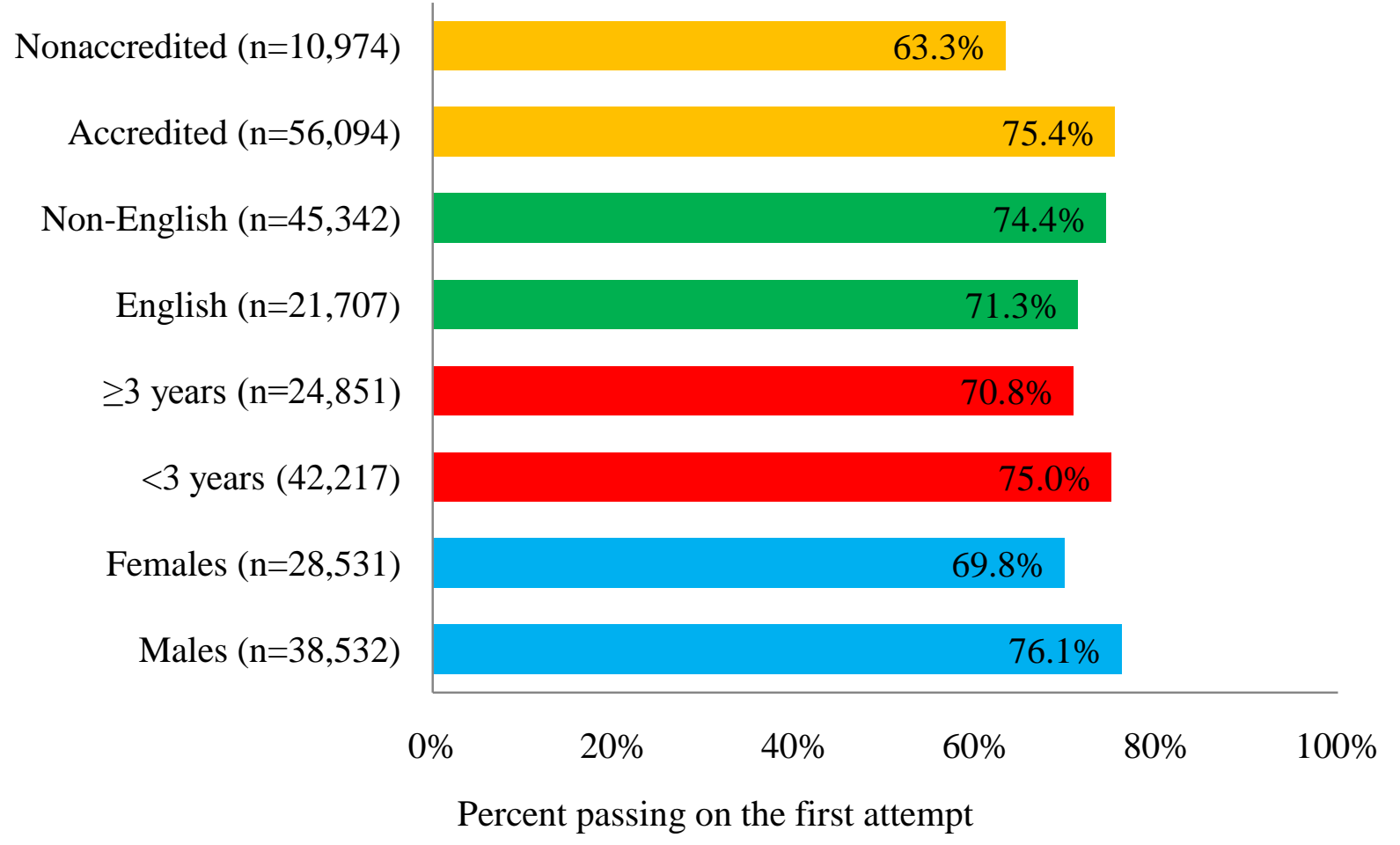

Figure 3. Step 1 first-attempt pass rates by gender, years since graduation, native language, and school accreditation status for the entire study population 
After controlling for factors that are associated with performance (gender, years since graduation, native language), accreditation continued to be positively associated with firstattempt pass rates. The odds of a student/graduate of an accredited school passing Step 1 on the first attempt were 1.8 times greater than the odds of a student/graduate from a nonaccredited school passing the examination on the first attempt.

\section{Step 1 (Caribbean)}

The results for Step 1 for only the students/graduates of schools located in the Caribbean are presented in Figure 4. Males were more likely to pass the examination on their first attempt $(69.9 \% ; n=10,171)$ as compared to females $(63.2 \% ; n=8,155)$. This gender association is a difference of $6.7 \%\left(\mathrm{OR}=1.3, \mathrm{CI}, 1.3-1.4, x^{2}=90.69, \mathrm{p}<.0001\right)$. Individuals who took Step 1 in a time period less than three years since graduation had a higher first-attempt pass rate $(68.8 \% ; n=17,037)$ compared to those individuals who took the examination in a time period equal to or greater than three years since their graduation from medical school $(41.6 \% ; n=1,293)$, a difference of $27.2 \%\left(\mathrm{OR}=3.1, \mathrm{CI}, 2.8-3.5, x^{2}=402.5, \mathrm{p}<.0001\right)$. In contrast to the Step 1 results of the entire population, in the Caribbean individuals who self-reported English as their native language had a higher first attempt pass rate $(71.0 \% ; n=13,233)$ compared to those with a native language other than English $(56.3 \%$; $n=5,094)$, a difference of $14.7 \%(\mathrm{OR}=1.9, \mathrm{CI}, 1.8-$ $\left.2.0, x^{2}=360.5, \mathrm{p}<.0001\right)$.

In the Caribbean, there were 40 accredited schools located in 11 countries with 14,676 test takers, and 17 nonaccredited schools located in 8 countries with 3,654 test takers included in the study. Accreditation was positively associated with Step 1 performance (35.6\% difference), with students/graduates of accredited schools having a first-attempt pass rate of $74.0 \%$ compared 
to a pass rate of $38.4 \%$ for those individuals from nonaccredited schools (OR = 4.6, CI, 4.2 - 4.9, $\left.x^{2}=1680.2, \mathrm{p}<.0001\right)$.

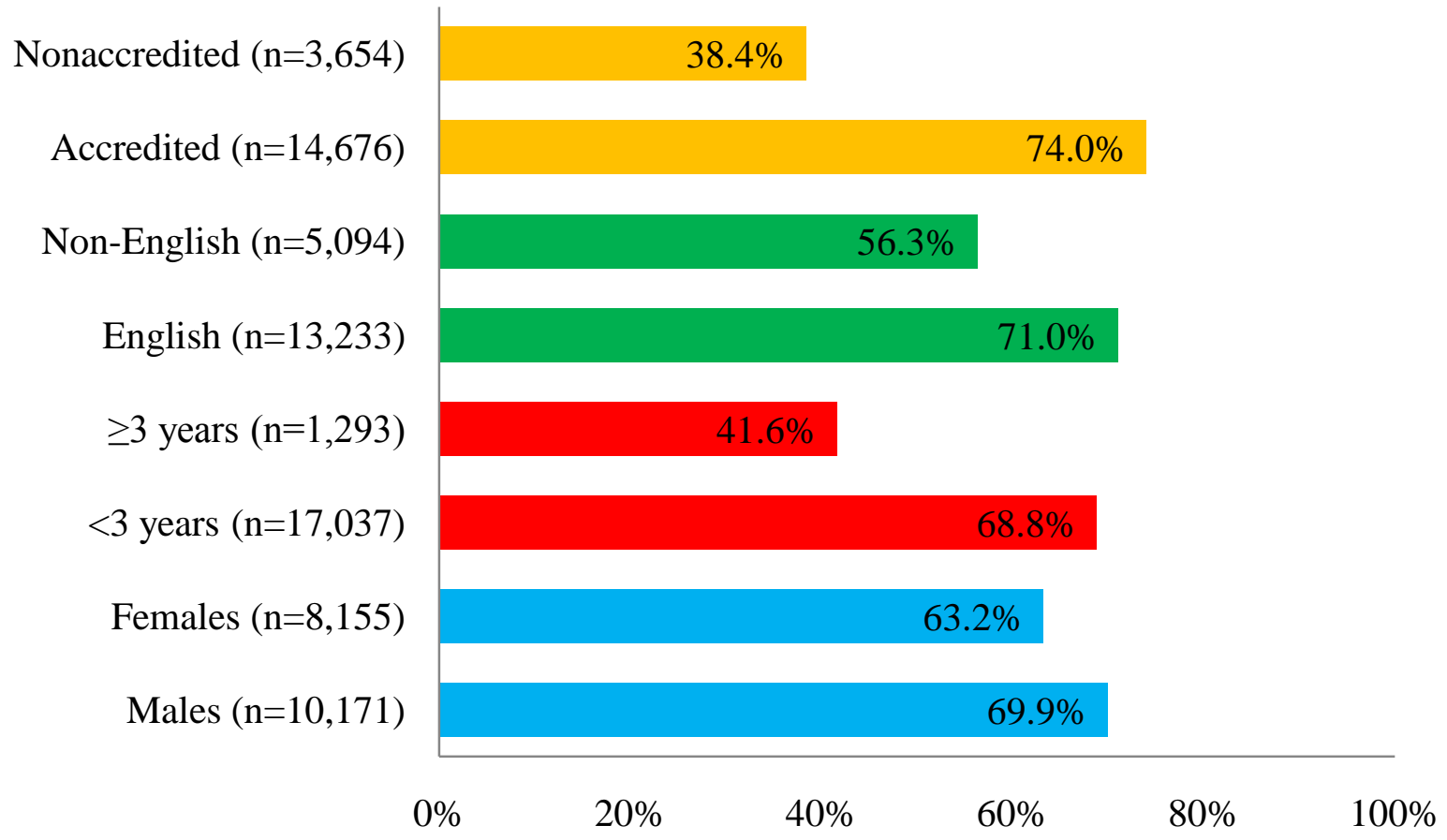

Percent passing on the first attempt

Figure 4. Step 1 first-attempt pass rates by gender, years since graduation, native language, and school accreditation status for students/graduates of Caribbean medical schools

Taking into account through a generalized estimating equations model factors that are associated with performance (gender, years since graduation, native language) accreditation remained positively associated with first-attempt pass rates. For this population from the Caribbean, the odds of a student/graduate of an accredited school passing Step 1 on the first attempt were 4.9 times greater than the odds of a student/graduate from a nonaccredited school passing the examination on the first attempt. 


\section{Step 1 (Non-Caribbean)}

The results for Step 1, for individuals who were students/graduates of schools located in all non-Caribbean countries, are presented in Figure 5. Similar to the results for the global and Caribbean groups for this examination, males were more likely to pass the examination on their first attempt $(78.3 \% ; \mathrm{n}=28,361)$ compared to females $(72.4 \% ; \mathrm{n}=20,376)$. This is a $5.9 \%$ difference in first attempt pass rates $\left(\mathrm{OR}=1.4, \mathrm{CI}, 1.3-1.4, x^{2}=227.9, \mathrm{p}<.0001\right)$. NonCaribbean educated individuals who took Step 1 in a time period less than three years since graduation had a higher first-attempt pass rate $(79.1 \%$; $n=25,180)$ compared to those individuals who took the examination in a time period equal to or greater than three years since their graduation from medical school $(72.4 \%$; $\mathrm{n}=23,558)$, a difference of $6.7 \%(\mathrm{OR}=1.4, \mathrm{CI}, 1.4-$ $\left.1.5, x^{2}=300.0, \mathrm{p}<.0001\right)$. Similar to the Step 1 results of the global group, individuals from non-Caribbean schools who self-reported a native language other than English had a 5.0\% higher first-attempt pass rate $(76.7 \% ; n=40,248)$ compared to those with English as their native language $(71.7 \% ; \mathrm{n}=8,474)\left(\mathrm{OR}=0.7, \mathrm{CI}, 0.7-0.8, x^{2}=97.4, \mathrm{p}<.0001\right)$.

There was effectively no association between accreditation and Step 1 performance for the non-Caribbean educated group, with students/graduates of accredited schools having a firstattempt pass rate of $75.9 \%(n=41,418)$ compared to a pass rate of $75.8 \%(n=7,320)$ for those individuals from nonaccredited schools ( $\left.\mathrm{OR}=1.0, \mathrm{CI}, 0.9-1.1, x^{2}=0, \mathrm{p}=.9209\right)$. 


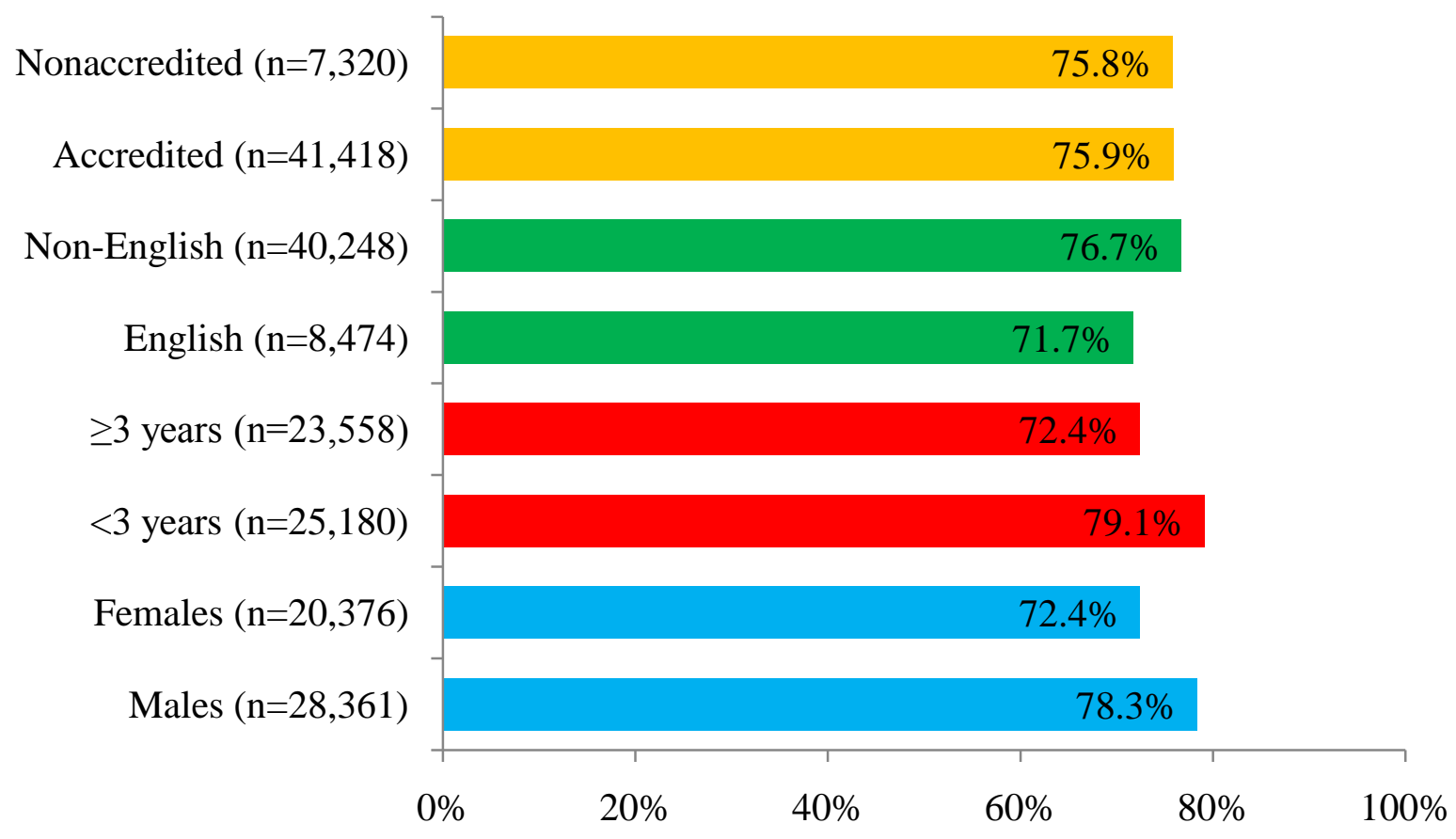

Percent passing on the first attempt

Figure 5. Step 1 first-attempt pass rates by gender, years since graduation, native language, and school accreditation status for students/graduates of non-Caribbean medical schools

After controlling for factors associated with performance (gender, years since graduation, native language), accreditation did not have an association with Step 1 first-attempt pass rates for this non-Caribbean educated group. The odds of a student/graduate of an accredited school passing Step 1 on the first attempt were equivalent (1.0) to the odds of a student/graduate from a nonaccredited school passing the examination on the first attempt.

\section{Step 2 Clinical Knowledge (CK) (Global)}

The results for Step $2 \mathrm{CK}$, for the entire population of test takers during the study period, are presented in Figure 6. In contrast to the results for Step 1, for this examination males were 
slightly less likely to pass the examination on their first attempt $(81.4 \%$; $=32,195)$ as compared to females $(83.0 \% ; \mathrm{n}=23,405)$, a difference of $1.6 \%\left(\mathrm{OR}=0.9, \mathrm{CI}, 0.8-0.9, x^{2}=23.4, \mathrm{p}<\right.$ $.0001)$. There was little difference $(0.8 \%)$ in first-attempt pass rates between individuals who took Step $2 \mathrm{CK}$ in a time period less than three years since graduation $(82.4 \% ; \mathrm{n}=30,020)$, as compared to those individuals who took the examination in a time period equal to or greater than three years since their graduation from medical school $(81.6 \%$; $=25,582)(\mathrm{OR}=1.1, \mathrm{CI}, 1.0-$ $\left.1.1, x^{2}=6.9, \mathrm{p}=.009\right)$. Similar to the global and non-Caribbean results for Step 1, individuals who self-reported English as their native language had a lower first-attempt pass rate (78.6\%; $\mathrm{n}=16,710)$ as compared to those with a native language other than English $(83.5 \% ; \mathrm{n}=38,884)$, a difference of $4.9 \%\left(\mathrm{OR}=0.7, \mathrm{CI}, 0.7-0.8, x^{2}=191.8, \mathrm{p}<.0001\right)$.

Accreditation was positively associated with Step 2 CK performance, a difference of $2.9 \%$, with students/graduates of accredited schools having a first-attempt pass rate of $82.5 \%$ $(n=47,701)$ compared to a pass rate of $79.6 \%(n=7,901)$ for those individuals from nonaccredited schools $\left(\mathrm{OR}=1.2, \mathrm{CI}, 1.1-1.3, x^{2}=37.9, \mathrm{p}<.0001\right)$. 


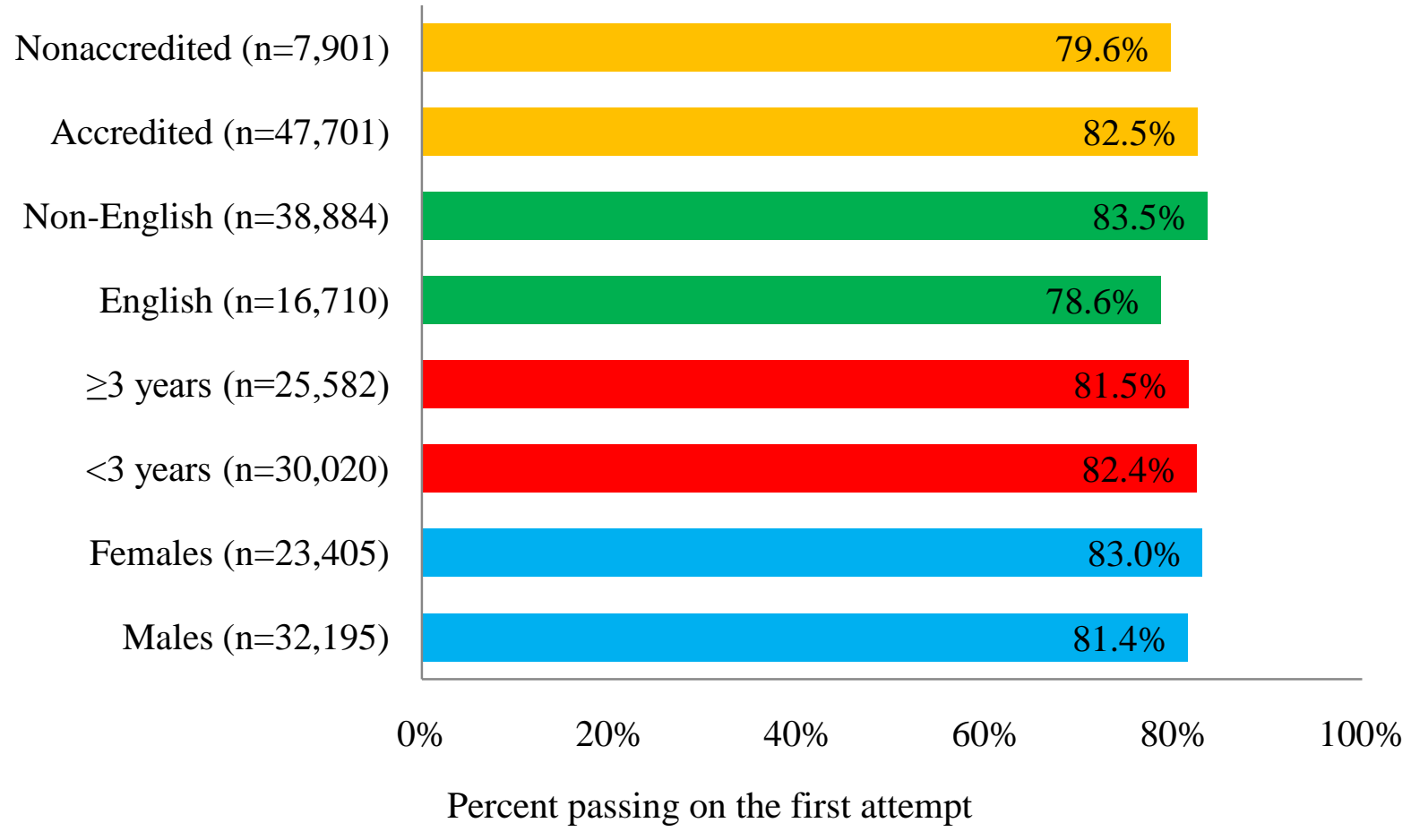

Figure 6. Step 2 CK first-attempt pass rates by gender, years since graduation, native language, and school accreditation status for the entire study population

After controlling for factors that are associated with performance (gender, years since graduation, native language), accreditation continued to have a slight positive association with Step 2 CK first-attempt pass rates. The odds of a student/graduate of an accredited school passing Step $2 \mathrm{CK}$ on the first attempt were 1.3 times greater than the odds of a student/graduate from a nonaccredited school passing the examination on the first attempt.

\section{Step 2 Clinical Knowledge (CK) (Caribbean)}

The results for Step $2 \mathrm{CK}$, for only the individuals who were students/graduates of schools located in the Caribbean, are presented in Figure 7. Similar to the global results for this examination, males were less likely to pass the examination on their first attempt $(73.8 \%$; 
$\mathrm{n}=7,508)$ as compared to females $(76.1 \% ; \mathrm{n}=5,758)$. This is a $2.3 \%$ difference in first-attempt pass rates $\left(\mathrm{OR}=0.9, \mathrm{CI}, 0.8-1.0, x^{2}=9.1, \mathrm{p}=.0003\right)$. Individuals who took Step $2 \mathrm{CK}$ in a time period less than three years since graduation had a higher first-attempt pass rate $(75.6 \%$; $\mathrm{n}=12,082$ ) compared to those individuals who took the examination in a time period equal to or greater than three years since their graduation from medical school $(66.4 \% ; n=1,186)$, a difference of $9.2 \%\left(\mathrm{OR}=1.6, \mathrm{CI}, 1.4-1.8, x^{2}=47.7, \mathrm{p}<.0001\right)$. In contrast to the results of the entire population, and similar to the Caribbean-only results for Step 1, individuals from schools located in the Caribbean who self-reported English as their native language had a $5.9 \%$ higher Step 2 CK first-attempt pass rate $(76.3 \% ; n=9,789)$ as compared to those with a native language other than English $(70.4 \% ; \mathrm{n}=3,475)\left(\mathrm{OR}=1.4, \mathrm{CI}, 1.2-1.5, x^{2}=47.2, \mathrm{p}<.0001\right)$.

There were 40 accredited schools with 11,758 Step 2 CK test takers and 17 nonaccredited schools with 1,510 Step 2 CK test takers located in the Caribbean and included in the study. Accreditation had a positive association with Step 2 CK performance, with students/graduates of accredited schools having a first-attempt pass rate of $76.8 \%$ compared to a pass rate of $59.0 \%$ for those individuals from nonaccredited schools, a difference of $17.8 \%\left(\mathrm{OR}=2.3, \mathrm{CI}, 2.1-2.6, x^{2}\right.$ $=224.1, \mathrm{p}<.0001)$. 


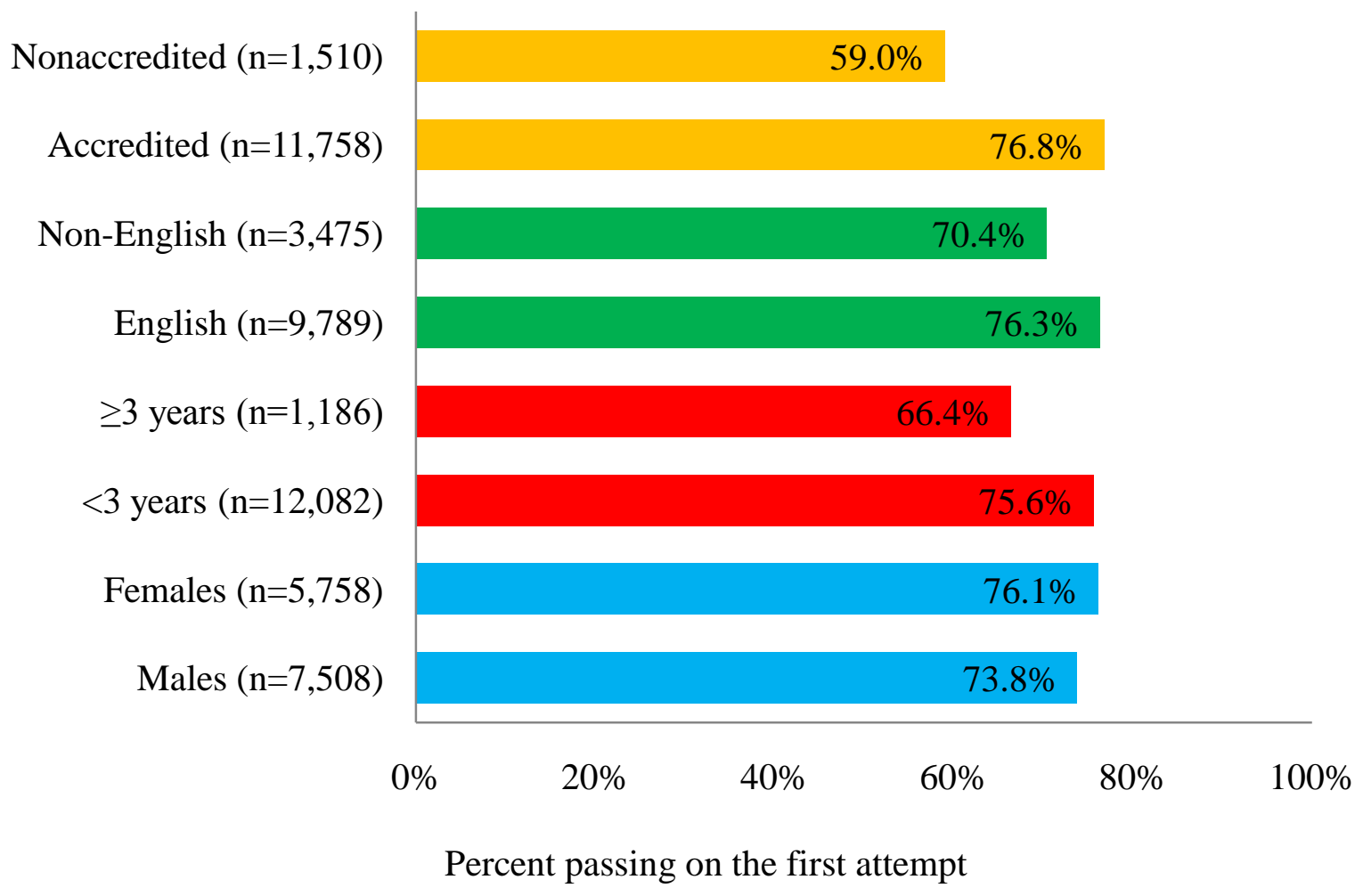

Figure 7. Step 2 CK first-attempt pass rates by gender, years since graduation, native language, and school accreditation status for students/graduates of Caribbean medical schools

After controlling for factors that are associated with performance (gender, years since graduation, native language), accreditation continued to be positively associated with Step 2 CK first-attempt pass rates for individuals from Caribbean schools. For this population, the odds of a student/graduate of an accredited school passing Step $2 \mathrm{CK}$ on the first attempt were 2.3 times greater than the odds of a student/graduate from a nonaccredited school passing the examination on the first attempt. 
The results for Step 2 CK for non-Caribbean test takers during the study period are presented in Figure 8. Females were more likely to pass the examination on their first attempt $(85.2 \% ; \mathrm{n}=17,647)$ compared to males $(83.7 \% ; \mathrm{n}=24,687)$. This gender association is a difference of $1.5 \%\left(\mathrm{OR}=0.9, \mathrm{CI}, 0.8-0.9, x^{2}=18.4, \mathrm{p}<.0001\right)$. Individuals who took Step 2 CK in a time period less than three years since graduation had a higher first-attempt pass rate $(87.1 \% ; \mathrm{n}=17,647)$ compared to those individuals who took the examination in a time period equal to or greater than three years since graduating from medical school $(82.3 \% ; n=24,396)$, a difference of 4.8\%. (OR = 1.4, CI, $\left.1.4-1.5, x^{2}=176.2, \mathrm{p}<.0001\right)$. Native English speakers had a 2.9\% lower first-attempt pass rate than non-native English speakers. Non-Caribbean educated individuals who self-reported English as their native language had a first-attempt pass rate of 81.9\% $(\mathrm{n}=6,921)$. Those with a native language other than English had a first-attempt pass rate of $84.8 \%(\mathrm{n}=35,409)\left(\mathrm{OR}=0.8, \mathrm{CI}, 2.1-2.6, x^{2}=224.1, \mathrm{p}<.0001\right)$.

Accreditation was not associated with examination performance. Students/graduates from accredited schools had a first-attempt pass of $84.3 \%(n=35,943)$, compared to a firstattempt pass rate of $84.5 \%(n=6,391)$ for those from nonaccredited schools, a difference of $0.2 \%$ $\left(\mathrm{OR}=1.0, \mathrm{CI}, 0.9-1.1, x^{2}=0.1, \mathrm{p}=.7835\right)$. 


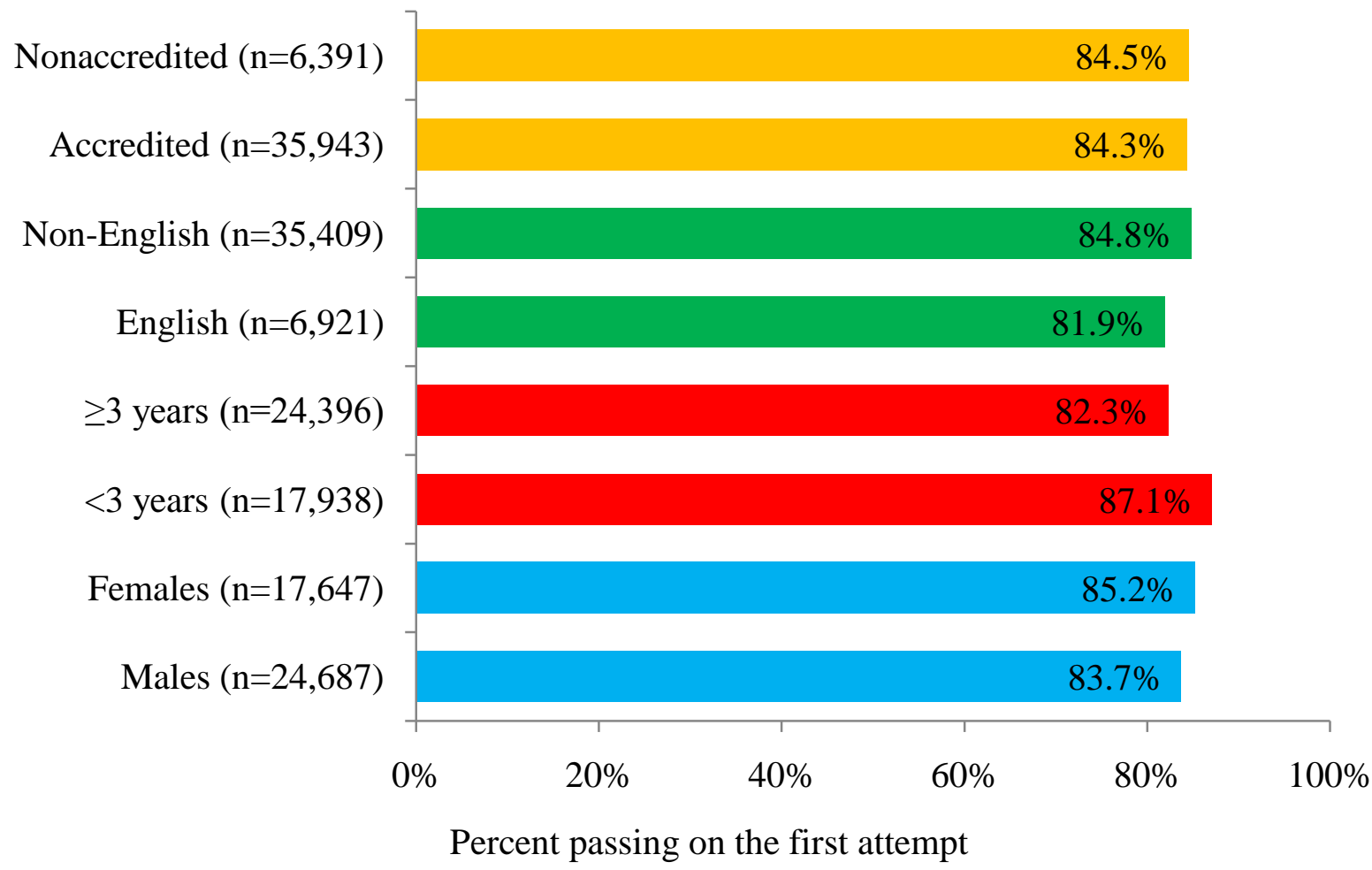

Figure 8. Step $2 \mathrm{CK}$ first-attempt pass rates by gender, years since graduation, native language, and school accreditation status for students/graduates of non-Caribbean medical schools

After controlling for factors associated with performance (gender, years since graduation, native language), accreditation did not have an association with Step $2 \mathrm{CK}$ first-attempt pass rates for this non-Caribbean educated group. The odds of a student/graduate of an accredited school passing Step 1 on the first attempt were equivalent (1.0) to the odds of a student/graduate from a nonaccredited school passing the examination on the first attempt. 
The first-attempt pass rates results for Step 2 CS, for the entire population of test takers during the study period, are presented in Figure 9. Gender was associated with examination performance. In contrast to the global data for Step 1 and Step 2 CK, for this examination males were less likely to pass the examination on their first attempt $(69.6 \% ; n=33,750)$ as compared to females $(83.5 \%$; $\mathrm{n}=24,516)$, a $13.9 \%$ difference $\left(\mathrm{OR}=0.2, \mathrm{CI}, 0.2-0.3, x^{2}=5617.3, \mathrm{p}<.0001\right)$. Individuals who took Step 2 CS in a time period less than three years since graduation had a higher first-attempt pass rate $(81.8 \% ; n=29,133)$ compared to those individuals who took the examination in a time period equal to or greater than three years since their graduation from medical school $(69.1 \% ; \mathrm{n}=29,135)$, a difference of $12.7 \%\left(\mathrm{OR}=2.0, \mathrm{CI}, 1.9-2.1, x^{2}=1262.0\right.$, $\mathrm{p}<.0001)$. In contrast to the global results for Step 1 and Step 2 CK, individuals who selfreported English as their native language had a higher first-attempt pass rate $(84.9 \% ; n=17,569)$ as compared to those with a native language other than English $(71.4 \% ; n=40,690)$, a difference of $13.5 \%\left(\mathrm{OR}=2.3, \mathrm{CI}, 2.1-2.4, x^{2}=1208.2, \mathrm{p}<.0001\right)$.

Accreditation was positively associated with Step 2 CS performance, with students/ graduates of accredited schools having a first-attempt pass rate of $76.4 \%(\mathrm{n}=49,898)$, compared to a pass rate of $70.1 \%(\mathrm{n}=8,370)$ for those individuals from nonaccredited schools, a $6.3 \%$ difference for this variable $\left(\mathrm{OR}=1.4, \mathrm{CI}, 1.3-1.5, x^{2}=154.7, \mathrm{p}<.0001\right)$. 


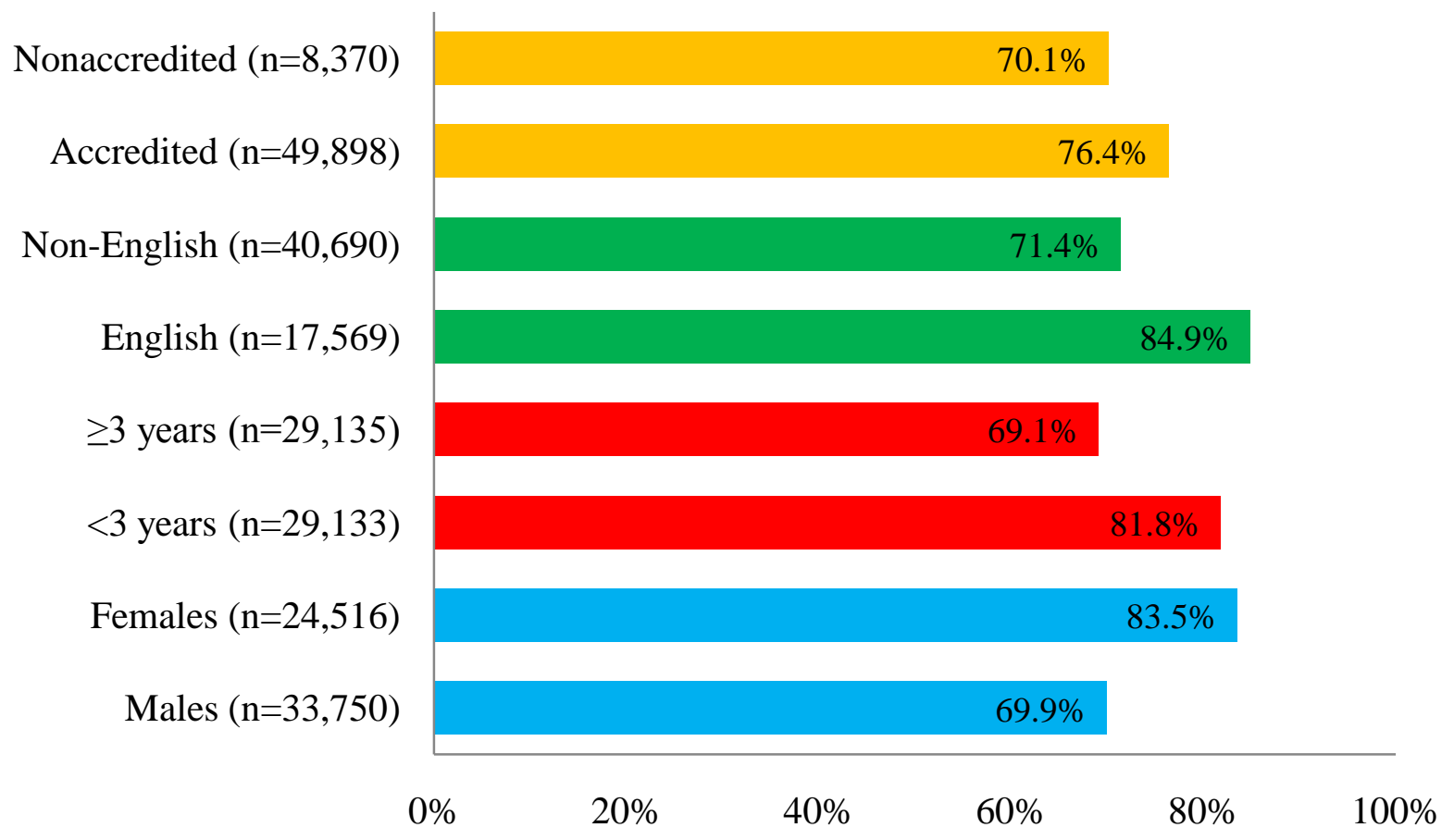

Percent passing on the first attempt

Figure 9. Step 2 CS first-attempt pass rates by gender, years since graduation, native language, and school accreditation status for the entire study population

Taking into account through a generalized estimating equations model these factors that are associated with performance (gender, years since graduation, native language), accreditation continued to have a slight positive association with Step 2 CS first-attempt pass rates. The odds of a student/graduate of an accredited school passing Step 2 CS on the first attempt were 1.3 times greater than the odds of a student/graduate from a nonaccredited school passing the examination on the first attempt. 


\section{Step 2 Clinical Skills (CS) (Caribbean)}

The results for Step 2 CS, for only the individuals who are students/graduates of schools located in the Caribbean, are presented in Figure 10. Males were less likely to pass the examination on their first attempt $(78.4 \% ; n=8,038)$ as compared to females $(90.2 \% ; n=6,185)$, an $11.8 \%$ difference $\left(\mathrm{OR}=0.4, \mathrm{CI}, 0.4-0.4, x^{2}=350.4, \mathrm{p}<.0001\right)$. There was a $27.5 \%$ difference in first-attempt pass rates between individuals who took Step 2 CS in a time period less than three years since graduation $(86.4 \% ; n=12,756)$ compared to those individuals who took the examination in a time period equal to or greater than three years since their graduation from medical school $(58.9 \% ; \mathrm{n}=1,469)\left(\mathrm{OR}=4.4, \mathrm{CI}, 3.9-5.0, x^{2}=723.9, \mathrm{p}<.0001\right)$. Similar to the Step 2 CS results for the entire population, individuals from schools located in the Caribbean who self-reported English as their native language had a higher Step 2 CS firstattempt pass rate $(87.8 \% ; \mathrm{n}=10,311)$ as compared to those with a native language other than English $(72.3 \% ; \mathrm{n}=3,910)$, a difference of $15.5 \%\left(\mathrm{OR}=2.8, \mathrm{CI}, 2.5-3.0, x^{2}=494.3, \mathrm{p}<.0001\right)$.

There were 40 accredited schools with 12,431 test takers and 17 nonaccredited schools with 1,794 test takers located in the Caribbean and included in the study. There was a 13.3\% difference in Step 2 CS performance by medical school accreditation status, with students/graduates of accredited schools having a first-attempt pass rate of $85.2 \%(\mathrm{n}=12,431)$ compared to a pass rate of $71.9 \%(\mathrm{n}=1,794)$ for those individuals from nonaccredited schools $\left(\mathrm{OR}=2.3, \mathrm{CI}, 2.0-2.5, x^{2}=203.8, \mathrm{p}<.0001\right)$. 


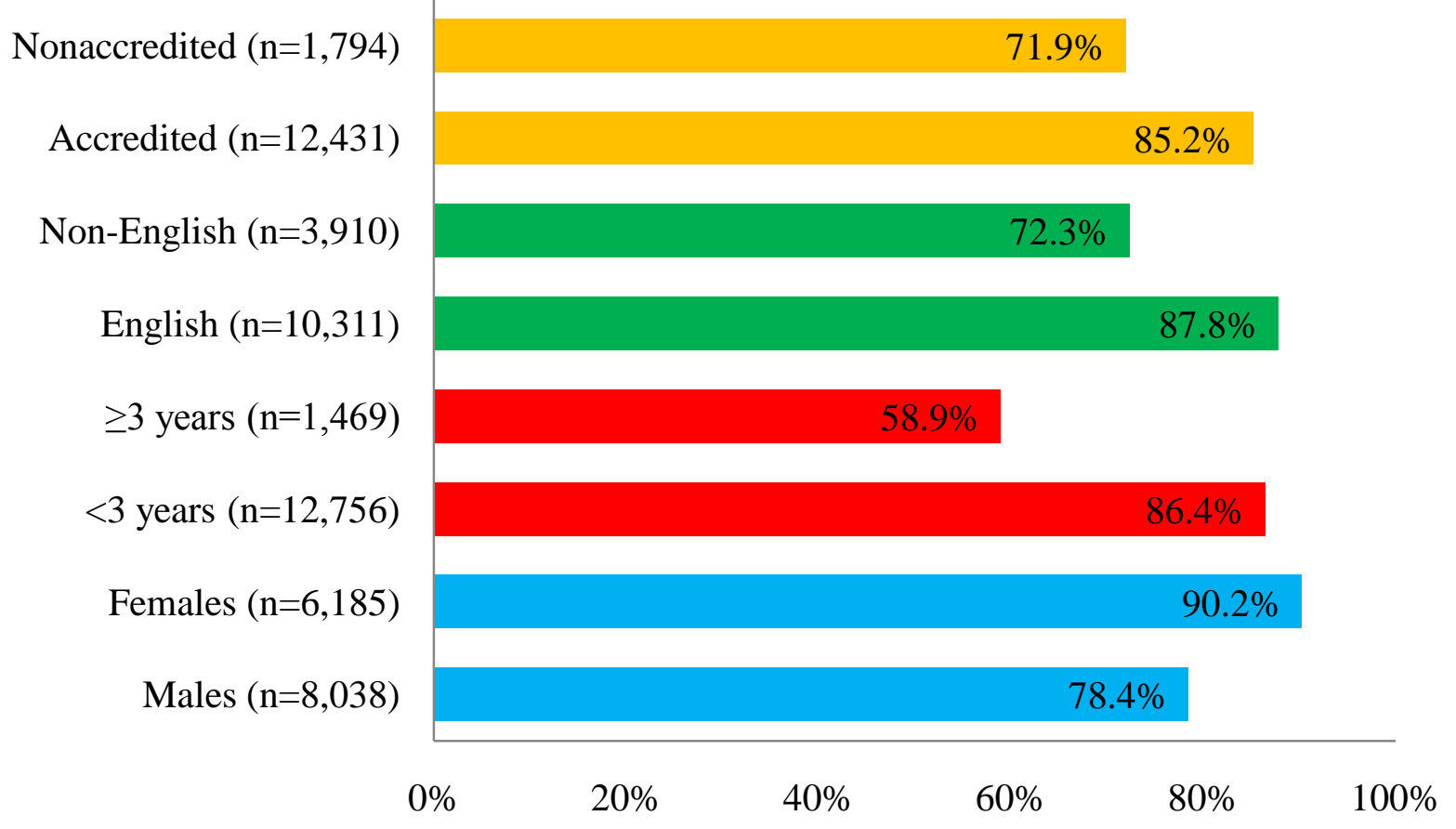

Percent passing on the first attempt

Figure 10. Step 2 CS first-attempt pass rates by gender, years since graduation, native language, and school accreditation status for students/graduates of Caribbean medical schools

Accreditation continued to be positively associated with Step 2 CS first-attempt pass rates for individuals from Caribbean schools after controlling for the other variables of interest. For this population from the Caribbean, the odds of a student/graduate of an accredited school passing Step 2 CS on the first attempt were 2.4 times greater than the odds of a student/graduate from a nonaccredited school passing the examination on the first attempt.

\section{Step 2 Clinical Skills (CS) (Non-Caribbean)}

The results for Step 2 CS for non-Caribbean educated students/graduates are presented in Figure 11. Similar to the results for the global and Caribbean groups, females were more likely 
to pass this examination on their first attempt $(81.3 \% ; \mathrm{n}=18,331)$ compared to males $(66.9 \%$; $\mathrm{n}=25,712)$. This is a $14.4 \%$ difference in first-attempt pass rates $\left(\mathrm{OR}=0.5, \mathrm{CI}, 0.4-0.5, x^{2}=\right.$ 1126.3, $\mathrm{p}<.0001)$. Students/graduates who took Step 2 CS in a time period less than three years since graduation had a higher first-attempt pass rate $(78.2 \%$; $=16,377)$ compared to those individuals who took the examination in a time period equal to or greater than three years since graduation $(69.7 \%$; $\mathrm{n}=27,666)$, a difference of $8.5 \%\left(\mathrm{OR}=1.6, \mathrm{CI}, 1.5-1.6, x^{2}=381.2\right.$, $\mathrm{p}<.0001)$. Similar to the Step 2 CS results for the global and the Caribbean groups, in the nonCaribbean educated group native English speakers had a higher first-attempt pass rate (80.8\%; $\mathrm{n}=7,258)$ compared to those with a native language other than English $(71.3 \% ; n=36,780)$, a difference of $9.5 \%\left(\mathrm{OR}=1.7, \mathrm{CI}, 1.6-1.8, x^{2}=276.2, \mathrm{p}<.0001\right)$.

In contrast to the non-Caribbean results for Step 1 and Step 2 CK that showed no association between accreditation status and examination performance, for Step 2 CS accreditation was positively associated with the first-attempt pass rate. Students/graduates of accredited schools had a first-attempt pass rate of $73.5 \%(n=37,467)$ compared to a first-attempt pass rate of $69.6 \%(n=6,576)$ for individuals from nonaccredited schools $(\mathrm{OR}=1.2, \mathrm{CI}, 1.1-$ $\left.1.3, x^{2}=42.5, \mathrm{p}<.0001\right)$, a difference of $3.9 \%$. 


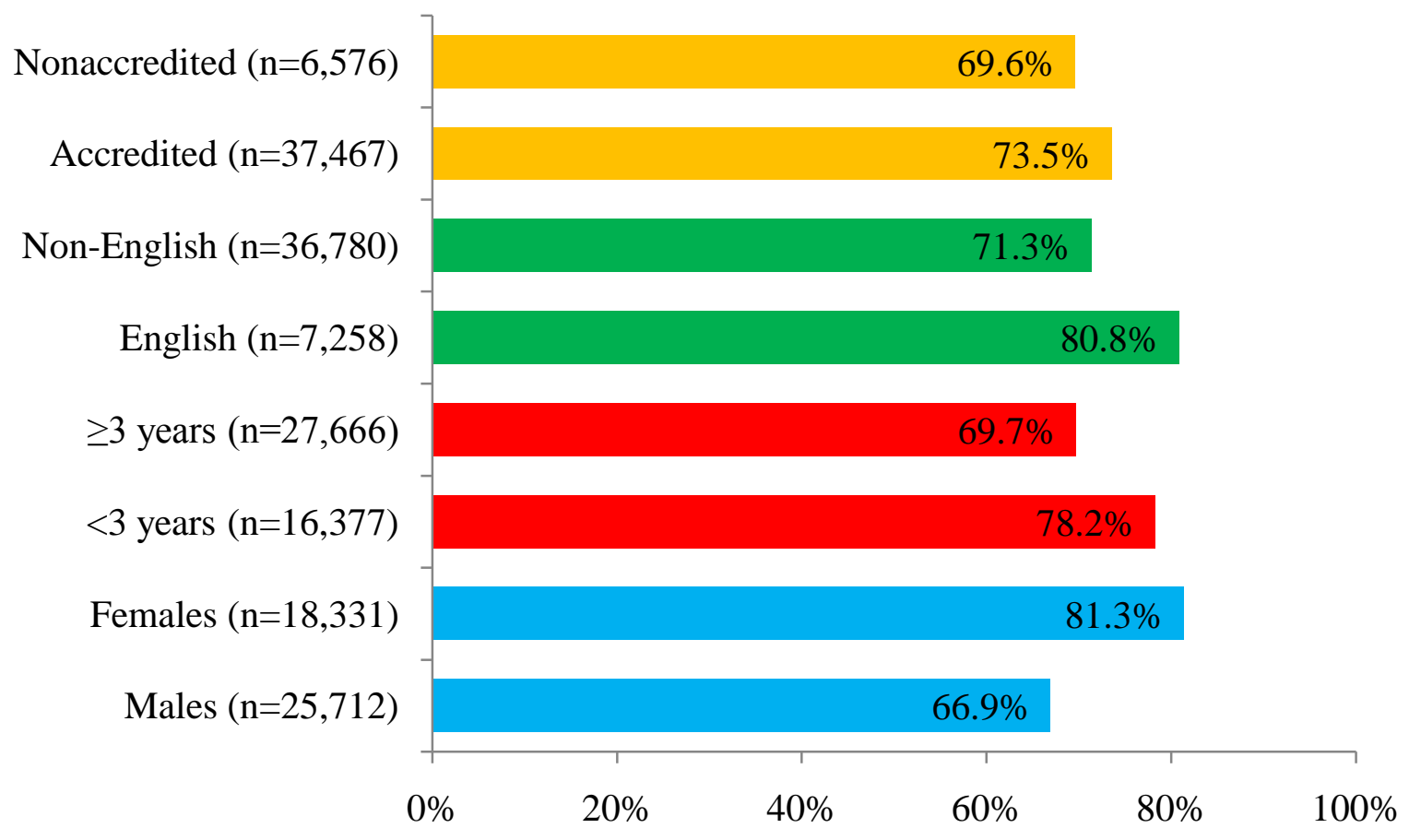

Percent passing on the first attempt

Figure 11. Step 2 CS first-attempt pass rates by gender, years since graduation, native language, and school accreditation status for students/graduates of non-Caribbean medical schools

Accreditation was positively associated with the Step 2 CS first-attempt pass rate for individuals from non-Caribbean schools after controlling for the other variables of interest. For this population from schools located outside of the Caribbean, the odds of a student/graduate of an accredited school passing Step 2 CS on the first attempt were 1.1 times greater than the odds of a student/graduate from a nonaccredited school passing the examination on the first attempt.

\section{Accreditation Data Summary}

A summary of the associations between accreditation and student/graduate performance for the three groups across the three examinations is displayed in Table 3. 
Table 3. Summary of the Association Between Accreditation and USMLE First-Attempt Pass Rates

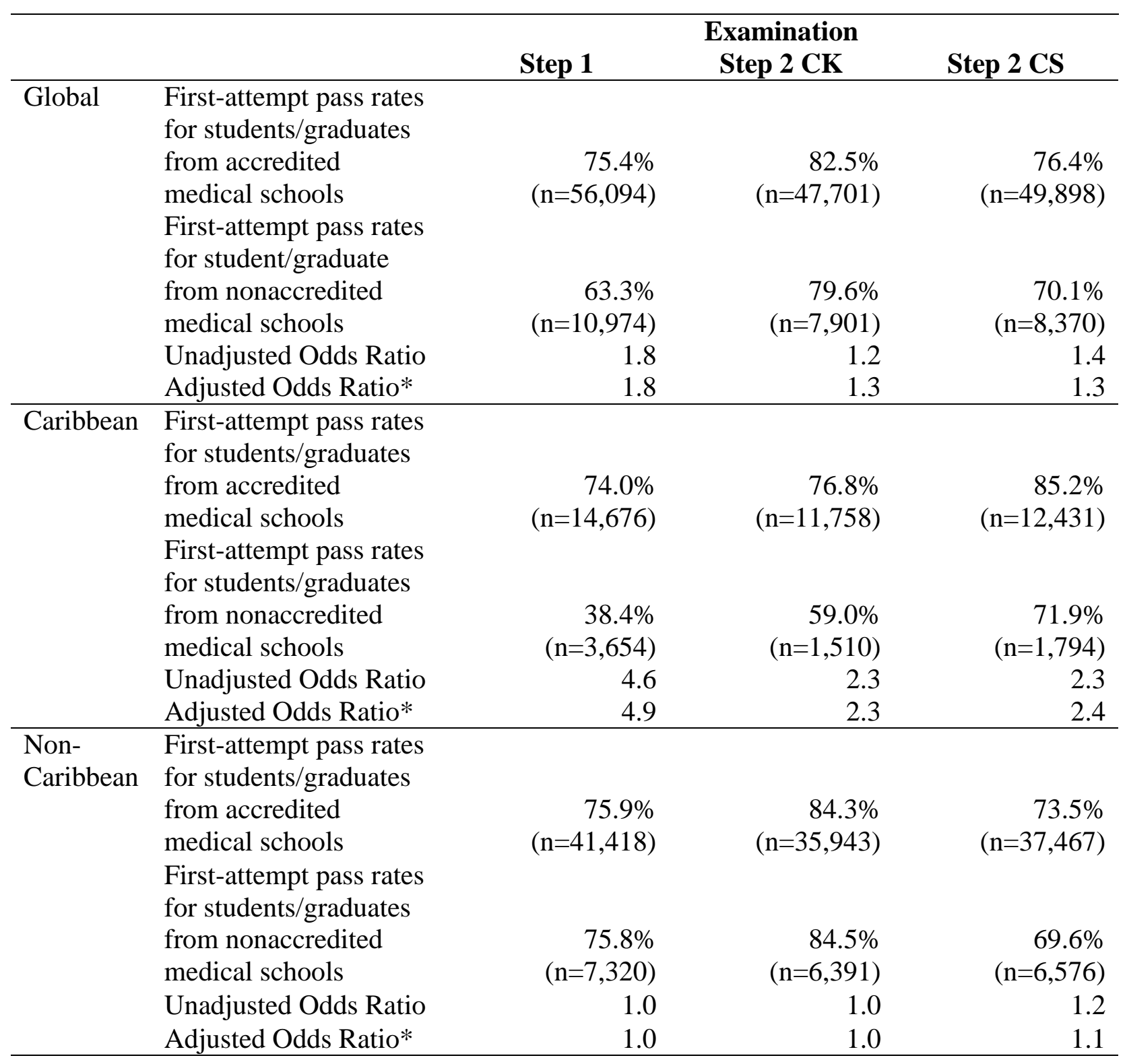

*After controlling for gender, years since graduation, and native language, increase in odds of a student/graduate from an accredited school passing the examination on the first attempt as compared to the odds of a student/graduate from a nonaccredited school passing the examination on the first attempt. 


\section{Phase 2 (Quality of Accreditation)}

The aim of Phase 2 was to investigate the impact of robustness of various accreditation systems and the association between the quality of the accreditation system and student outcomes. The hypothesis for Phase 2 was that students who attended schools accredited by a system that met predetermined criteria (and received a grade of A) are more likely to pass USMLE on their first attempt as compared to students from schools accredited by systems that did not meet the criteria (and received a grade of B). To create the grading scheme for accrediting agencies, international accreditation experts were contacted and requested to complete an anonymous survey on the importance of various accreditation standards.

\section{Survey to Determine Essential Standards}

Eight surveys were returned within the first response period of one month, and two reminder emails sent in the second month produced an additional five responses for a total of 13 completed surveys (59\% response rate).

There were 39 occurrences of a respondent rating a standard as N/R (not able to rate) and 33 occurrences of no rating provided. These responses were eliminated from the analyses. Two standards were each rated as N/R by three respondents ("The process of applying for residency programs does not disrupt the general medical education" and "Letters of reference or other credentials are not provided until the student's final year"), and the remaining occurrences of N/R ratings or no rating were distributed generally evenly across the standards.

For each of the 13 respondents, Table 4 displays the number of ratings provided and the mean across all standards. The number of ratings provided by each of the 13 experts ranged 
from 138 to 150 . Totals less than 150 indicate that the rater either provided N/R ratings or left questions blank. The mean for each rater ranged from 2.32 to $2.87,(1-3$ scale) indicating that some raters were more selective than others. However, based on the magnitude of individual means, most standards were considered to be important (range: $1.62-3.00$ ).

Table 4. Number of Ratings Provided and Mean (SD) for Each of the 13 Expert Raters

\begin{tabular}{rrr}
\hline Rater & $\begin{array}{c}\text { Number of } \\
\text { ratings } \\
\text { provided }\end{array}$ & Mean (SD) \\
\hline 1 & 150 & $2.76(0.47)$ \\
2 & 145 & $2.35(0.57)$ \\
3 & 124 & $2.85(0.38)$ \\
4 & 150 & $2.87(0.34)$ \\
5 & 142 & $2.83(0.38)$ \\
6 & 150 & $2.54(0.64)$ \\
7 & 149 & $2.62(0.59)$ \\
8 & 140 & $2.59(0.55)$ \\
9 & 141 & $2.32(0.68)$ \\
10 & 149 & $2.77(0.47)$ \\
11 & 138 & $2.41(0.75)$ \\
12 & 150 & $2.82(0.40)$ \\
13 & 150 & $2.83(0.38)$ \\
\hline
\end{tabular}

Fourteen standards received the highest rating of 3.00 ("Essential”) from all survey participants, and four standards received mean ratings of equal to or less than 2.00 ("Important but not essential"). Variability in the ratings across the experts for individual standards ranged from 0 (unanimous agreement) to 0.76 (moderate disagreement). The results displaying the standards that had complete agreement from all raters as being "Essential," the standards that received mean ratings of 2.00 or less, and the standards with variances across respondents equal to or greater than 0.50 , are presented in Table 5 . 
Table 5. Standards That Received Unanimous Agreement as Being Essential, Standards That Received Mean Ratings Equal to or Less Than 2.00, and Standards With Variances Equal or Greater Than 0.50

\begin{tabular}{|c|c|c|c|}
\hline Standards & $\begin{array}{l}\text { WFME } \\
\text { Category }\end{array}$ & Mean rating & Variance \\
\hline \multicolumn{4}{|c|}{ Standards with means $=3.00$ and variances $=0.00$ "Essential Standards" } \\
\hline $\begin{array}{l}\text { The medical school teaches the principles of } \\
\text { scientific method and evidence-based } \\
\text { medicine, including analytical and critical } \\
\text { thinking, throughout the curriculum. }\end{array}$ & $\begin{array}{l}\text { Educational } \\
\text { Program }\end{array}$ & 3.00 & 0.00 \\
\hline $\begin{array}{l}\text { The medical school ensures that students have } \\
\text { patient contact and acquire sufficient clinical } \\
\text { knowledge and skills to assume appropriate } \\
\text { clinical responsibility upon graduation. }\end{array}$ & $\begin{array}{l}\text { Educational } \\
\text { Program }\end{array}$ & 3.00 & 0.00 \\
\hline $\begin{array}{l}\text { Students' clinical experiences utilize both } \\
\text { outpatient and inpatient settings. }\end{array}$ & $\begin{array}{l}\text { Educational } \\
\text { Program }\end{array}$ & 3.00 & 0.00 \\
\hline $\begin{array}{l}\text { The medical school defines and states the } \\
\text { methods used for assessment of its students, } \\
\text { including the criteria for passing examinations. }\end{array}$ & $\begin{array}{l}\text { Assessment of } \\
\text { Students }\end{array}$ & 3.00 & 0.00 \\
\hline $\begin{array}{l}\text { Assessment principles, methods and practices } \\
\text { are clearly compatible with educational } \\
\text { objectives and promote learning. }\end{array}$ & $\begin{array}{l}\text { Assessment of } \\
\text { Students }\end{array}$ & 3.00 & 0.00 \\
\hline $\begin{array}{l}\text { The size of student intake is defined and } \\
\text { related to the capacity of the medical school at } \\
\text { all stages of education and training. }\end{array}$ & Students & 3.00 & 0.00 \\
\hline $\begin{array}{l}\text { The medical school has access to a well- } \\
\text { maintained library and information facilities, } \\
\text { sufficient in size, breadth of holdings, and } \\
\text { information technology to support its } \\
\text { education and other missions. }\end{array}$ & $\begin{array}{l}\text { Educational } \\
\text { Resources }\end{array}$ & 3.00 & 0.00 \\
\hline $\begin{array}{l}\text { The medical school ensures adequate clinical } \\
\text { experience and the necessary resources, } \\
\text { including sufficient patients and clinical } \\
\text { training facilities. }\end{array}$ & $\begin{array}{l}\text { Educational } \\
\text { Resources }\end{array}$ & 3.00 & 0.00 \\
\hline $\begin{array}{l}\text { Program evaluation addresses the context of } \\
\text { the educational process, the specific } \\
\text { components of the curriculum and the general } \\
\text { outcome. }\end{array}$ & $\begin{array}{l}\text { Program } \\
\text { Evaluation }\end{array}$ & 3.00 & 0.00 \\
\hline $\begin{array}{l}\text { Student performance is analyzed in relation to } \\
\text { the curriculum and the mission and objectives } \\
\text { of the medical school. }\end{array}$ & $\begin{array}{l}\text { Program } \\
\text { Evaluation }\end{array}$ & 3.00 & 0.00 \\
\hline $\begin{array}{l}\text { Governance structures and functions of the } \\
\text { medical school are defined, including their } \\
\text { relationships within the university. }\end{array}$ & $\begin{array}{l}\text { Governance and } \\
\text { Administration }\end{array}$ & 3.00 & 0.00 \\
\hline
\end{tabular}


Table 5. (Continued)

\begin{tabular}{|c|c|c|c|}
\hline Standards & $\begin{array}{l}\text { WFME } \\
\text { Category }\end{array}$ & Mean rating & Variance \\
\hline $\begin{array}{l}\text { The responsibilities of the academic leadership } \\
\text { of the medical school for the medical } \\
\text { educational program are clearly stated. }\end{array}$ & $\begin{array}{l}\text { Governance and } \\
\text { Administration }\end{array}$ & 3.00 & 0.00 \\
\hline $\begin{array}{l}\text { The dean is qualified by education and } \\
\text { experience to provide leadership in medical } \\
\text { education, scholarly activity, and care of } \\
\text { patients. }\end{array}$ & $\begin{array}{l}\text { Governance and } \\
\text { Administration }\end{array}$ & 3.00 & 0.00 \\
\hline $\begin{array}{l}\text { The present and anticipated financial resources } \\
\text { of a medical school are adequate to sustain a } \\
\text { sound program of medical education and to } \\
\text { accomplish other institutional goals. }\end{array}$ & $\begin{array}{l}\text { Governance and } \\
\text { Administration }\end{array}$ & 3.00 & 0.00 \\
\hline Standards with mean ratings $=<2.00$ & & & \\
\hline $\begin{array}{l}\text { The medical school has dormitory/hostel } \\
\text { provision for at least } 75 \% \text { of the total intake of } \\
\text { students at a given time. }\end{array}$ & $\begin{array}{l}\text { Educational } \\
\text { Resources }\end{array}$ & 1.62 & 0.39 \\
\hline $\begin{array}{l}\text { The medical course is set in the context of an } \\
\text { active research program within the school. }\end{array}$ & $\begin{array}{l}\text { Educational } \\
\text { Resources }\end{array}$ & 1.92 & 0.22 \\
\hline $\begin{array}{l}\text { The medical school has a teaching hospital } \\
\text { with a ratio of a minimum of five beds per } \\
\text { student admission per year. }\end{array}$ & $\begin{array}{l}\text { Educational } \\
\text { Resources }\end{array}$ & 2.00 & 0.36 \\
\hline $\begin{array}{l}\text { Transfer students are not be accepted into the } \\
\text { final year of the program except under rare } \\
\text { circumstances. }\end{array}$ & $\begin{array}{l}\text { Educational } \\
\text { Resources }\end{array}$ & 2.00 & 0.76 \\
\hline \multicolumn{4}{|l|}{ Standards with variances $=>0.50$} \\
\hline $\begin{array}{l}\text { Basic sciences and clinical sciences are } \\
\text { integrated in the curriculum. }\end{array}$ & $\begin{array}{l}\text { Educational } \\
\text { Program }\end{array}$ & 2.54 & 0.56 \\
\hline $\begin{array}{l}\text { The medical school recognizes the unique } \\
\text { challenges faced by the indigenous health } \\
\text { sector and has effective partnerships with } \\
\text { relevant local communities, organizations, and } \\
\text { individuals. }\end{array}$ & $\begin{array}{l}\text { Educational } \\
\text { Program }\end{array}$ & 2.38 & 0.54 \\
\hline $\begin{array}{l}\text { The medical school has clear and equitable } \\
\text { policies for the refund of tuition, fees, and } \\
\text { other allowable payments. }\end{array}$ & Students & 2.46 & 0.56 \\
\hline $\begin{array}{l}\text { The medical school follows accepted } \\
\text { guidelines in determining appropriate } \\
\text { immunizations for medical students. }\end{array}$ & Students & 2.62 & 0.54 \\
\hline $\begin{array}{l}\text { The medical school has adequately } \\
\text { indemnified students for relevant activities. }\end{array}$ & Students & 2.36 & 0.60 \\
\hline $\begin{array}{l}\text { Transfer students are not be accepted into the } \\
\text { final year of the program except under rare } \\
\text { circumstances. }\end{array}$ & $\begin{array}{l}\text { Educational } \\
\text { Resources }\end{array}$ & 2.00 & 0.76 \\
\hline
\end{tabular}

(continued) 
Table 5. (Continued)

\begin{tabular}{lllc}
\hline \multicolumn{1}{c}{ Standards } & \multicolumn{1}{c}{$\begin{array}{c}\text { WFME } \\
\text { Category }\end{array}$} & Mean rating & Variance \\
\hline $\begin{array}{l}\text { Student performance is analyzed in relation to } \\
\text { student background, conditions, and entrance } \\
\text { qualifications and is used to provide feedback } \\
\text { to the committees responsible for student } \\
\begin{array}{l}\text { selection, curriculum planning, and student } \\
\text { counseling. }\end{array}\end{array}$ & $\begin{array}{l}\text { Program } \\
\text { Evaluation }\end{array}$ & 2.33 & 0.56 \\
\hline $\begin{array}{l}\text { The medical school has a constructive } \\
\text { interaction with the health and health-related } \\
\text { sectors of society and government. }\end{array}$ & $\begin{array}{l}\text { Governance and } \\
\text { Administration }\end{array}$ & 2.54 & 0.56 \\
\hline $\begin{array}{l}\text { Collaboration with partners of the health } \\
\text { sector are formalized. }\end{array}$ & $\begin{array}{l}\text { Governance and } \\
\text { Administration }\end{array}$ & 2.46 & 0.56 \\
\hline
\end{tabular}

Mean ratings, aggregated across respondents, for all of the standards within each of the nine WFME categories were also calculated. Results were as follows: Mission and Objectives [mean=2.72 (SD=0.49)]; Educational Program [mean=2.72 (SD=0.52)]; Assessment of Students $[$ mean=2.72 $(\mathrm{SD}=0.45)] ;$ Students $[$ mean=2.53 $(\mathrm{SD}=0.62)]$; Academic Staff $/$ Faculty [mean=2.77 ( $\mathrm{SD}=0.46)]$; Educational Resources [mean=2.52 (SD=0.58)]; Program Evaluation $[$ mean=2.75 $(\mathrm{SD}=0.51)]$; Governance and Administration [mean=2.73 ( $\mathrm{SD}=0.55)]$; Continuous Renewal [mean=2.64 $(\mathrm{SD}=0.62)]$.

The 14 essential standards were used to create the rating scheme of accrediting agencies.

\section{Accreditation Agency Quality}

As previously described, the Phase 2 population is a subset of the Phase 1 population.

Phase 2 includes those individuals who met the inclusion criteria for Phase 1 and who graduated from /attended at the time of testing a school located in a country that met the following accreditation criteria: a) a system of accreditation exists in the country and all schools are 
accredited, b) the accreditation standards were available in English, and c) the accreditation standards were available either on the accrediting agency's website or by written request. The countries/territories included in Phase 2 were Australia, Barbados, Cayman Islands, Dominica, Grenada, India, Jamaica, New Zealand, Nigeria, Pakistan, Poland, Saba (Special Municipality of the Netherlands), Saudi Arabia, Sint Maarten, South Korea, Switzerland, Trinidad and Tobago, and the United Kingdom.

Results of the analyses of the accrediting agencies' standards determining which of the 14 essential standards are used are included in Appendix C. Table 6 displays the summary of these data: the number and percent of the 14 essential standards used by the agency and the agency names and the country(ies) where the agencies have accredited medical schools. The proportion of the 14 essential standards used by the accreditation standards ranged from $42.9 \%$ (6 standards) to $92.9 \%$ (13 standards). 
Table 6. Number and Percent of the 14 Essential Standards Used by Accrediting Agencies and the Country(ies) Where the Agencies Have Accredited Medical Schools

\begin{tabular}{|c|c|c|}
\hline $\begin{array}{c}\text { Number } \\
\text { (Percent) of } \\
\text { Standards Used } \\
\text { of the } 14 \\
\text { Essential } \\
\text { Standards }\end{array}$ & Accrediting Agency & Country(ies) \\
\hline $6(42.9 \%)$ & $\begin{array}{l}\text { Accreditation Committee for Polish University Medical } \\
\text { Schools (KAAUM) }\end{array}$ & Poland \\
\hline $7(50 \%)$ & $\begin{array}{l}\text { Medical and Dental Council of Nigeria (MDC) } \\
\& \text { National Universities Commission (NUC) }\end{array}$ & Nigeria \\
\hline $8(57.1 \%)$ & $\begin{array}{l}\text { National Commission for Academic Accreditation and } \\
\text { Assessment (NCAAA) }\end{array}$ & Saudi Arabia \\
\hline $9(64.3 \%)$ & Medical Council of India (MCI) & India \\
\hline $10(71.4 \%)$ & $\begin{array}{l}\text { Pakistan Medical and Dental Council (PMDC) } \\
\text { Korean Institute of Medical Education and Evaluation } \\
\text { (KIMEE) }\end{array}$ & $\begin{array}{l}\text { Pakistan } \\
\text { South Korea }\end{array}$ \\
\hline $11(78.6 \%)$ & $\begin{array}{l}\text { General Medical Council (GMC) } \\
\text { Centre of Accreditation and Quality Assurance of the } \\
\text { Swiss Universities (OAQ) }\end{array}$ & $\begin{array}{l}\text { United Kingdom } \\
\text { Switzerland }\end{array}$ \\
\hline $12(85.7 \%)$ & Dominican Medical Board (DMB) & Dominica \\
\hline $13(92.9 \%)$ & $\begin{array}{l}\text { Australian Medical Council (AMC) } \\
\text { Accreditation Commission on Colleges of Medicine } \\
\text { (ACCM) }\end{array}$ & $\begin{array}{l}\text { Barbados } \\
\text { Grenada } \\
\text { Jamaica } \\
\text { Trinidad and } \\
\text { Tobago } \\
\text { Australia } \\
\text { New Zealand } \\
\text { Cayman Islands } \\
\text { Saba } \\
\text { Sint Maarten }\end{array}$ \\
\hline
\end{tabular}

Data from the accrediting agencies and associated countries that had the same number of the 14 essential standards incorporated into their standards were grouped together into eight groups according to the actual number of essential standards that were used by the accrediting 
body. First-attempt pass rates for each examination (Step 1, Step 2 CK, and Step 2 CS) were calculated separately for each of the eight groups.

First-attempt pass rates for Step 1 by number of essential standards (range: 6 - 13) are displayed in Figure 12. For the following Figures $12-14$, the number of students/graduates who took the examination in the five-year study period is provided for each of the eight groupings of accreditation standards.

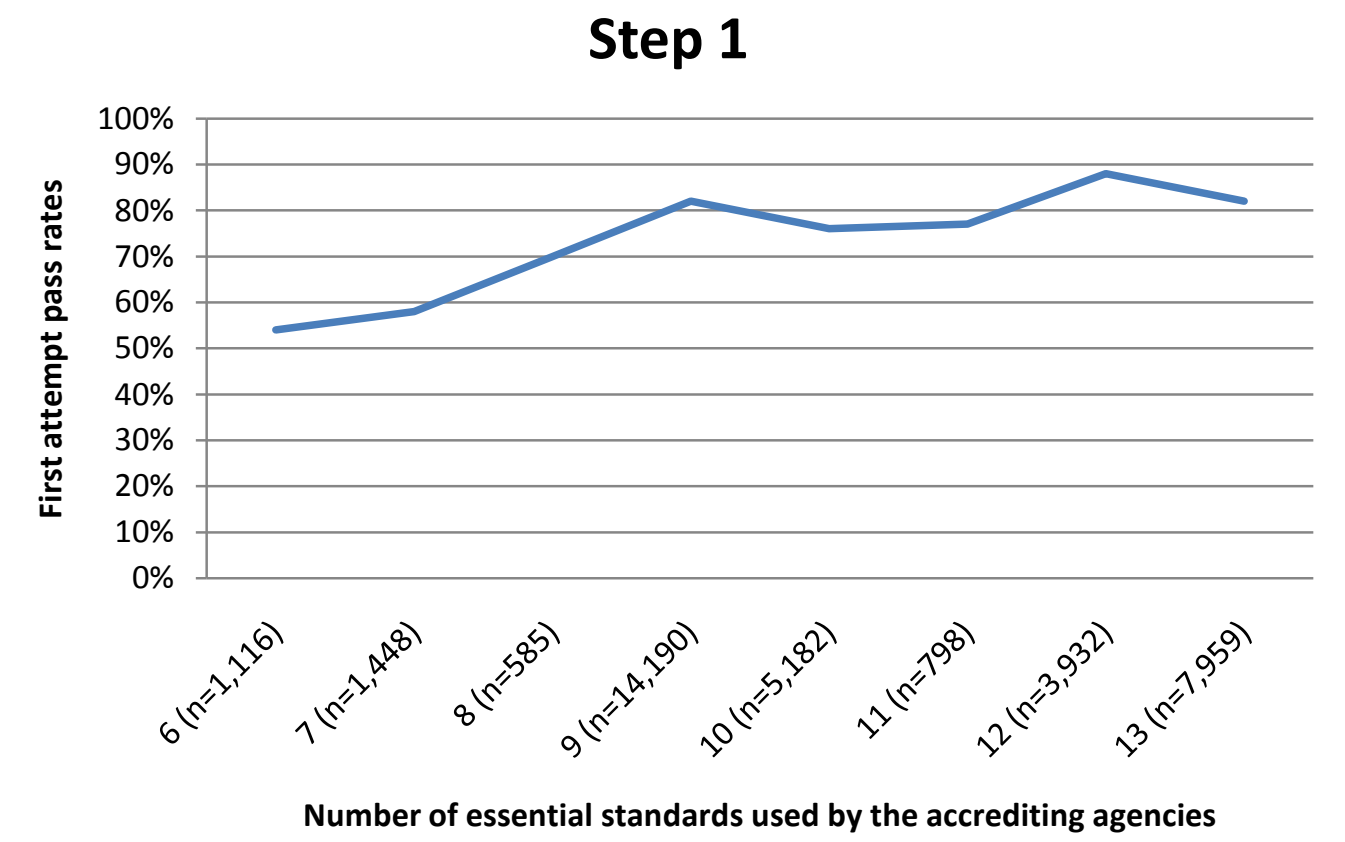

Figure 12. First-attempt pass rates for Step 1 by number of essential standards used by the accrediting agencies 
First-attempt pass rates for Step 2 Clinical Knowledge (CK) by number of essential standards (range: 6-13) are displayed in Figure 13.

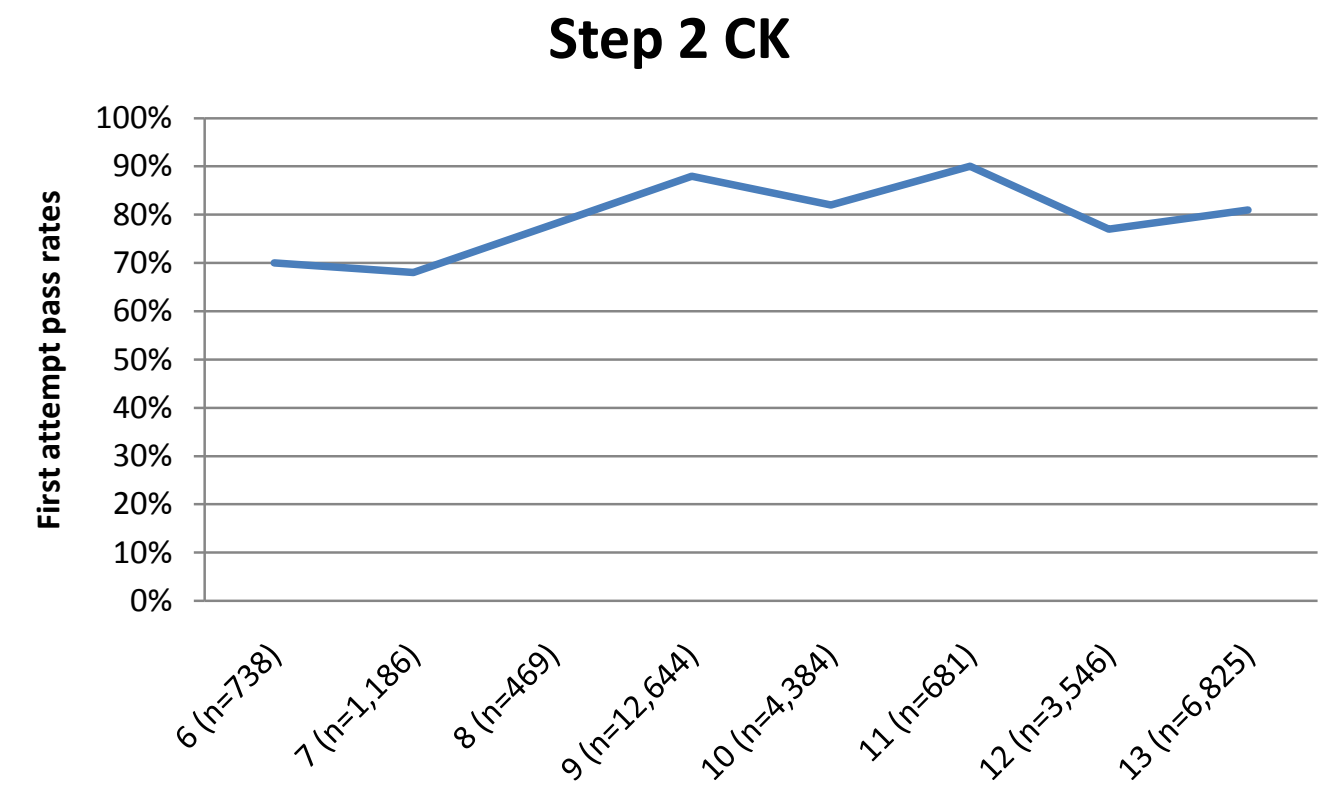

Number of essential standards used by the accrediting agencies

Figure 13. First-attempt pass rates for Step 2 Clinical Knowledge (CK) by number of essential standards used by the accrediting agencies 
First-attempt pass rates for Step 2 Clinical Skills (CS) by number of essential standards (range: $6-13$ ) are displayed in Figure 14.

Step 2 CS

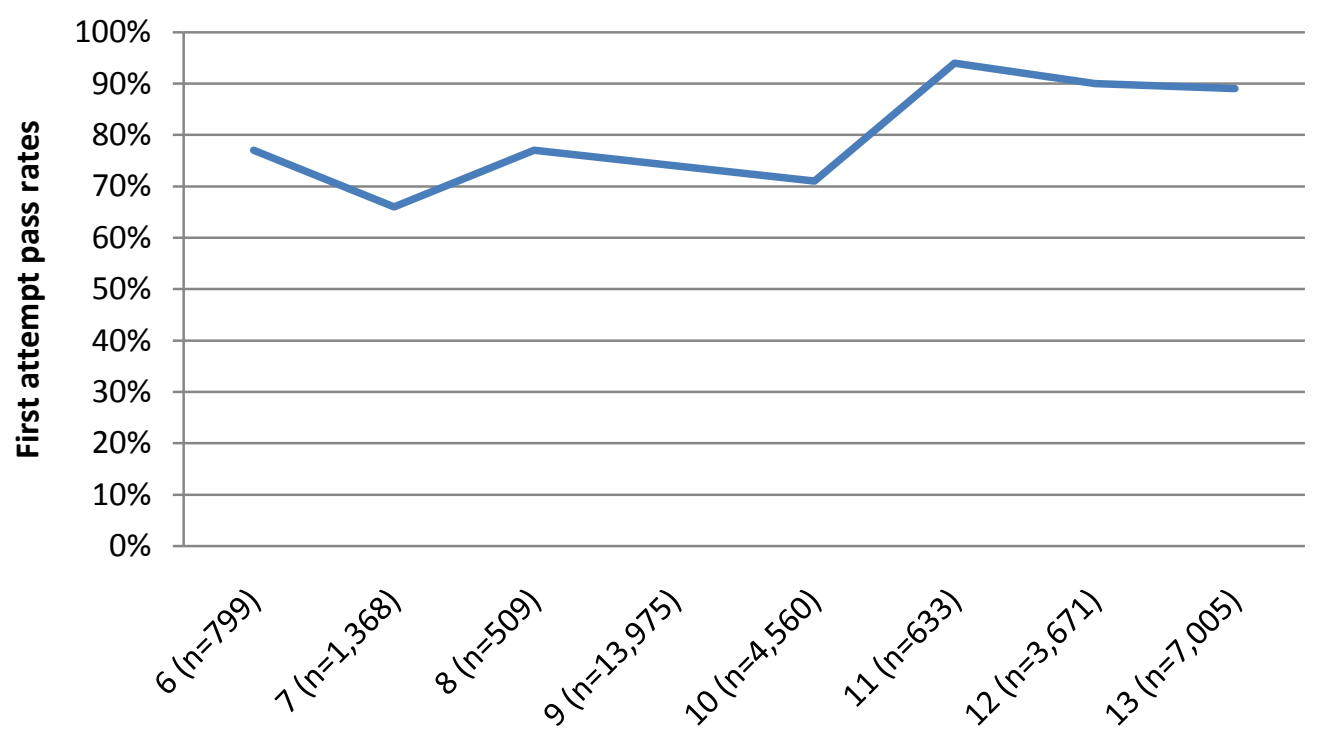

Number of essential standards used by the accrediting agencies

Figure 14. First-attempt pass rates for Step 2 Clinical Skills (CS) by number of essential standards used by the accrediting agencies 
Figure 15 presents the same data as Figures 12 - 14 (above) and also includes regression lines depicting that despite some variability across the specific data points, overall, performance on all three examinations improves as the number of essential standards incorporated by the various accrediting agencies increases.

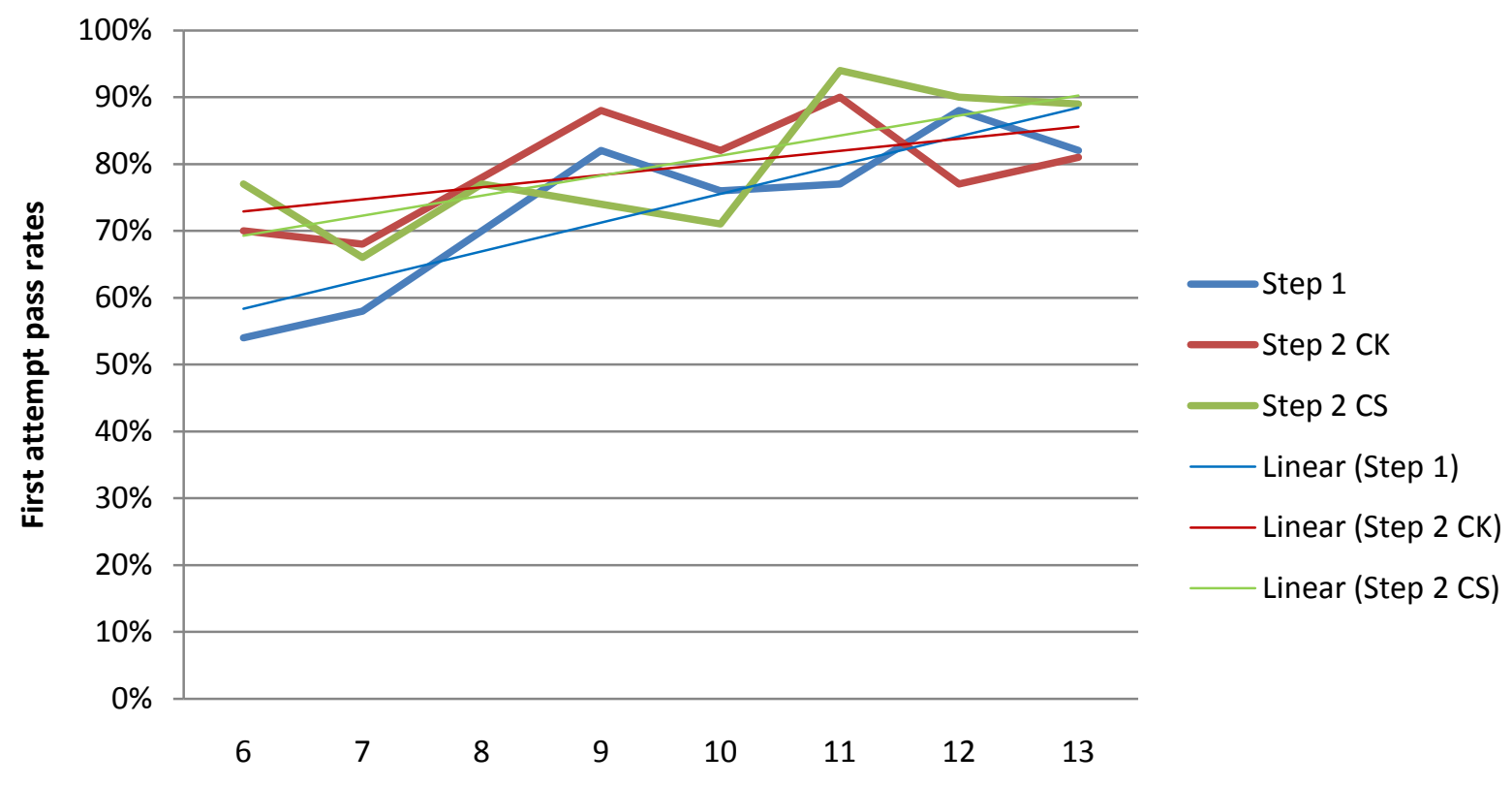

Number of essential standards used by the accrediting agencies

Figure 15. First-attempt pass rates for Step 1, Step 2 CK, and Step 2 CS by number of essential standards used by the accrediting agencies 
Next, first-attempt pass rates were calculated for each of the three examinations based on the quality grade given to the accrediting agencies. Agencies that utilized $80 \%$ or greater (12 or more) of the 14 essential standards were given a Grade A. Agencies that utilized less than $80 \%$ (11 or fewer) were given a Grade of B. Four accreditation systems used in 10 countries were given a grade of $\mathrm{A}$, and eight accreditation systems used in eight countries were given a grade of B. The results of this analysis are presented in Figure 16.

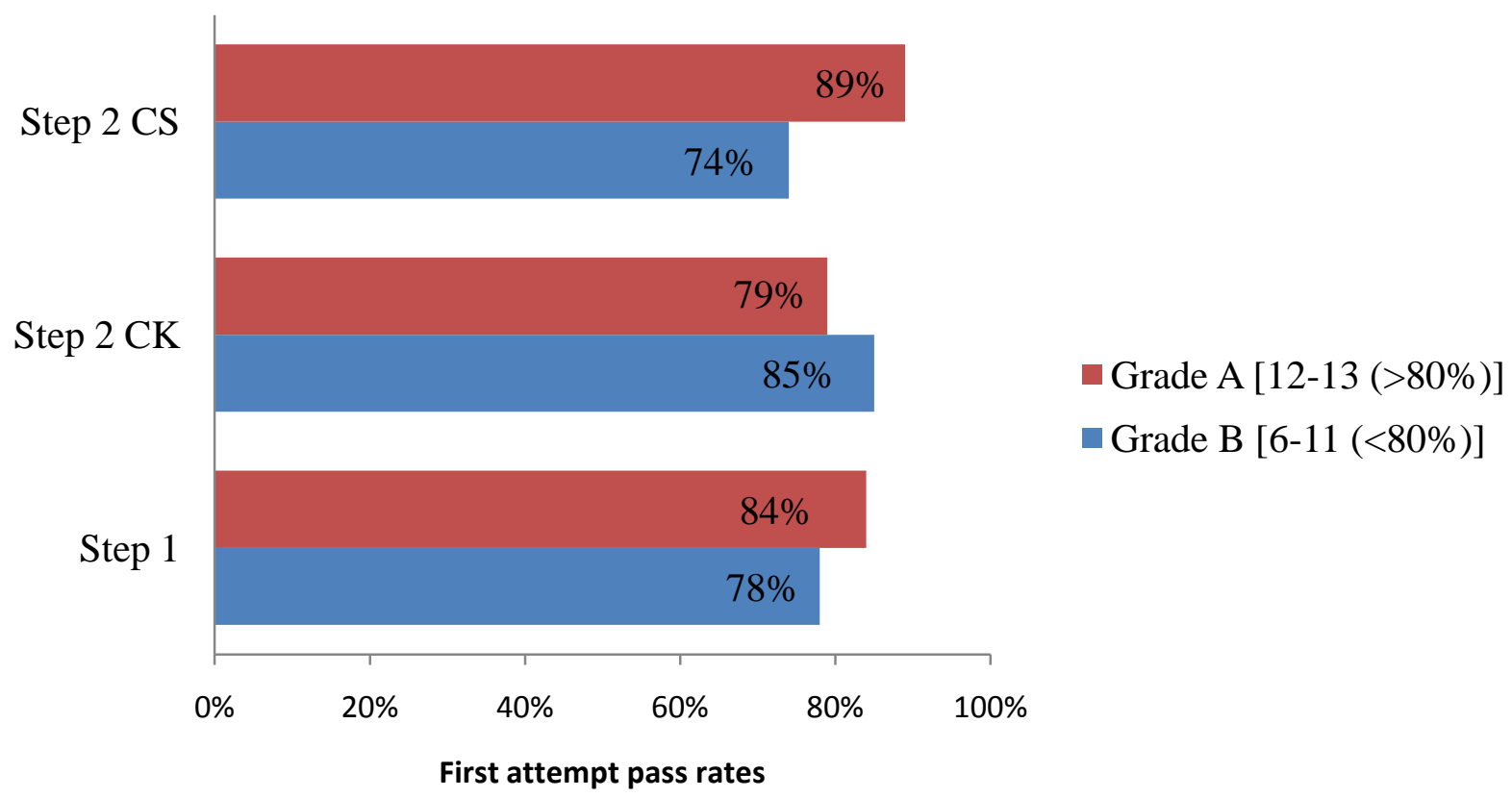

Figure 16. First-attempt pass rates for Step 1, Step 2 CK and Step 2 CS by quality grade given to the accrediting agencies that accredited the schools attended by the test takers

Grade A Step $1 \mathrm{n}=11,891$

Grade B Step $1 \mathrm{n}=23,319$

Grade A Step 2 CK $n=10,371$

Grade B Step 2 CK n=20,102

Grade A Step 2 CS n=10,676

Grade B Step 2 CS n=21,844 
Specific Essential Standards

Finally, first attempt exam performance was analyzed based on each of the specific essential standards used by the agency accrediting the medical school attended by the students/graduates. These results are presented in Table 7. The presence of certain essential criteria (i.e., B, C, H, L, and M) in the standards used by accrediting agencies was associated with better performance across all three examinations. For other standards (i.e., F and K), their associations with student/graduate examination performance were equivocal.

Table 7. The Presence or Absence of "Essential" Accreditation Standards in Relation to Pass Rates on First Attempt for Step 1, Step 2 CK, and Step 2 CS

\begin{tabular}{|c|c|c|c|c|}
\hline \multirow[t]{2}{*}{ "Essential" Accreditation Standards } & \multirow{2}{*}{$\begin{array}{c}\text { Present/ } \\
\text { Absent }\end{array}$} & \multicolumn{3}{|c|}{ Percentage Passing Examination } \\
\hline & & Step 1 & Step 2 CK & Step 2 CS \\
\hline \multirow{2}{*}{$\begin{array}{l}\text { A: The medical school teaches the } \\
\text { principles of scientific method and } \\
\text { evidence-based medicine, including } \\
\text { analytical and critical thinking, throughout } \\
\text { the curriculum. }\end{array}$} & Present & $81 \%$ & $85 \%$ & $79 \%$ \\
\hline & Absent & $78 \%$ & $79 \%$ & $79 \%$ \\
\hline $\begin{array}{l}\text { B: The medical school ensures that } \\
\text { students have patient contact and acquire }\end{array}$ & Present & $82 \%$ & $84 \%$ & $80 \%$ \\
\hline $\begin{array}{l}\text { sufficient clinical knowledge and skills to } \\
\text { assume appropriate clinical responsibility } \\
\text { upon graduation. }\end{array}$ & Absent & $59 \%$ & $71 \%$ & $71 \%$ \\
\hline \multirow{2}{*}{$\begin{array}{l}\text { C: Students' clinical experiences utilize } \\
\text { both outpatient and inpatient settings. }\end{array}$} & Present & $81 \%$ & $83 \%$ & $79 \%$ \\
\hline & Absent & $59 \%$ & $73 \%$ & $77 \%$ \\
\hline \multirow{2}{*}{$\begin{array}{l}\text { D: The medical school defines and states } \\
\text { the methods used for assessment of its } \\
\text { students, including the criteria for passing } \\
\text { examinations. }\end{array}$} & Present & $79 \%$ & $83 \%$ & $78 \%$ \\
\hline & Absent & $81 \%$ & $84 \%$ & $82 \%$ \\
\hline \multirow{2}{*}{$\begin{array}{l}\text { E: Assessment principles, methods and } \\
\text { practices are clearly compatible with } \\
\text { educational objectives and promote } \\
\text { learning. }\end{array}$} & Present & $80 \%$ & $79 \%$ & $87 \%$ \\
\hline & Absent & $79 \%$ & $86 \%$ & $74 \%$ \\
\hline
\end{tabular}


Table 7. (Continued)

\begin{tabular}{|c|c|c|c|c|}
\hline \multirow[t]{2}{*}{ "Essential" Accreditation Standards } & \multirow{2}{*}{$\begin{array}{c}\text { Present/ } \\
\text { Absent }\end{array}$} & \multicolumn{3}{|c|}{ Percentage Passing Examination } \\
\hline & & Step 1 & Step 2 CK & Step 2 CS \\
\hline \multirow{2}{*}{$\begin{array}{l}\text { F: The size of student intake is defined } \\
\text { and related to the capacity of the medical } \\
\text { school at all stages of education and } \\
\text { training. }\end{array}$} & Present & $80 \%$ & $85 \%$ & $78 \%$ \\
\hline & Absent & $79 \%$ & $76 \%$ & $83 \%$ \\
\hline \multirow{2}{*}{$\begin{array}{l}\text { G: The medical school has access to a } \\
\text { well-maintained library and information } \\
\text { facilities, sufficient in size, breadth of } \\
\text { holdings, and information technology to } \\
\text { support its education and other missions. }\end{array}$} & Present & $80 \%$ & $83 \%$ & $79 \%$ \\
\hline & Absent & $84 \%$ & $85 \%$ & $83 \%$ \\
\hline \multirow{2}{*}{$\begin{array}{l}\text { H: The medical school ensures adequate } \\
\text { clinical experience and the necessary } \\
\text { resources, including sufficient patients } \\
\text { and clinical training facilities. }\end{array}$} & Present & $80 \%$ & $83 \%$ & $79 \%$ \\
\hline & Absent & $70 \%$ & $78 \%$ & $77 \%$ \\
\hline \multirow{2}{*}{$\begin{array}{l}\text { I: Program evaluation addresses the } \\
\text { context of the educational process, the } \\
\text { specific components of the curriculum and } \\
\text { the general outcome. }\end{array}$} & Present & $78 \%$ & $79 \%$ & $83 \%$ \\
\hline & Absent & $82 \%$ & $88 \%$ & $74 \%$ \\
\hline \multirow{2}{*}{$\begin{array}{l}\mathrm{J} \text { : Student performance is analyzed in } \\
\text { relation to the curriculum and the mission } \\
\text { and objectives of the medical school. }\end{array}$} & Present & $82 \%$ & $82 \%$ & $84 \%$ \\
\hline & Absent & $78 \%$ & $84 \%$ & $76 \%$ \\
\hline \multirow{2}{*}{$\begin{array}{l}\text { K: Governance structures and functions } \\
\text { of the medical school are defined, } \\
\text { including their relationships within the } \\
\text { university. }\end{array}$} & Present & $81 \%$ & $81 \%$ & $84 \%$ \\
\hline & Absent & $78 \%$ & $86 \%$ & $74 \%$ \\
\hline \multirow{2}{*}{$\begin{array}{l}\text { L: The responsibilities of the academic } \\
\text { leadership of the medical school for the } \\
\text { medical educational program are clearly } \\
\text { stated. }\end{array}$} & Present & $82 \%$ & $85 \%$ & $86 \%$ \\
\hline & Absent & $78 \%$ & $81 \%$ & $73 \%$ \\
\hline \multirow{2}{*}{$\begin{array}{l}\text { M: The dean is qualified by education } \\
\text { and experience to provide leadership in } \\
\text { medical education, scholarly activity, and } \\
\text { care of patients. }\end{array}$} & Present & $83 \%$ & $84 \%$ & $81 \%$ \\
\hline & Absent & $71 \%$ & $80 \%$ & $74 \%$ \\
\hline \multirow{2}{*}{$\begin{array}{l}\mathrm{N} \text { : The present and anticipated financial } \\
\text { resources of a medical school are } \\
\text { adequate to sustain a sound program of } \\
\text { medical education and to accomplish } \\
\text { other institutional goals. }\end{array}$} & Present & $81 \%$ & $83 \%$ & $79 \%$ \\
\hline & Absent & $64 \%$ & $79 \%$ & $84 \%$ \\
\hline
\end{tabular}




\section{CHAPTER 4}

\section{DISCUSSION}

Phase 1 (Existence of Accreditation)

Accreditation systems for undergraduate medical educational programs can have many goals (Schirlo \& Heusser, 2010), including ensuring minimal quality standards are met, encouraging ongoing improvement, fostering international recognition of medical programs, guaranteeing that students and graduates of accredited programs have comparable opportunities in the global labor market, and providing relevant stakeholders with transparent and credible information on the quality of various educational programs.

Despite the prevalence of accreditation systems and the perceived face validity of these quality assurance methods, there are limited data linking an educational oversight mechanism to outcomes, such as better performance of the graduates on measures of skills or ability, and ultimately, enhanced care provided to patients (Davis \& Ringsted, 2006). This lack of research related to the value of accreditation is likely due to a number of factors. In many countries, all medical programs are accredited, precluding country-specific comparisons of performance of students/graduates from accredited versus nonaccredited schools. In looking at outcomes from students who attended schools in various countries or regions with or without accreditation systems, criteria such as admission standards, resources available to students, curriculum factors, etc., may differ widely across schools, making comparisons based solely on isolated accreditation variables difficult. In addition, valid outcome measures (i.e., test results) that are comparable across schools are frequently not available. In light of these challenges, the purpose 
of this study was to investigate the association between accreditation of medical educational programs and the USMLE performance of a population of internationally educated physicians seeking certification in the United States.

Research on accreditation is also needed because ECFMG is taking the global lead on creating incentives for countries to develop robust accreditation processes. While ECFMG currently defers acceptability of an IMG's medical school to the Ministry of Education or Health or other appropriate agency in the country where the school is located, this quality requirement will become more rigorous in the future. ECFMG has announced that, effective in 2023, physicians applying for ECFMG certification will be required to graduate from a medical school that has been appropriately accredited. To satisfy this requirement, the physician's medical school must be accredited through a formal process that uses criteria comparable to those established by the LCME or that uses other globally accepted criteria, such as those put forth by the WFME (ECFMG, 2010).

The purpose of Phase 1 was to examine if the presence of a national system of accreditation of undergraduate medical education is associated with the examination performance of graduates of international medical schools who voluntarily seek ECFMG certification, a prerequisite to graduate medical education and subsequent licensure to practice in the United States. Because examination performance can be influenced by a number of factors unrelated to ability, various potentially confounding personal variables were also considered and accounted for in the analyses. Due to the increasing proportion of IMGs seeking ECFMG certification who were educated at medical schools located in the Caribbean, student/graduate examination performance data from this region were examined separately. 
Overall, for the global group and the Caribbean group, students/graduates from medical schools located in countries with a system of accreditation had higher first-attempt pass rates for all three tests as compared to their peers educated in countries without accreditation. When the Caribbean data were removed from the global data and the non-Caribbean group was examined, accreditation continued to have a small positive association with examination performance only for Step 2 CS. There was no association between the existence of accreditation and Step 1 or Step 2 CK performance.

While the lack of an association between accreditation status and performance on some examinations in the non-Caribbean group was unexpected, there are numerous potential reasons for this finding. For example, in some countries, such as many of the former Soviet Republics, others located in Eastern Europe, and elsewhere, accreditation systems have been recently implemented as part of governmental educational reforms. Despite these new oversight mechanisms, medical education in these countries may still be of lower quality compared to the education in countries without formal systems of accreditation. More time may be needed to allow enhancements in the educational programs dictated by accreditation systems to manifest as improved student performance on examinations. In addition, some countries use methods other than accreditation for monitoring the quality of education, such as requiring the implementation of a common curriculum. In other countries with just one high-quality medical school, which is generally under governmental control, accreditation is sometimes viewed as unnecessary due to the lack of variability across educational programs in the country. Finally, these results reveal that in some regions of the world, simply the existence of a system of accreditation may be of less importance compared to the incorporation of specific elements within a system of accreditation, as demonstrated in the results of Phase 2 of this study. 
Step 1

In examining the data from the global group and the Caribbean group across the three tests, the difference was greatest for Step 1. The odds of a student/graduate passing Step 1 on the first attempt are 1.8 times greater for the global group and 4.9 times greater for the Caribbean group than the odds of a corresponding peer from a nonaccredited school passing the test on the first attempt. For the non-Caribbean educated individuals, accreditation had no association with this examination, indicating that the observed differences in the global group were due to the associations in the Caribbean group. Based on these results, accreditation activities seem most beneficial for enhancing student performance on this basic science test in the Caribbean region. This finding was expected, as the purpose of many accreditation criteria used in the Caribbean region are directly related to inputs and processes affecting the first phase of medical education. For example, accreditation standards related to the physical infrastructure of the school and library resources likely impact the experiences of students during their pre-clinical education. Students attending lectures and participating in other forms of basic science learning may be more homogenized in their knowledge, as is manifested in their performance on Step 1. Further research is necessary in other regions of the world outside of the Caribbean to determine the association, if any, between accreditation and basic science examination performance. Step 2 CK

The knowledge and skill domain tested as part of Step 2 CK was positively associated with accreditation systems for the global and Caribbean groups, although the effect was smaller compared to Step 1. Similar to the results for Step 1, the association of accreditation with examination performance was stronger for the Caribbean group than the global group. For the global group, the odds of a student/graduate passing Step $2 \mathrm{CK}$ on the first attempt were 1.3 
times greater for the global group and 2.3 times greater for the Caribbean group than the odds of a corresponding peer from a nonaccredited school passing the examination on the first attempt. Similar to the results for Step 1, when the Caribbean data were removed and only data from nonCaribbean educated students/graduates were examined, accreditation was no longer associated with Step 2 performance, indicating that the associations observed in the global group resulted from the Caribbean data. As with Step 1, further research is necessary to determine if other specific regions of the world, in addition the Caribbean, show a positive association between accreditation and Step $2 \mathrm{CK}$ performance.

Step 2 CS

For Step 2 CS, accreditation was positively associated with performance across all three groups (global, Caribbean, non-Caribbean). The adjusted odds ratios were 1.3, 2.4, and 1.1 respectively. In addition to the inclusion of accreditation criteria that are related to the preclinical phase of education, accreditation systems likely also incorporate numerous standards that aim to ensure the quality of the clinical phase, and curriculum related to appropriate physician - patient interaction. Nevertheless, once students enter the clinical training portion of their undergraduate education, their experiences are likely more varied compared to the preclinical phase because the students interact with large numbers of patients, faculty, clinical setting staff, and other students. This format for dispersing students to a wide variety of settings for clinical education is especially true in the Caribbean schools that educate large numbers of students aimed at entering the U.S. health care system. Therefore the likely effect of accreditation activities on clinical examination performance, while still positive, may be more diluted as additional factors are introduced that may also affect student performance on examinations. However, as demonstrated by the results of Phase 2 of this study, accreditation 
criteria related to ensuring the quality of the clinical aspects of education are important elements in enhancing student outcomes. Step 2 CS is also the examination that most closely tests the skills physicians need for treating patients, indicating that accreditation efforts linked to increased performance on this examination could be beneficial for improving actual physician practice.

\section{Global Group Versus Caribbean Group Versus Non-Caribbean Group}

Across all three tests, the association of accreditation with performance was stronger for the Caribbean group compared to the global group, and remained positive for the non-Caribbean group only for Step 2 CS. While not necessarily directly related to these results, it is important to note some elements that are unique to medical education in the Caribbean. For example, the Caribbean has numerous medical schools that are aimed specifically at the international student market (Boulet et al., 2007; Eckhert, 2010). Therefore the large majority of students at these schools likely attempt ECFMG certification and are included in the study population. In contrast, in most other regions of the world, only a self-selected group of students/graduates, who may or may not be representative of the entire student population, attempt ECFMG certification.

In many countries in the Caribbean, accreditation of medical education programs is not mandatory, although all schools in the country are accredited. Schools that seek accreditation even though it is not required may differ from schools that do not seek voluntary accreditation in that these accredited schools are very likely to be of high quality and, therefore, the administration staff is optimistic about the school's chances of positive achievement. This initial differentiation in school quality, which may influence whether a school seeks voluntary accreditation or not, likely contributes to a growing discrepancy in the quality of 
Caribbean schools. Because these schools are, in general, all targeting the same international student population, the higher quality schools will increasingly attract higher ability students and at the same time be successful in voluntary accreditation endeavors.

Regardless of these associations and motivations for a school to seek voluntary accreditation, as mentioned previously, due to the large numbers of IMGs seeking ECFMG certification that graduated from medical schools located in the Caribbean, the clear positive relationship between accreditation and test outcomes in this region is an important finding considering the large number of Caribbean-educated physicians who treat patients in the United States.

\section{Variables Associated With USMLE Performance}

\section{Gender}

USMLE performance varied by gender. As expected, males had a higher Step 1 firstattempt pass rate, while females performed better on Step 2 CK and Step 2 CS. The gender differences in performance were directionally the same for the global group, the Caribbean group, and the non-Caribbean group.

Step 1

Studies of students educated at schools accredited by the LCME (U.S. and Canadian schools) have documented that over the past decades, males have consistently outperformed females on Step 1 (Case et al., 1993; Cuddy et al., 2008). While the exact reasons for this differentiation in performance based on gender are unknown, and prematriculate variables such as the Medical College Admission Test (MCAT) or undergraduate grade point average (GPA), 
were not available for this current study population, it is hypothesized that males may enter medical school with superior knowledge in the basic sciences (Case et al., 1993; Cuddy et al., 2008). In addition, while information regarding specific undergraduate majors was also not available for this study population, it is likely that males disproportionally choose to study basic science disciplines prior to entry to medical school, a factor which may better prepare them for Step 1 (Cuddy et al., 2008).

Step 2 CK

Consistent with previous research on students at schools accredited by the LCME (U.S. and Canadian schools) that demonstrated higher performance by females on Step 2 CK (Cuddy et al., 2006; Cuddy et al., 2007), in this current study population females outperformed males on this examination. In contrast to Step 1, which tests basic science information in a relatively isolated format, in the Step 2 CK examinees answer questions requiring the integration of clinical knowledge. While results from this study and past research on other populations have demonstrated that women overall have weaker basic science knowledge as compared to men, as evident in females' lower first-attempt pass rates on Step 1, it appears that females close this gap through their medical school training to the extent that is evident in their performance on Step 2 CK. Reasons for this difference in performance by gender are unknown (Cuddy et al., 2007), but interestingly the pattern holds true for various populations of test takers. Females may be more adept than males at integrating the isolated facts learned throughout their medical education and translating these pieces into relevant clinical knowledge. Compared to males, females may also find the clinical aspects of medical education more engaging and relevant to what they envision doing as physicians. 
Step 2 CS

In contrast to the multiple-choice question formats of Step 1 and Step 2 CK, Step 2 CS is a performance examination requiring examinees to interact with lay persons portraying patients in a simulated clinical environment. Consistent with the literature on performance of students/graduates from LCME accredited schools (Cuddy et al., 2011) and other populations of IMGs (van Zanten et al., 2003; van Zanten et al., 2007), women in the current study outperformed men on this test. Indeed, the performance disparity by gender was greatest for Step 2 CS as compared to the other two examinations, and the pattern held true for the global group (13.9\% difference) as well as the Caribbean-educated group (11.8\% difference).

There are numerous potential explanations for this finding. The Step 2 CS examination setting mirrors actual physician-patient clinical interaction, and studies have demonstrated that, on average, real patients rate the interpersonal skill and clinical skills (i.e., "bedside manner") of female physicians higher than that of male physicians (Roter et al., 1991; Roter \& Hall, 1998; Roter et al., 2002). Female physicians may spend more time with patients than male physicians, engage in more patient-centered communication, and be more socialized in ways that produce somewhat stronger person-to-person relational skills (Roter \& Hall, 1998).

Similar to real life situations, in the examination environment females also scored better on the Step 2 CS in investigations of U.S. and Canadian test takers (Cuddy et al., 2011) and IMGs (van Zanten et al., 2003; van Zanten et al., 2007). Because the Step 2 CS is an examination required for licensure, it was important for the examination providers to investigate potential variability posed by the use of human raters. Threats to the validity of the examination were investigated to determine if female and male standardized patients were biased in their ratings of the examinees based on gender. No standardized patient and examinee interaction 
effect was found (Cuddy et al., 2011), providing evidence that differences in examinee scores by gender represented true variability in ability, not bias in ratings.

\section{Years Elapsed Since Graduation at Time of Testing}

In the current study, students/graduates who took any of the three examinations less than three years since graduation from medical school (or prior to graduation) had higher first-attempt pass rates than those who took the examination three or more years after graduation. Logically, it is considered advantageous to take a test in a timeframe close to instruction in the topic. Also, while it is unknown how the physicians spent their time between graduation from medical school and taking USMLE, there are a number of factors that could influence performance. Physicians may be spending the years between graduating from medical school and taking examinations gaining experience in a clinical setting, although the skills learned in their practical work may be too specialized to help them in performing well on tests of broad knowledge. Interestingly, in comparison to the other variables of interest (gender, native language) the difference in performance based on years elapsed since graduation at time of testing was very large when comparing the global data and the non-Caribbean data to the Caribbean-educated group, especially for Step 1 (4.2\% difference for global data; $6.7 \%$ difference for the non-Caribbean data; $27.2 \%$ difference for Caribbean data). This variability could be due to the fact that most Caribbean students/graduates in the study population attended medical schools that required Step 1 for progression in the curriculum.

Step 1

The impact of timing of examination on performance of students at U.S. and Canadian schools has not been investigated because all students take Step 1 at a prescribed interval 
between their basic science and clinical training, and the examination is required for graduation. No additional literature regarding the association of this variable with Step 1 performance was found. Nevertheless, these results were anticipated as it is logical that the basic science content covered in Step 1 would be recalled best soon after learning the material.

Step 2 CK

Similar to Step 1, the association of timing of examination with performance of students at U.S. and Canadian schools has not been investigated because Step 2 CK is required for graduation. One study did examine student age and found a negative correlation between Step 2 CK examination performance and students' increasing age (Ogunyemi \& Taylor-Harris, 2005). While the congruence is not exact between the variables of age at time of testing and years elapsed since graduation at time of testing, the association between these two variables could be expected to be similar. Comparable to the results for Step 1, taking an examination closer to the time of learning the material poses a logical advantage.

Step 2 CS

Similar to the results of this study, in an investigation of correlates of performance on the analogous ECFMG Clinical Skills Assessment (CSA) (offered from 1998 to 2004), better performance of IMGs was associated with taking the examination closer to graduation (van Zanten et al., 2003). While it is unknown how physicians spent their time between graduation from medical school and taking the Step 2 CS examination, time away from patient interactions would be expected to negatively affect a physician's clinical skills. In a study of IMGs who took the Step 2 CS, older physicians tended to receive lower ratings on the Communication and Interpersonal Skills portion of the examination. Again, it is unknown if the physicians spent time between medical school and taking examinations working in a relevant 
environment. Even if the doctors were engaged in patient care during the intervening years, older IMGs' experience practicing medicine may have been in a country with a very different style of physician-patient communication compared to the United States, which would potentially be reflected as lower ratings from the standardized patients (van Zanten et al., 2007).

\section{Native Language}

The results for the English speaking and native language variables were somewhat surprising. Native English background did not necessarily provide an advantage, depending on the examination and the region of medical education. As was anticipated, in the Caribbeaneducated group, native English speakers outperformed non-native English speakers on all three examinations.

In contrast to the other variables, the self reported nature of the language data may have introduced minor inaccuracies. For example, a non-native speaker may attempt to increase the value of his or her application for ECFMG certification by indicating English as a native language on the ECFMG application. While potential inaccuracies in self-reported data were possible, there is no evidence to suggest that they existed, or that they were disproportionally provided in any one direction. Therefore the results, even with acknowledgement of the selfreported nature of this particular variable, should be generalizable across the two groups. Step 1

Counter-intuitively, in the global and non-Caribbean data for Step 1, individuals who self-reported a native language other than English had higher first-attempt pass rates than native English speakers. This result is opposite of that reported in a study conducted on students of 
U.S. and Canadian schools, which found that non-native English speakers performed worse on Step 1 than native English speaking peers (Cuddy et al., 2006).

Despite the potentially unexpected nature of this finding, several investigations of IMG performance have provided evidence that does support these results. A 2006 study of USMLE performance of USIMGs versus non-U.S. citizen IMGs (non-USIMGs) demonstrated that USIMGs do not perform as well as non-USIMGs on Step 1. The first-attempt pass rates for USIMGs versus non-USIMGs for Step 1 were 60.5\% versus 64.3\% (Boulet et al., 2006b). Another 2006 study also reported non-USIMGs outperforming USIMGs on Step 1 (Norcini et al., 2006a). While the variables of U.S. citizen status and native English speaker status are not entirely overlapping, in the Boulet (2006b) study, 69.8\% of USIMGs reported English as a native language, compared to only $9.3 \%$ of non-USIMGs who reported this status.

The present results revealed better performance of non-native English speakers that, while seemingly not logical (but nonetheless expected based on past studies of IMGs performance), could be due to a number of reasons. Step 1 is a multiple-choice test and, therefore, only requires one skill associated with language fluency, the ability to comprehend written language. The skills of speaking, writing, and listening are not required for this test. Due to the increasing global nature of medical knowledge, many medical schools in countries that use an official language other than English may use English-language textbooks, journals, notes, databases, etc., in the curriculum. Non-native English-speaking physicians may already be very accustomed to reading medical information in English. Therefore, it appears that for this particular test, speaking English as a native language does not provide any meaningful advantage. 
In examining the data from the Caribbean-educated group, native English speakers had a higher first-attempt pass rate compared to non-native speakers. ECFMG registrants educated in countries in the Caribbean that primarily educated physicians who speak a native language other than English that are included in this study are Cuba, the Dominica Republic, and Haiti. Due to the lower economic status of these countries, it is possible that the resources available for medical education are not as extensive compared to what is available in the other Caribbean countries, many of which have schools that educate large numbers of U.S. citizens. Step 2 CK

Similar to the unexpected results for Step 1, in the global and non-Caribbean groups nonnative English speakers outperformed native English speakers on Step 2 CK, and within the Caribbean group, the reverse was true. Since both Step 1 and Step 2 CK are delivered in a multiple-choice test format, the many of the same potential rationales stated above explaining the results of Step 1 are also applicable for this examination.

Step 2 CS

As was predicted, and is consistent with past research on IMGs (van Zanten et al., 2003; van Zanten et al., 2007), across all three groups native English speakers outperformed non-native English speakers on Step 2 CS. For this performance test, which involves the skills of speaking to patients using clear and understandable language, understanding the patients' verbal responses, and writing up pertinent findings in the form of a post-encounter patient note, native English language status clearly provides an advantage to the test taker. While there are elements of the Step 2 CS that do not involve language ability (i.e., the ability to perform a physical examination, drape a patient to minimize skin exposure during a physical examination, and nonverbal interpersonal behaviors such as maintaining appropriate eye contact, providing 
reassuring, nonjudgmental facial expressions, touch, etc.), a large part of the examination is likely directly influenced by a physician's proficiency in English. For example, it is likely challenging for a nonproficient examinee to ask questions about personal or sensitive information in a tactful and appropriate manner. The language nuances necessary to effectively counsel a patient about changing unhealthy behaviors might also pose difficulties if the examinee did not have a strong grasp of the English language.

\section{Phase 2 (Quality of Accreditation)}

The purpose of Phase 2 was to create a quality rating scheme for select accrediting agencies and to determine the association between quality of accreditation and student outcomes.

Based on the analysis of the survey responses from a globally diverse pool of medical education accreditation experts, while there was some global variation in importance of some accreditation standards, there was unanimous agreement among the respondents that 14 of the standards are essential for determining quality. These essential standards are somewhat evenly distributed across the WFME categories, indicating that experts believe standards covering a range of inputs and processes are mandatory. These 14 standards describe globally accepted key features necessary for the successful production of graduates.

For example, the standard "The medical school teaches the principles of scientific method and evidence-based medicine, including analytical and critical thinking, throughout the curriculum" states that medical education must include higher order thinking and be more than simple memorization of a large quantity of information. The standard "The medical school ensures that students have patient contact and acquire sufficient clinical knowledge and skills to 
assume appropriate clinical responsibility upon graduation" speaks to the essential nature of students' applied clinical education as part of the curriculum. Other essential standards, such as "Assessment principles, methods, and practices are clearly compatible with educational objectives and promote learning" and "Student performance is analyzed in relation to the curriculum and the mission and objectives of the medical school" ensure the appropriateness of evaluation activities. Essential standards also related to issues such as the library, school leadership, and the school's financial stability and demonstrated crucial aspects of learning not directly related to curriculum delivery.

The experts' unanimous agreement on these 14 essential standards suggests that these are core concepts that all accrediting systems should incorporate. The data also validate that standards that are used by accreditation agencies conform to globally accepted minimum criteria, and agencies should ensure that the concepts covered in these 14 essential standards are implemented as part of their systems. This does not, however, mean that other standards are not important. Instead, it suggests that there is a hierarchical structure of accreditation standards that needs to be acknowledged in the process of medical school review.

There were four standards, all in the Educational Resources category, where the average rating was 2 or less. This corresponds to an aggregate expert opinion somewhere between "not important" and "important but not essential." Two of the standards, "The medical school has dormitory/hostel provision for at least $75 \%$ of the total intake of students at a given time" and "The medical school has a teaching hospital with a ratio of a minimum of five beds per student," both refer to very specific resource requirements. While it is the tradition in certain cultures to specify in detail the inputs required for a medical school, this level of particularization is not the norm worldwide. Of particular interest is the relatively low aggregate rating of the standard, 
"The medical course is set in the context of an active research program within the school." While it has become increasingly important over the past century for medical schools in most high-income countries in the world to devote large resources to research programs, based on the results of this study, this concept is not considered a priority worldwide. Interestingly, many of the more recently founded institutions that educate a large number of medical students who pursue postgraduate training and licensure in the United States, (i.e., U.S. Osteopathic schools, some M.D. granting institutions located in the Caribbean, etc.,) have only small research programs, if at all. Therefore, despite the tradition promoted by Abraham Flexner in the early 1900s of medical schools incorporating research opportunities for faculty, staff, and students (Flexner, 1910), it appears that, at least from a global perspective, this emphasis on research programs associated with medical schools may no longer be considered relevant today in ensuring the production of qualified graduates.

Nine standards had rater variability that was greater than 0.50 , indicating that the experts disagreed substantially on these standards' levels of importance in ensuring quality. These standards likely represent aspects of medical education that vary significantly across geographic and cultural realms. For example, while it is the tradition in many parts of the world to teach basic sciences and clinical sciences separately, in other regions the convention is that these aspects of knowledge and skills should be fully integrated. Standards related to the health of indigenous populations or considerations of other sectors of society are also not universally relevant. Finally, experts do not agree on the importance of including standards that pertain to the rights of students in ensuring a quality education.

Only two standards were rated as N/R (not able to rate) by three respondents; other instances of N/R ratings or questions left blank were distributed evenly across the pool of 
standards. These results indicate that, overall, most of the experts felt that they were able to make an informed opinion on the appropriateness of the content of the standard for virtually all of the 150 standards included in the survey.

While differences in opinion would be expected, especially for standards that are nonspecific, or have cultural implications, future studies should be conducted to more fully understand the complexity and context-specificity of "nonessential" quality indicators. Some of the variability could also be explained by the generic nature of many of the WFME standards, which are specifically designed to be flexible and to apply to a wide range of cultures and contexts. Likewise, while inter-rater variability might be expected for respondents from different regions, it would be informative to know more about the consistency of responses (opinions) for experts within a specific jurisdiction.

Fortunately, while consensus may never be reached for some "standards," at least for some key indicators (i.e., "The medical school teaches the principles of scientific method and evidence-based medicine") the global set of experts all deemed the standard to be essential for maintaining quality. As mentioned previously, while certainly not comprehensive, these particular standards form the basis for best practices in medical school accreditation.

The mean ratings, over respondents, aggregated for all of the standards within each of the nine WFME categories demonstrate that, overall, the experts rated categories of standards relatively equally. Standards related to Academic Staff / Faculty received the highest mean rating (2.77), and the categories of standards related to Educational Resources (2.52) and Students (2.53) received the lowest. The emphasis on standards that ensure high-quality teachers was expected and clearly is an important determinant of quality (Darling-Hammond, 1999). In contrast, the somewhat lower rating of standards related to a school's physical resources and 
the rights of students is an interesting outcome that may be explained by variations in culture and tradition. For example, the inclusion of standards that protect the rights of students to view and challenge their academic records may reflect the level of openness and transparency of a country's government.

\section{Accreditation Agency Quality}

The results of the analyses of examination performance by quality of accreditation agency were generally anticipated, albeit there were some unexpected variations. For Step 1, there was a direct linear relationship in first-attempt pass rates as the number of essential elements of an accrediting agency increased from 6 to 9. Once an agency utilized 10 or more of the essential standards, while overall the performance of students/graduates on Step 1 remained relatively high, the relationship between quality of accrediting agency and performance remained relatively constant. It therefore appears that for this multiple-choice examination which covers basic science concepts, the quality of the accreditation system was positively associated with student/graduate performance at the lower half of the scale, but after the threshold of 10 standards (71.4\% of the 14 essential standards) was met, further increasing the number utilized did not appear to continue to have an additional positive effect.

The results for Step $2 \mathrm{CK}$ are similar to the results of Step 1, with a positive relationship between accreditation criteria and performance only at the lower end of the scale. After a threshold of $9(64.3 \%)$ standards was met, further increasing the number of standards incorporated in the accrediting systems no longer had any further positive effect.

For Step 2 CS, despite some variability at the lower end, the utilization of $11(78.6 \%)$ standards appeared to be the upper limit where accreditation affects performance. 


\section{Accreditation Agency Quality (Grade A Versus Grade B)}

For Step 1, students/graduates who attended a medical school located in a country that has an accreditation system utilizing $80 \%$ or more of the essential standards (Grade A) performed better than those individuals who attended medical school in a country that utilized fewer than $80 \%$ of the essential standards (Grade B). The first-attempt pass rates for these two groups were $84 \%$ versus $78 \%$, respectively, a difference of $6 \%$. This examination is a multiplechoice test covering basic science concepts and a more robust system of accreditation which covers the large majority of essential items appears to positively affect student/graduate performance. The numerous reasons mentioned previously hypothesizing why the existence of an accreditation system likely improves Step 1 performance are supported by these Phase 2 results.

In contrast, the results for Step $2 \mathrm{CK}$ were not expected. Overall, students/graduates attending a medical school in a country with a lower-quality rating performed better on this examination. There are other unknown factors beyond accreditation quality that clearly affect performance. Step $2 \mathrm{CK}$ is a multiple-choice test that covers clinical concepts and requires integration of knowledge. The complex erudition required for this examination may draw on intelligence levels that are less directly influenced by the elements reflected in a more robust accreditation system. For example, as mentioned previously in the section describing potential reasons why the existence of an accreditation system positively affects student performance on this examination, the variability in the clinical phase of education may introduce elements that are not reflected directly in the essential criterion for accreditation.

For Step 2 Clinical Skills (CS), the results of performance based on the quality of accreditation system analyses were expected, and, in fact, were quite strong. Students/graduates 
who attended a medical school located in a country that has a Grade A accreditation system performed better than those individuals who attended medical school in a country with a Grade B accreditation system. The first-attempt pass rates for these two groups were $74 \%$ versus $89 \%$ respectively, a difference of $15 \%$. Clearly, for this test, the quality of an accreditation system is positively associated with performance. In contrast to Step 1 and Step 2 CK which are multiplechoice tests, the Step 2 CS is a performance examination where physician examinees interact with standardized patients in a mock clinical environment. The format of the Step 2 CS is designed to mimic the real world medical setting and tap the knowledge and skills necessary for a physician to function appropriately with patients. Also, the examinee is required to determine, explain, and document the necessary clinical information needed by other members of the health care team. Essential elements of accreditation systems that are incorporated into an agency's standards appear to affect student/graduate performance on Step 2 CS more than for the other two examinations. This finding in support of high-quality accreditation systems is of key importance as the Step 2 CS examination represents the portion of the testing series that is directly related to what physicians do in actual practice environments.

\section{Specific Essential Standards}

The analyses based on each of the specific essential standards used by the agency accrediting the medical school attended by the students/graduates revealed some findings of interest, although overall the results were somewhat difficult to interpret with certainty.

Some specific essential standards (e.g., B, C, H, L, and M) were associated with better performance across all three examinations. Essential standards B, C, and $\mathrm{H}$ are related to ensuring the quality of aspects of students' clinical experiences, and essential standards L and M 
are related to aspects of ensuring adequate institutional leadership. It appears that these themes within the 14 essential criteria are the most consistently salient features for quality assurance across the spectrum of medical education in ensuring the production of highly skilled physicians.

\section{Limitations}

While this study provides some evidence linking the existence of medical accreditation activities to better performance of physicians on examinations, depending on the region of the world and the examination, there are a number of important factors to consider when interpreting these results. Numerous limitations exist, both within the study design, the outcome measures used, the chosen analyses, and the data that may have potentially influenced the findings.

Although attending a medical school located in a country with a system of accreditation was generally associated with better performance on the USMLE, these results only applied to a self-selected group of individuals. Students/graduates who voluntarily chose to take USMLE may have differed appreciably from a school's total student population. To graduate from an international medical school and then decide to pursue graduate training in the United States requires a high level of motivation and financial resources. Preparing for tests, examination fees, and participating in the residency interview processes are all expensive endeavors and require travel to the United States. Therefore, in the case of international schools that primarily educated physicians for the country's own domestic needs, individuals in the study population were probably not representative of all students from a particular medical school. While the study design ensured that at least 10 individuals for a country took each of the three examinations during the study period $(2006-2010)$ in order for the country to be included in the data, the 
potential lack of representativeness of students/graduates taking USMLE as compared to their schools' total population may have limited the generalizability of the results.

While it is important to recognize this potential source of bias, the separate investigations of the association between accreditation and USMLE performance in the Caribbean minimized this potential self-selection limitation because the majority of students at many of these schools seek ECFMG certification.

Homogenization of examination performance across the certification cycle could also impact the results. The majority of IMGs seeking ECFMG certification take Step 1 first, and the following examinations after passing this hurdle. In many schools in the Caribbean that predominately educate students seeking to enter the U.S. health care system, Step 1 is required for progression in the curriculum. Therefore, for some of the variables, differences observed in Step 1 performance, especially for the Caribbean group, may have decreased in subsequent examinations due to attrition of non-successful individuals.

The prior ability of students/graduates in the study population was unknown. No MCAT scores, prior higher education GPA, or other performance variables were available. The extent to which prior ability for this study population influenced the performance outcomes of interest was a limitation that was not accounted for in the study.

This was a cross-sectional study and, therefore, it provided no support for causation. It is logical that students in many of the countries who are included in this study pursue their medical education in their country of citizenship and, therefore, do not make a conscious effort to attend an accredited medical school versus a nonaccredited school. (In this study the countries with voluntary accreditation were eliminated from the data.) There are also a significant number of students who, for a variety of reasons, migrate to another country for their medical education. 
In a 2007 study of IMG applicants for ECFMG certification from 1981 to 2005, over 70,000 individuals had left their home countries to pursue undergraduate medical education. More than half $(57 \%)$ of these migrating students were citizens of the United States (Hallock et al., 2007). The extent to which a student who migrates for medical education makes a conscious decision to attend an accredited school over a nonaccredited school is unknown, but this phenomenon could affect the results, as better schools may be more likely to seek accreditation and also attract higher quality students. Even if applicants to nonaccredited versus accredited schools differ based on prior ability level, the consequential impact of accreditation remains positive.

In addition, it is important to consider the potential impact accreditation could have on student performance solely due to the quality assurance system's standards related to admission requirements. To the extent that an accreditation system mandates students' demonstrated high performance on preadmission variables as a threshold for admittance, this single accreditation variable could account for large differences in student performance across medical schools with and without a system of accreditation. Variability in the quality of the various medical schools' teaching faculties, while potentially accounted for in accreditation standards, could also be the source of large differences in student outcomes.

Using test performance as the outcome measure is not an exact representation of the quality of a physician or the quality of the medical schools they attended. Research in secondary schools has demonstrated that using examination results to judge the quality of educational institutions can be somewhat biased for a variety of reasons, including failing to take into account the prior achievement levels of the students (Goldstein \& Thomas, 1996).

In addition to individual factors which may have potentially biased the results, there were school/country level limitations in the data related to timing of accreditation that may have 
influenced findings. The population of students/graduates used on this study included any individual who took a USMLE examination leading to ECFMG certification between January 1, 2006 and December 31, 2010. The accreditation status of a country was determined as of December 2009. Therefore, it was possible that the accreditation status of a school/country did not match exactly to the status assigned to some students/graduates. In an investigation of the association between accreditation and outcomes, it is important to recognize that any effect an accreditation decision has on the quality of education will not be manifest until after students have spent sufficient time in a newly accredited study program. In addition, an accreditation decision is usually granted a number of months or up to a few years after a school has implemented changes in preparation for the quality review process, and educational programs are likely to undergo improvements as part of a ramping-up period prior to accreditation. Therefore, it was not possible to determine an exact date when the influence of accreditation would have been manifested in the performance of students, as arguments can be made for moving the theoretical date earlier, or later, than the exact date of a school receiving a positive accreditation status. Despite this potential limitation, it is important to note that there is no evidence indicating that any potential misclassification of accreditation status was unidirectional.

Other confounding variables at the country level that are not directly related to accreditation status of the medical schools may be associated with student examination performance. For example, country's gross domestic product (GDP) or other economic indicators may be connected to the existence of a national system of accreditation, and also student/graduate performance on USMLE.

The survey used to determine quality of accrediting agencies also has several limitations. First, although the response rate could be considered to be acceptable, due to the very specific 
nature of the expertise required of professions qualified to answer the survey, the overall number of individuals contacted and the number who completed the survey was small. Also, while an anonymous survey has the advantage of encouraging truthful responses, it was not possible to determine if respondents were representative of the group sampled. Despite this potential limitation, the wide geographic distribution of the 22 potential respondents ensured a globally diverse response pool. Finally, the language of the survey (English) may have disproportionally deterred non-native English-speaking individuals from responding.

There are also numerous limitations that could have affected the results of the quality of accrediting agency analyses. Accreditation is a multifaceted process, and despite the utilization of a proportion of these 14 essential standards, there could be other aspects of systems that are not equivalent across agencies, such as the protocols employed and credentials and experience of the individuals conducting reviews. Finally, this study was based on published documentation of standards but did not take into account interpretation of these criteria in actual use.

\section{Conclusions}

Although this study lends some evidence supporting the value of accreditation by linking it to improved student outcomes, especially in the Caribbean region, further research on this topic is warranted. Additional cross-sectional studies using USMLE performance or other outcome measures should be conducted with data from other countries with voluntary accreditation. The relationship between accreditation and outcomes could also be strengthened by examining performance of students from accredited schools versus performance of students from schools that attempted accreditation but were denied (eliminate data from schools that 
never attempted accreditation). Additional school variables unrelated to accreditation, such as public versus private status, could also be examined for possible relationships to student outcomes.

Due to the many limitations of cross-sectional investigations, future work in this field should also include longitudinal studies for specific schools pre- and post-accreditation. Data demonstrating that schools show marked increases in student performance after making the improvements dictated by an accreditation review would provide strong evidence for promoting the value of quality assurance activities.

This study lends some support to the value of accreditation. Due to the substantial resources needed to design and implement accreditation processes, including monetary costs and time expenditures, these types of studies are needed to provide positive evidence beyond face validity and to encourage support from the relevant stakeholders. These results provide positive evidence that quality assurance oversight of educational programs, especially those systems that incorporate certain essential criteria, produce more highly skilled physicians, which in turn should improve the health care of patients. 


\section{REFERENCES CITED}

Alkhenizan, A. \& Shaw, C. (2011). Impact of accreditation on the quality of healthcare services: a systematic review of the literature. Annals of Saudi Medicine, 31, 407-416.

Asch, D. A., Epstein, A., \& Nicholson, S. (2007). Evaluating medical training programs by the quality of care delivered by their alumni. JAMA, 298, 1049-1051.

Blanco, C., Carvalho, C., Olfson, M., Finnerty, M., \& Pincus, H. A. (1999). Practice patterns of international and U.S. medical graduate psychiatrists. American Journal of Psychiatry, $156,445-450$.

Boelen, C. \& Boyer, M. H. (2001). A view of the world's medical schools: Defining new roles. Retrieved March 1, 2012 from www.iaomc.org/WHOReptMedSchools.pdf

Boulet, J., Bede, C., McKinley, D., \& Norcini, J. (2007). An overview of the world's medical schools. Medical Teacher, 29, 20-26.

Boulet, J. R., Norcini, J. J., Whelan, G. P., Hallock, J. A., \& Seeling, S. S. (2006a). The international medical graduate pipeline: recent trends in certification and residency training. Health Affairs, 25, 469-477.

Boulet, J. R., Swanson, D. B., Cooper, R. A., Norcini, J. J., \& McKinley, D. W. (2006b). A comparison of the characteristics and examination performances of U.S. and non-U.S. citizen international medical graduates who sought Educational Commission for Foreign Medical Graduates certification: 1995-2004. Academic Medicine, 81, S116-S119.

Braithwaite, J., Westbrook, J., Pawsey, M., Greenfield, D., Naylor, J., Iedema, R. et al. (2006). A prospective, multi-method, multi-disciplinary, multi-level, collaborative, socialorganisational design for researching health sector accreditation. BMC Health Services Research, 6, 113.

Brotherton, S. E. \& Etzel, S. I. (2011). Graduate medical education, 2010-2011. JAMA, 306, 1015-1030.

Busari, O. J., Vervoort, M., Hermans, S. M., \& Blom, J. R. (2001). Medical education in the new millennium - a Caribbean perspective. Medical Education, 35, 703-706.

Caldwell, B. E., Kunker, S. A., Brown, S. W., \& Saiki, D. Y. (2011). COAMFTE Accreditation and California MFT Licensing Exam Success. Journal of Marital and Family Therapy, 37, 468-478.

Caribbean Accreditation Authority for Education in Medicine and other Health Professions. (2012). Upcoming Site Visits and Accreditation Requests. Retrieved March 1, 2012 from www.caam-hp.org 
Case, S. M., Becker, D. F., \& Swanson, D. B. (1993). Performances of men and women on NBME Part I and Part II: the more things change... Academic Medicine, 68, S25-S27.

Ceaser, M. (2005, October 28). Sun, Sand and an M.D. Chronicle of Higher Education, 52.

Cole, J. S. \& Cole, S. T. (2008). Accreditation and educational quality: Are students in accredited programs more academically engaged? Schole: A Journal of Leisure Studies and Recreational Education, 23, 75-90.

Commission for Evaluation and Accreditation of University Programs. (2012). Commission for Evaluation and Accreditation of University Programs. Retrieved March 1, 2012 from www.mes.edu.cu

Council for Higher Education Accreditation. Directory of CHEA-Recognized Organizations. Retrieved March 1, 2012 from www.chea.org

Croasdale, Myrle (2006, January 16). Quality concerns spur scrutiny of Caribbean medical schools. American Medical News.

Cuddy, M. M., Swanson, D. B., \& Clauser, B. E. (2007). A Multilevel analysis of the relationships between examinee gender and United States Medical Licensing Exam (USMLE) step 2 CK content area performance. Academic Medicine, 82, S89-S93.

Cuddy, M. M., Swanson, D. B., \& Clauser, B. E. (2008). A multilevel analysis of examinee gender and USMLE step 1 performance. Academic Medicine, 83, S58-S62.

Cuddy, M. M., Swanson, D. B., Dillon, G. F., Holtman, M. C., \& Clauser, B. E. (2006). A multilevel analysis of the relationships between selected examinee characteristics and United States Medical Licensing Examination Step 2 Clinical Knowledge performance: Revisiting old findings and asking new questions. Academic Medicine, 81, S103-S107.

Cuddy, M. M., Swygert, K. A., Swanson, D. B., \& Jobe, A. C. (2011). A multilevel analysis of examinee gender, standardized patient gender, and United States medical licensing examination step 2 clinical skills communication and interpersonal skills scores. Academic Medicine, 86, S17-S20.

Cueto, J., Jr., Burch, V. C., Adnan, N. A. M., Afolabi, B. B., Ismail, Z., Jafri, W. et al. (2006). Accreditation of undergraduate medical training programs: practices in nine developing countries as compared with the United States. Education for Health, 19, 207-222.

Darling-Hammond, L. (1999). Teacher Quality and Student Achievement: A Review of State Policy Evidence. Seattle, WA: The University of Washington: Center for the Study of Teaching and Policy.

Davis, D. J. \& Ringsted, C. (2006). Accreditation of undergraduate and graduate medical education: How do the standards contribute to quality? Advances in Health Sciences Education: Theory and Practice, 11, 305-313. 
Deaton, B. J. (2004). A theoretical framework for examining the role of third-party certifiers. Food Control, 15, 615-619.

Dickinson, P., Hostler, D., \& Platt, T. (2006). Program accreditation effect on paramedic credentialing examination success rate. Prehospital Emergency Care, 10, 224-228.

Donabedian, A. (1980). Methods for deriving criteria for assessing the quality of medical care. Medical Care Review, 37, 653-698.

Eckhert, N. L. (2010). Private schools of the Caribbean: outsourcing medical education. Academic Medicine, 85, 622-630.

Educational Commission for Foreign Medical Graduates. (2011). Educational Commission for Foreign Medical Graduates 2010 Annual Report. Philadelphia, PA, Educational Commission for Foreign Medical Graduates. Philadelphia, PA: ECFMG.

Educational Commission for Foreign Medical Graduates. (2010). Medical School Accreditation Requirement for ECFMG Certification. Retrieved March 1, 2012 from www.ecfmg.org/annc/accreditation-requirement.html

Fernandez, A. R., Studnek, J. R., \& Margolis, G. S. (2008). Estimating the probability of passing the national paramedic certification examination. Academic Emergency Medicine, 15, 258-264.

Flexner, A. (1910). Medical education in the United States and Canada (Rep. No. 4). New York, NY: The Carnegie Foundation for the Advancement of Teaching.

Foundation for Advancement of International Medical Education and Research (2012). Directory of Organizations that Recognize/Accredit Medical Schools. Retrieved March 1, 2012 from www.faimer.org/resources/dora/index.html

Gohmann, S. F. (2006). Factors influencing NCQA accreditation decisions of HMOs. Atlantic Economic Journal, 34, 209-217.

Goldstein, H. \& Thomas, S. (1996). Using examination results as indicators of school and college performance. Journal of the Royal Statistical Society, 159, 149-163.

Gropper, R.G. (1996). Educational Outcomes and Specialized Accreditation. Nurse Education, $21,8-10$.

Hagerty, B. M. K. \& Stark, J. S. (1989). Comparing educational accreditation standards in selected professional fields. Journal of Higher Education, 60, 1-20.

Hallock, J. A., McKinley, D. W., \& Boulet, J. R. (2007). Migration of doctors for undergraduate medical education. Medical Teacher, 29, 98-105. 
Hamdy, H., Prasad, K., Anderson, M. B., Scherpbier, A., Williams, R., Zwierstra, R. et al. (2006). BEME systematic review: predictive values of measurements obtained in medical schools and future performance in medical practice. Medical Teacher, 28, 103-116.

Hanley, J.A., Negassa, A., Edwardes, M.D., \& Forrester, J.E. (2003). Statistical Analysis of Correlated Data Using Generalized Estimating Equations: An Orientation. American Journal of Epidemiology, 157, 364-375.

Hecker, K. \& Violato, C. (2008). How much do differences in medical schools influence student performance? A longitudinal study employing hierarchical linear modeling. Teaching and Learning in Medicine, 20, 104-113.

Hing, E. \& Lin, S. (2009). Role of International Medical Graduates Providing Office-based Medical Care: United States, 2005-2006 (Rep. No. 13). Hyattsville, MD: National Center for Health Statistics.

Jalbert, T., Jalbert, M., \& Furumo, K. (2011). Does AACSB accreditation matter? Evidence from large firm CEOs. Journal of Applied Business Research, 27, 93-106.

Joly, B. M., Polyak, G., Davis, M. V., Brewster, J., Tremain, B., Raevsky, C. et al. (2007). Linking accreditation and public health outcomes: a logic model approach. Journal of Public Health Management and Practice, 13, 349-356.

Karle, H. (2004). International trends in medical education: diversification contra convergence. Medical Teacher, 26, 205-206.

Karle, H. (2006). Global standards and accreditation in medical education: a view from the WFME. Academic Medicine, 81, S43-S48.

Karle, H. (2008). International recognition of basic medical education programmes. Medical Education, 42, 12-17.

Kassebaum, D. G. (1992). Origin of the LCME, the AAMC-AMA partnership for accreditation. Academic Medicine, 67, 85-87.

Kassebaum, D. G., Cutler, E. R., \& Eaglen, R. H. (1998). On the importance and validity of medical accreditation standards. Academic Medicine, 73, 550-564.

Lejeune, C. \& Vas, A. (2009). Organizational culture and effectiveness in business schools: a test of the accreditation impact. Journal of Management Development, 28, 728-741.

Liaison Committee on Medical Education (2011). Functions and Structure of a Medical School. Retrieved March 1, 2012 from www.lcme.org/functions.pdf

Lurie, S. J., Mooney, C. J., \& Lyness, J. M. (2009). Measurement of the general competencies of the accreditation council for graduate medical education: a systematic review. Academic Medicine, 84, 301-309. 
McGlynn, E. A., Asch, S. M., Adams, J., Keesey, J., Hicks, J., DeCristofaro, A. et al. (2003). The quality of health care delivered to adults in the United States. New England Journal of Medicine, 348, 2635-2645.

McManus, I. C., Elder, A. T., De Champlain, A., Dacre, J. E., Mollon, J., \& Chis, L. (2008). Graduates of different UK medical schools show substantial differences in performance on MRCP(UK) Part 1, Part 2 and PACES examinations. BMC Medicine, 6, 5.

Medical Board of Dominica. (2006). Standards and Procedures for Certification of Medical Education Programmes. Roseau, Dominica: Ministry of Health and Social Security.

Mick, S. S. \& Lee, S. Y. (1999a). International and US medical graduates in US cities. Journal of Urban Health, 76, 481-496.

Mick, S. S. \& Lee, S. Y. (1999b). Are there need-based geographical differences between international medical graduates and U.S. medical graduates in rural U.S. counties? Journal of Rural Health, 15, 26-43.

Ministry of Constitutional and Interior Affairs and the Project Organisation Dismantling of the Country Netherlands Antilles (POLNA). (2009). Info Bulletin: Dismantling of the Netherlands Antilles. Retrieved March 1, 2012 from www.curacao-law.com/wpcontent/uploads/2009/01/polna-newsletter-5.pdf

National Committee on Foreign Medical Education and Accreditation (2012). Decisions of Comparability. Retrieved March 1, 2012 from www2.ed.gov/about/bdscomm/list/ ncfmea.html

National Committee on Foreign Medical Education and Accreditation (2007a). US Department of Education Staff Analysis of the Report Submitted by Mexico. Washington, DC: US Department of Education.

National Committee on Foreign Medical Education and Accreditation (2007b). US Department of Education Staff Analysis of the Report Submitted by St. Maarten. Washington, DC: US Department of Education.

National Committee on Foreign Medical Education and Accreditation (2007c). US Department of Education Staff Analysis of the Report Submitted by the Cayman Islands. Washington, DC: US Department of Education.

National Committee on Foreign Medical Education and Accreditation (2009a). Staff Analysis of the Standards for the Evaluation of Medical Schools Used by Cayman Islands. Washington, DC: US Department of Education.

National Committee on Foreign Medical Education and Accreditation(2009b). Staff Analysis of the Standards for the Evaluation of Medical Schools Used by Saba. Washington, DC: US Department of Education. 
National Committee on Foreign Medical Education and Accreditation (2011a). US Department of Education Staff Analysis of the Report Submitted by Mexico. Washington, DC: US Department of Education.

National Committee on Foreign Medical Education and Accreditation (2011b). Staff Analysis of the Standards for the Evaluation of Medical Schools Used by Sint Maarten. Washington, DC: US Department of Education.

Netherlands-Flemish Accrediting Organization (2012). Accreditation. Retrieved March 1, 2012 from http://nvao.com

Norcini, J., Anderson, M. B., \& McKinley, D. W. (2006a). The medical education of United States citizens who train abroad. Surgery, 140, 338-346.

Norcini, J. J., Boulet, J. R., Dauphinee, W. D., Opalek, A., Krantz, I. D., \& Anderson, S. T. (2010). Evaluating the quality of care provided by graduates of international medical schools. Health Affairs, 29, 1461-1468.

Norcini, J. J., McKinley, D. W., Boulet, J. R., \& Anderson, M. B. (2006b). Educational Commission for Foreign Medical Graduates certification and specialty board certification among graduates of the Caribbean medical schools. Academic Medicine, 81, S112-S115.

Ogunyemi, D. \& Taylor-Harris, D. (2005). Factors that correlate with the U.S. Medical Licensure Examination Step-2 scores in a diverse medical student population. Journal of the National Medical Association, 97, 1258-1262.

Pinkham, F. O. (1955). The accreditation problem. Annals of the American Academy of Political and Social Science, 301, 65-74.

Relman, A. S. (1978). Americans studying medicine abroad: the distressing facts. New England Journal of Medicine, 299, 887-889.

Roter, D., Lipkin, M., Jr., \& Korsgaard, A. (1991). Sex differences in patients' and physicians' communication during primary care medical visits. Medical Care, 29, 1083-1093.

Roter, D. L. \& Hall, J. A. (1998). Why physician gender matters in shaping the physician-patient relationship. Journal of Women's Health, 7, 1093-1097.

Roter, D. L., Hall, J. A., \& Aoki, Y. (2002). Physician gender effects in medical communication: a meta-analytic review. JAMA, 288, 756-764.

Schirlo, C. \& Heusser, R. (2010). Quality assurance of medical education: a case study from Switzerland. GMS Zeitschrift fur Medizinische Ausbildung, 72, 1-5.

Schray, V. (2005). Assuring quality in higher education: recommendations for improving accreditation (Rep. No. 14). The Secretary of Education's Commission on the Future of Higher Education. Washington DC: US Department of Education. 
Secretary of State for Higher Education, Science and Technology. (2011). Secretary of State for Higher Education, Science and Technology. Retrieved March 1, 2012 from www.seescyt.gov.do/default.aspx

Starr, P. (1982). The social transformation of American medicine. New York, NY: Basic Books.

Stensaker, B., Langfeldt, L., Harvey, L., Huisman, J., \& Westerheijden, D. (2010). An in-depth study on the impact of external quality assurance. Assessment \& Evaluation in Higher Education, 789296667, 1-14.

Tamblyn, R., Abrahamowicz, M., Dauphinee, D., Wenghofer, E., Jacques, A., Klass, D. et al. (2007). Physician scores on a national clinical skills examination as predictors of complaints to medical regulatory authorities. JAMA, 298, 993-1001.

Tamblyn, R., Abrahamowicz, M., Dauphinee, W. D., Hanley, J. A., Norcini, J., Girard, N. et al. (2002). Association between licensure examination scores and practice in primary care. JAMA, 288, 3019-3026.

United States Medical Licensing Examination. (2012). 2012 Bulletin of Information. Retrieved March 1, 2012 from www.usmle.org/pdfs/bulletin/2012bulletin.pdf

van Zanten, M. \& Boulet, J. R. (2008). Medical education in the Caribbean: Variability in medical school programs and performance of students. Academic Medicine, 83, S33-S36.

van Zanten, M. \& Boulet, J. R. (2009). Medical education in the Caribbean: variability in Educational Commission for Foreign Medical Graduate certification rates and United States Medical Licensing Examination attempts. Academic Medicine, 84, S13-S16.

van Zanten, M. \& Boulet, J. R. (2011). Medical education in the Caribbean: a longitudinal study of United States medical licensing examination performance, 2000-2009. Academic Medicine, 86, 231-238.

van Zanten, M., Boulet, J. R., \& Greaves, I. (2012). The importance of medical education accreditation standards. Medical Teacher, 34, 136-45.

van Zanten, M., Boulet, J. R., \& McKinley, D. W. (2003). Correlates of performance of the ECFMG Clinical Skills Assessment: influences of candidate characteristics on performance. Academic Medicine, 78, S72-S74.

van Zanten, M., Boulet, J. R., McKinley, D. W., De Champlain, A., \& Jobe, A. C. (2007). Assessing the communication and interpersonal skills of graduates of international medical schools as part of the United States Medical Licensing Exam (USMLE) Step 2 Clinical Skills (CS) Exam. Academic Medicine, 82, S65-S68.

van Zanten M., McKinley, D., Durante, I., \& Pijano, C. V. (in press). Medical Education Accreditation in Mexico and the Philippines: Impact on Student Outcomes. Medical Education. 
van Zanten, M., Norcini, J. J., Boulet, J. R., \& Simon, F. (2008). Overview of accreditation of undergraduate medical education programmes worldwide. Medical Education, 42, 930937.

van Zanten, M., Parkins, L. M., Karle, H., \& Hallock, J. A. (2009). Accreditation of undergraduate medical education in the Caribbean: Report on the Caribbean Accreditation Authority for Education in Medicine and Other Health Professions (CAAM-HP). Academic Medicine, 84, 771-775.

Viksveen, P. \& Steinsbekk, A. (2011). Undergraduate homeopathy education in Europe and the influence of accreditation. Homeopathy, 100, 253-258.

Volkwein, J.F., Lattuca, L.R., Harper, B.J. \& Domingo, R.J. (2007). Measuring the impact of professional accreditation on student experiences and learning outcomes. Research in Higher Education, 48, 251-282.

Waters, T. M., Lefevre, F. V., \& Budetti, P. P. (2003). Medical school attended as a predictor of medical malpractice claims. Quality and Safety in Health Care, 12, 330-336.

Weinberg, E. \& Bell, A. I. (1978). Performance of United States citizens with foreign medical education on standardized medical examinations. New England Journal of Medicine, 299, 858-862.

Wood, D. L. \& Hahn, M. B. (2009). Accreditation standards of osteopathic and allopathic medical schools: could they affect educational quality? Academic Medicine, 84, 724-728.

World Federation for Medical Education (2003). Basic Medical Education: WFME Global Standards for Quality Improvement. Copenhagen, Denmark: WFME Office, University of Copenhagen.

Yang, E. B. (2002). A study on the content validity and factor validity of accreditation standards for medical schools in Korea. Korean Journal of Medical Education, 14, 85-97. 


\section{APPENDICES}


APPENDIX A

\section{SURVEY INSTRUCTIONS AND CONSENT}




\section{College of Health Professions}

TEMPIE UNIVERSITY*

September 23, 2010

\section{A Survey of Medical Education Accreditation Standards}

Dear Survey Participant:

Thank you very much for agreeing to participate in this survey regarding undergraduate medical education accreditation standards. This study is part of an investigation I am conducting that will inform my dissertation research, leading to a doctoral degree in Health Studies at Temple University in Philadelphia, Pennsylvania. You were chosen to participate in this study because you have expertise in undergraduate medical education quality assurance and accreditation practices within your home country and/or regionally/internationally.

Your responses to this survey will be kept strictly confidential. Please do not provide your name or any other identifying details on the survey or on the return envelope. Results of the survey will be reported only in aggregate, across all participants. Your data will be coded under a random identifier that will not be linked to you personally. Individual responses to the survey will not be identified in any way in reports or subsequent publications.

Instructions for Completing the Survey:

Please read each standard, and then rate the standard based on your expert opinion of the relative importance of the standard in determining and ensuring the quality of undergraduate medical education programs. Please base your ratings only on the appropriateness of the content or meaning of the standard, not on the level of written clarity of the standard or the degree of attainability of the standard.

Please use the following scale to check the column in the accompanying table that is most appropriate for each standard:

(1) Not important

(The standard is not useful for determining quality.)

(2) Important but not essential

(The standard is somewhat useful for determining quality, but is not required.)

(3) Essential

(The standard is very useful for determining quality, and is required.)

(N/R) Not able to rate

(The meaning of the standard is not clear.) 
The standards included in this survey were taken directly or adapted from numerous published documents describing criteria used to accredit undergraduate medical education programs around the world. The organizations that produced these standards include, but are not limited to, the World Federation for Medical Education (WFME), the Liaison Committee on Medical Education (LCME), the Medical Council of India (MCI), the Pakistan Medical and Dental Council (PMDC), the Caribbean Accreditation Authority for Education in Medicine and other Health Professions (CAAM-HP), the Accreditation Commission on Colleges of Medicine (ACCM), the Gulf Cooperation Council Medical Colleges Dean's Committee, the Australian Medical Council (AMC), and the Commission on Osteopathic College Accreditation (COCA).

This research proposal has been reviewed and approved by the Temple University Institutional Review Board (IRB). Please contact the Temple IRB at (215) 707-3390 if you have further questions regarding this approval.

I greatly appreciate your valuable participation. If you have any questions or concerns regarding this survey, please feel free to contact me.

Sincerely,

Marta van Zanten, $\mathrm{PhD}$ (candidate)

Temple University, Department of Public Health

(610) 969-8196

martavz@temple.edu 


\section{Survey Consent}

\section{Request to Participate in a Research Study}

As part of my dissertation research leading to a Ph.D. in Health Studies at Temple University in Philadelphia, Pennsylvania, I will be conducting a preliminary study on international experts' opinions of the relative importance of standards used to evaluate and/or accredit undergraduate medical education programs. Results of this study will be used to inform my research on the impact of accreditation of medical education programs on the quality of physician graduates. This preliminary study will be in the form of a survey.

As an expert in quality assurance and accreditation practices of undergraduate medical education programs, you are invited to participate in this survey.

\section{Nature of the Survey Questions}

You will be asked to provide your expert opinion on the relative importance of standards used by accrediting organizations throughout the world to evaluate and/or accredit medical education programs. Survey questions will be in form of rating exercises. Total time required to participate is expected to be approximately 30 minutes.

\section{Confidentiality}

The data obtained in this study will be kept strictly confidential. Please do not provide your name or any other identifying details on the survey or return envelope. Results of the survey will be reported only in aggregate, across all participants. Your data will be coded under a random identifier that will not be linked to you personally. Your responses will not be identified in any way in the reports or subsequent publications.

\section{Agreement to Participate}

If you agree to participate in this research study, please reply to this email indicating your agreement to participate, and I will send you the survey. Your indication of willingness to participate will indicate consent and agreement with confidentiality procedures.

\section{University Institutional Review Board (IRB) Approval}

This research proposal has been reviewed and approved by the Temple University Institutional Review Board (IRB). Please contact the Temple IRB if you have further questions regarding this approval at (215) 707-3390.

\section{Voluntary Participation \& Early Withdrawal}

Your participation in the study is voluntary. If you decide to participate, you are free to withdraw from the study at any time.

Please feel free to contact me, or my advisor at Temple University, Dr. Ian Greaves (igreaves@temple.edu) if you have further questions regarding this study.

I would greatly appreciate your valuable assistance with this project! 
Sincerely,

Marta van Zanten, PhD (candidate)

Temple University, Department of Public Health

(610) 969-8196

martavz@temple.edu 
APPENDIX B SURVEY 
(1) Not important

(2) Important but not essential

(3) Essential

(N/R) Not able to rate

\begin{tabular}{|c|c|c|c|c|c|}
\hline & \multirow{2}{*}{ Standard } & \multicolumn{4}{|c|}{ Rating } \\
\hline & & 1 & 2 & 3 & $\mathbf{N} / \mathbf{R}$ \\
\hline 1. & The medical school defines its mission and objectives and makes them known to its constituency. & & & & \\
\hline 2. & $\begin{array}{l}\text { The mission and objectives encompasses social responsibility, research attainment, community } \\
\text { involvement, and address readiness for postgraduate medical training. }\end{array}$ & & & & \\
\hline 3. & $\begin{array}{l}\text { The mission statement and objectives of a medical school are defined by its principal } \\
\text { stakeholders (dean, faculty board/council, university, government authorities, the profession). }\end{array}$ & & & & \\
\hline 4. & $\begin{array}{l}\text { Formulation of mission statements and objectives are based on input from a wider range of } \\
\text { stakeholders (academic staff, students, the community, education and healthcare authorities, } \\
\text { professional organizations, postgraduate educators). }\end{array}$ & & & & \\
\hline 5. & $\begin{array}{l}\text { There is an implemented policy, for which the administration and faculty/academic staff of the } \\
\text { medical school are responsible, within which they have freedom to design the curriculum and } \\
\text { allocate the resources necessary for its delivery. }\end{array}$ & & & & \\
\hline 6. & The contributions of all academic staff address the actual curriculum. & & & & \\
\hline 7. & The educational resources are distributed in relation to the educational needs. & & & & \\
\hline 8. & $\begin{array}{l}\text { The medical school defines the competencies that students should exhibit on graduation in } \\
\text { relation to their subsequent training and future roles in the health system. }\end{array}$ & & & & \\
\hline 9. & $\begin{array}{l}\text { The linkage of competencies to be acquired by graduation with that to be acquired in } \\
\text { postgraduate training is specified. }\end{array}$ & & & & \\
\hline 10. & $\begin{array}{l}\text { Measures of, and information about, competencies of the graduates is used as feedback to } \\
\text { program development. }\end{array}$ & & & & \\
\hline 11. & The medical school defines the curriculum models and instructional methods employed. & & & & \\
\hline
\end{tabular}




\begin{tabular}{|c|c|c|c|c|c|}
\hline & \multirow{2}{*}{ Standard } & \multicolumn{4}{|c|}{ Rating } \\
\hline & & 1 & 2 & 3 & $\mathbf{N} / \mathbf{R}$ \\
\hline 12. & $\begin{array}{l}\text { The curriculum and instructional methods ensure that students have responsibility for their } \\
\text { learning process and are prepared for lifelong, self-directed learning. }\end{array}$ & & & & \\
\hline 13. & $\begin{array}{l}\text { The medical school teaches the principles of scientific method and evidence-based medicine, } \\
\text { including analytical and critical thinking, throughout the curriculum. }\end{array}$ & & & & \\
\hline 14. & $\begin{array}{l}\text { The curriculum includes elements for training students in scientific thinking and research } \\
\text { methods. }\end{array}$ & & & & \\
\hline 15. & $\begin{array}{l}\text { The medical school identifies and incorporates in the curriculum the contributions of the basic } \\
\text { biomedical sciences to create understanding of the scientific knowledge, concepts and methods } \\
\text { fundamental to acquiring and applying clinical science. }\end{array}$ & & & & \\
\hline 16. & $\begin{array}{l}\text { The contributions in the curriculum of the biomedical sciences are adapted to the scientific, } \\
\text { technological and clinical developments as well as to the health needs of society. }\end{array}$ & & & & \\
\hline 17. & $\begin{array}{l}\text { Instruction within the basic sciences includes laboratory or other practical exercises that facilitate } \\
\text { the ability to make accurate quantitative observations of biomedical phenomena and critical } \\
\text { analysis of data. }\end{array}$ & & & & \\
\hline 18. & $\begin{array}{l}\text { The medical school identifies and incorporates in the curriculum the contributions of the } \\
\text { behavioral sciences, social sciences, medical ethics and medical jurisprudence that enable } \\
\text { effective communication, clinical decision making and ethical practices. }\end{array}$ & & & & \\
\hline 19. & $\begin{array}{l}\text { The contributions of the behavioral and social sciences and medical ethics are adapted to } \\
\text { scientific developments in medicine, to changing demographic and cultural contexts and to health } \\
\text { needs of society. }\end{array}$ & & & & \\
\hline 20. & $\begin{array}{l}\text { Medical students learn to recognize and appropriately address gender and cultural biases in } \\
\text { themselves and others, and in the process of health care delivery. }\end{array}$ & & & & \\
\hline 21. & $\begin{array}{l}\text { The medical school ensures that the learning environment for medical students promotes the } \\
\text { development of explicit and appropriate professional attributes (attitudes, behaviors, and identity) } \\
\text { in their medical students. }\end{array}$ & & & & \\
\hline 22. & $\begin{array}{l}\text { The medical school ensures that students have patient contact and acquire sufficient clinical } \\
\text { knowledge and skills to assume appropriate clinical responsibility upon graduation. }\end{array}$ & & & & \\
\hline 23. & Every student has early patient contact leading to participation in patient care. & & & & \\
\hline
\end{tabular}




\begin{tabular}{|c|c|c|c|c|c|}
\hline & \multirow{2}{*}{ Standard } & \multicolumn{4}{|c|}{ Rating } \\
\hline & & 1 & 2 & 3 & $\mathbf{N} / \mathbf{R}$ \\
\hline 24. & $\begin{array}{l}\text { There is a system with central oversight to assure that the faculty define the types of patients and } \\
\text { clinical conditions that students must encounter, the appropriate clinical setting for the } \\
\text { educational experiences, and the expected level of student responsibility. }\end{array}$ & & & & \\
\hline 25. & Students' clinical experiences utilize both outpatient and inpatient settings. & & & & \\
\hline 26. & $\begin{array}{l}\text { Supervision of student learning experiences is provided throughout required clerkships by } \\
\text { members of the medical school's faculty. }\end{array}$ & & & & \\
\hline 27. & $\begin{array}{l}\text { Students are exposed to common medical problems of a more transient nature that are not seen in } \\
\text { the hospital setting. }\end{array}$ & & & & \\
\hline 28. & $\begin{array}{l}\text { Students experience the effect of the family and the community environment on symptom } \\
\text { expression and therapeutic responses. }\end{array}$ & & & & \\
\hline 29. & $\begin{array}{l}\text { There are written and signed affiliation agreements between the medical school and its clinical } \\
\text { affiliates that define, at a minimum, the responsibilities of each party related to the educational } \\
\text { program for medical students. }\end{array}$ & & & & \\
\hline 30. & $\begin{array}{l}\text { In the relationship between the medical school and its clinical affiliates, the educational program } \\
\text { for medical students remains under the control of the school's faculty. }\end{array}$ & & & & \\
\hline 31. & $\begin{array}{l}\text { The medical school describes the content, extent and sequencing of courses and other curricular } \\
\text { elements, including the balance between the core and optional content, and the role of health } \\
\text { promotion, preventive medicine and rehabilitation in the curriculum, as well as the interface with } \\
\text { unorthodox, traditional or alternative practices. }\end{array}$ & & & & \\
\hline 32. & Basic sciences and clinical sciences are integrated in the curriculum. & & & & \\
\hline 33. & $\begin{array}{l}\text { There are comparable educational experiences and equivalent methods of evaluation across all } \\
\text { alternative instructional sites within a given discipline. }\end{array}$ & & & & \\
\hline 34. & $\begin{array}{l}\text { Educational opportunities are available in multidisciplinary content areas, such as emergency } \\
\text { medicine and geriatrics, and in the disciplines that support general medical practice, such as } \\
\text { diagnostic imaging and clinical pathology. }\end{array}$ & & & & \\
\hline 35. & $\begin{array}{l}\text { The medical school makes available sufficient opportunities for medical students to participate in } \\
\text { service-learning activities, and encourage and support student participation. }\end{array}$ & & & & \\
\hline
\end{tabular}




\begin{tabular}{|c|c|c|c|c|c|}
\hline & \multirow{2}{*}{ Standard } & \multicolumn{4}{|c|}{ Rating } \\
\hline & & 1 & 2 & 3 & $\mathbf{N} / \mathbf{R}$ \\
\hline 36. & $\begin{array}{l}\text { The medical school has primary health centers/rural health training centers for training of } \\
\text { students in education for the rural community. }\end{array}$ & & & & \\
\hline 37. & $\begin{array}{l}\text { The medical school recognizes the unique challenges faced by the Indigenous health sector and } \\
\text { has effective partnerships with relevant local communities, organizations and individuals. }\end{array}$ & & & & \\
\hline 38. & $\begin{array}{l}\text { The curriculum committee is given the responsibility and authority for planning and } \\
\text { implementing the curriculum to secure the objectives of the medical school. }\end{array}$ & & & & \\
\hline 39. & $\begin{array}{l}\text { The curriculum committee is provided with resources for planning and implementing methods of } \\
\text { teaching and learning, student assessment, course evaluation, and innovations in the curriculum. }\end{array}$ & & & & \\
\hline 40. & There is representation on the curriculum committee of staff, students and other stakeholders. & & & & \\
\hline 41. & $\begin{array}{l}\text { The medical school collaborates with other educational institutions and compares its curriculum } \\
\text { with other programs. }\end{array}$ & & & & \\
\hline 42. & $\begin{array}{l}\text { Operational linkage is assured between the educational program and the subsequent stage of } \\
\text { training or practice that the student will enter after graduation. }\end{array}$ & & & & \\
\hline 43. & $\begin{array}{l}\text { The curriculum committee seeks input from the environment in which graduates will be expected } \\
\text { to work. }\end{array}$ & & & & \\
\hline 44. & $\begin{array}{l}\text { The curriculum committee undertakes program modification in response to feedback from the } \\
\text { community and society. }\end{array}$ & & & & \\
\hline 45. & $\begin{array}{l}\text { The medical school defines and states the methods used for assessment of its students, including } \\
\text { the criteria for passing examinations. }\end{array}$ & & & & \\
\hline 46. & $\begin{array}{l}\text { The reliability and validity of assessment methods is documented and evaluated and new } \\
\text { assessment methods developed. }\end{array}$ & & & & \\
\hline 47. & $\begin{array}{l}\text { Assessment principles, methods and practices are clearly compatible with educational objectives } \\
\text { and promote learning. }\end{array}$ & & & & \\
\hline 48. & $\begin{array}{l}\text { The number and nature of examinations are adjusted by integrating assessments of various } \\
\text { curricular elements to encourage integrated learning. }\end{array}$ & & & & \\
\hline 49. & $\begin{array}{l}\text { The need to learn excessive amounts of information is reduced and curriculum overload } \\
\text { prevented. }\end{array}$ & & & & \\
\hline 50. & $\begin{array}{l}\text { There is ongoing assessment that assures students have acquired and can demonstrate on direct } \\
\text { observation the core clinical skills, behaviors, and attitudes that have been specified in the } \\
\text { school's educational objectives. }\end{array}$ & & & & \\
\hline
\end{tabular}




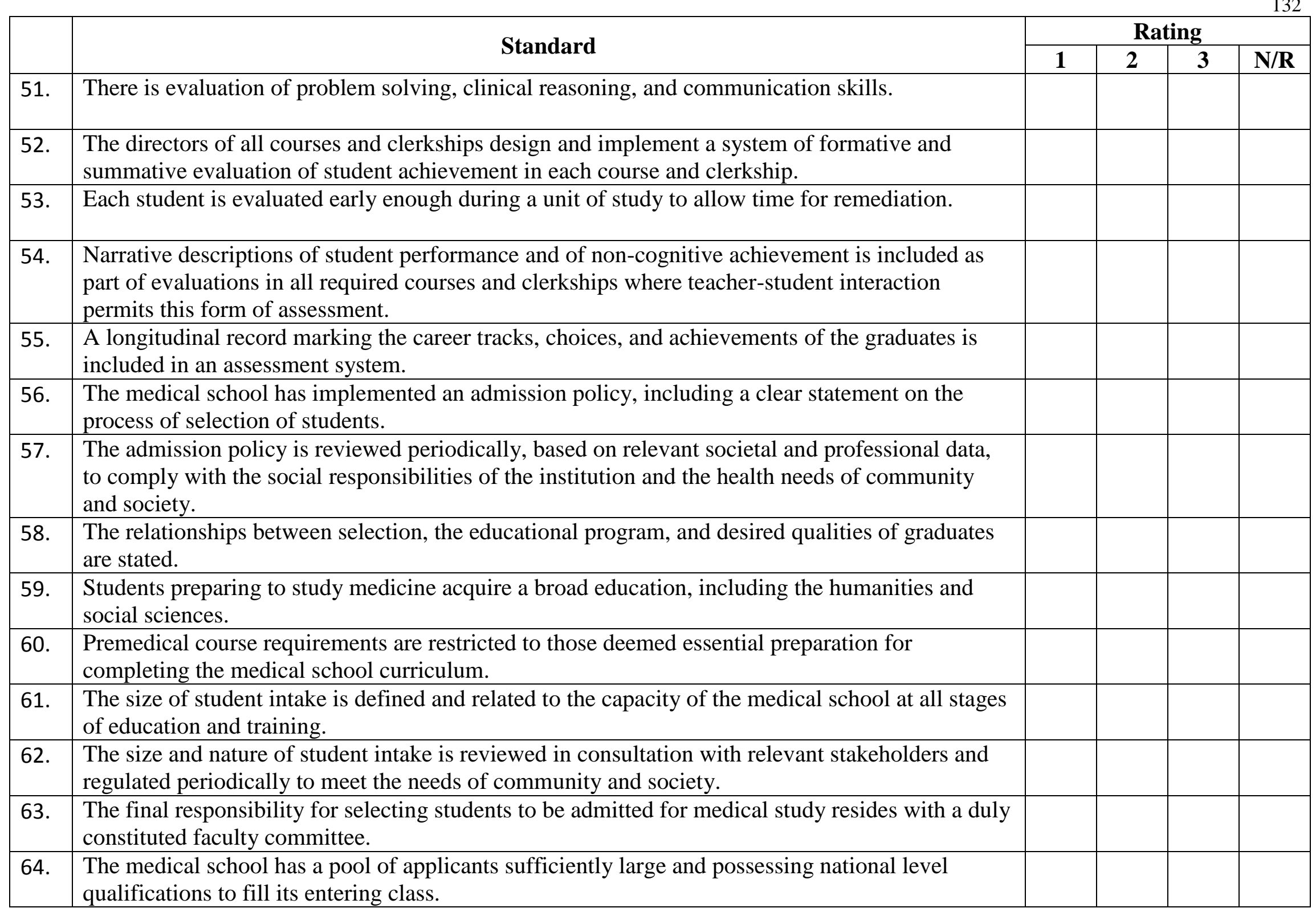




\begin{tabular}{|c|c|c|c|c|c|}
\hline & \multirow{2}{*}{ Standard } & \multicolumn{4}{|c|}{ Rating } \\
\hline & & 1 & 2 & 3 & $\mathbf{N} / \mathbf{R}$ \\
\hline 65. & $\begin{array}{l}\text { The medical school selects students who possess the intelligence, integrity, and personal and } \\
\text { emotional characteristics necessary for them to become effective physicians. }\end{array}$ & & & & \\
\hline 66. & The selection of individual students is not influenced by any political or financial factors. & & & & \\
\hline 67. & $\begin{array}{l}\text { The medical school develops and publishes technical standards for admission of handicapped } \\
\text { applicants, in accordance with legal requirements. }\end{array}$ & & & & \\
\hline 68. & $\begin{array}{l}\text { The medical school has policies and practices to achieve appropriate diversity among its students, } \\
\text { faculty, staff, and other members of its academic community, and engages in ongoing, } \\
\text { systematic, and focused efforts to attract and retain students, faculty, staff, and others from } \\
\text { demographically diverse backgrounds. }\end{array}$ & & & & \\
\hline 69. & $\begin{array}{l}\text { The medical school develops programs or partnerships aimed at broadening diversity among } \\
\text { qualified applicants for medical school admissions. }\end{array}$ & & & & \\
\hline 70. & A program of student support, including counseling, is offered by the medical school. & & & & \\
\hline 71. & $\begin{array}{l}\text { Counseling is provided based on monitoring of student progress, and addresses social and } \\
\text { personal needs of students. }\end{array}$ & & & & \\
\hline 72. & The process of applying for residency programs does not disrupt the general medical education. & & & & \\
\hline 73. & Letters of reference or other credentials are not provided until the student's final year. & & & & \\
\hline 74. & $\begin{array}{l}\text { The medical school has mechanisms in place to minimize the impact of direct educational } \\
\text { expenses on student indebtedness. }\end{array}$ & & & & \\
\hline 75. & $\begin{array}{l}\text { The medical school has clear and equitable policies for the refund of tuition, fees, and other } \\
\text { allowable payments. }\end{array}$ & & & & \\
\hline 76. & $\begin{array}{l}\text { Health insurance is available to all students and their dependents, and all students have access to } \\
\text { disability insurance. }\end{array}$ & & & & \\
\hline 77. & $\begin{array}{l}\text { The medical school follows accepted guidelines in determining appropriate immunizations for } \\
\text { medical students. }\end{array}$ & & & & \\
\hline 78. & $\begin{array}{l}\text { The medical school has policies addressing student exposure to infectious and environmental } \\
\text { hazards. }\end{array}$ & & & & \\
\hline
\end{tabular}




\begin{tabular}{|c|c|c|c|c|c|}
\hline & \multirow{2}{*}{ Standard } & \multicolumn{4}{|c|}{ Rating } \\
\hline & & 1 & 2 & 3 & $\mathbf{N} / \mathbf{R}$ \\
\hline 79. & $\begin{array}{l}\text { In the admissions process and throughout medical school, there is no discrimination on the basis } \\
\text { of gender, sexual orientation, age, race, creed, or national origin. }\end{array}$ & & & & \\
\hline 80. & $\begin{array}{l}\text { There is a fair and formal process for taking any action that adversely affects the status of a } \\
\text { student. }\end{array}$ & & & & \\
\hline 81. & $\begin{array}{l}\text { Student records are confidential and available only to members of the faculty and administration } \\
\text { with a need to know, unless released by the student or as otherwise governed by laws concerning } \\
\text { confidentiality. }\end{array}$ & & & & \\
\hline 82. & Students are allowed to review and challenge their records. & & & & \\
\hline 83. & The medical school has adequately indemnified students for relevant activities. & & & & \\
\hline 84. & $\begin{array}{l}\text { The medical school has an implemented policy on student representation and appropriate } \\
\text { participation in the design, management and evaluation of the curriculum, and in other matters } \\
\text { relevant to students. }\end{array}$ & & & & \\
\hline 85. & Student activities and student organizations are encouraged and facilitated. & & & & \\
\hline 86. & $\begin{array}{l}\text { The medical school has a staff recruitment policy which outlines the type, responsibilities and } \\
\text { balance of academic staff required to deliver the curriculum adequately, including the balance } \\
\text { between medical and non-medical academic staff, and between full-time and part-time staff, the } \\
\text { responsibilities of which are explicitly specified and monitored. }\end{array}$ & & & & \\
\hline 87. & $\begin{array}{l}\text { There is an implemented policy for staff selection criteria, including scientific, educational and } \\
\text { clinical merit, relationship to the mission of the institution, economic considerations and issues of } \\
\text { local significance. }\end{array}$ & & & & \\
\hline 88. & $\begin{array}{l}\text { The medical school has an implemented staff policy which addresses a balance of capacity for } \\
\text { teaching, research and service functions, and ensures recognition of meritorious academic } \\
\text { activities, with appropriate emphasis on both research attainment and teaching qualifications. }\end{array}$ & & & & \\
\hline 89. & The staff policy includes teacher training and development and teacher appraisal. & & & & \\
\hline
\end{tabular}




\begin{tabular}{|c|c|c|c|c|c|}
\hline & \multirow{2}{*}{ Standard } & \multicolumn{4}{|c|}{ Rating } \\
\hline & & 1 & 2 & 3 & $\mathbf{N} / \mathbf{R}$ \\
\hline 90. & $\begin{array}{l}\text { Residents who supervise or teach medical students, as well as graduate students and postdoctoral } \\
\text { fellows in the biomedical sciences who serve as teachers or teaching assistants, are familiar with } \\
\text { the educational objectives of the course or clerkship and are prepared for their roles in teaching } \\
\text { and evaluation. }\end{array}$ & & & & \\
\hline 91. & $\begin{array}{l}\text { The medical school defines and publicizes the standards of conduct for the teacher-learner } \\
\text { relationship, and develops written policies for addressing violations of those standards. }\end{array}$ & & & & \\
\hline 92. & $\begin{array}{l}\text { The medical school faculty makes decisions regarding student admissions, promotion, and } \\
\text { graduation. }\end{array}$ & & & & \\
\hline 93. & $\begin{array}{l}\text { The medical school has policies that deal with circumstances in which the private interests of } \\
\text { faculty members or staff may be in conflict with their official responsibilities. }\end{array}$ & & & & \\
\hline 94. & $\begin{array}{l}\text { Faculty members receive written information about their terms of appointment, responsibilities, } \\
\text { lines of communication, privileges and benefits, and, if relevant, the policy on practice earnings. }\end{array}$ & & & & \\
\hline 95. & The dean and a committee of the faculty determine medical school policies. & & & & \\
\hline 96. & $\begin{array}{l}\text { The full faculty meets often enough for all faculty members to have the opportunity to participate } \\
\text { in the discussion and establishment of medical school policies and practices. }\end{array}$ & & & & \\
\hline 97. & $\begin{array}{l}\text { The medical school has arrangements for indemnification of teaching staff, with regard to their } \\
\text { involvement in clinical research and the delivery of the teaching program. }\end{array}$ & & & & \\
\hline 98. & $\begin{array}{l}\text { The medical school has sufficient physical facilities for the staff and the student population to } \\
\text { ensure that the curriculum can be delivered adequately. }\end{array}$ & & & & \\
\hline 99. & $\begin{array}{l}\text { The learning environment for the students is improved by regular updating and extension of the } \\
\text { facilities to match developments in educational practices. }\end{array}$ & & & & \\
\hline 100. & $\begin{array}{l}\text { The medical school has access to a well-maintained library and information facilities, sufficient } \\
\text { in size, breadth of holdings, and information technology to support its education and other } \\
\text { missions. }\end{array}$ & & & & \\
\hline 101. & Appropriate security systems are in place at all educational sites. & & & & \\
\hline 102. & $\begin{array}{l}\text { The medical school has dormitory/hostel provision for at least } 75 \% \text { of the total intake of students } \\
\text { at a given time. }\end{array}$ & & & & \\
\hline
\end{tabular}




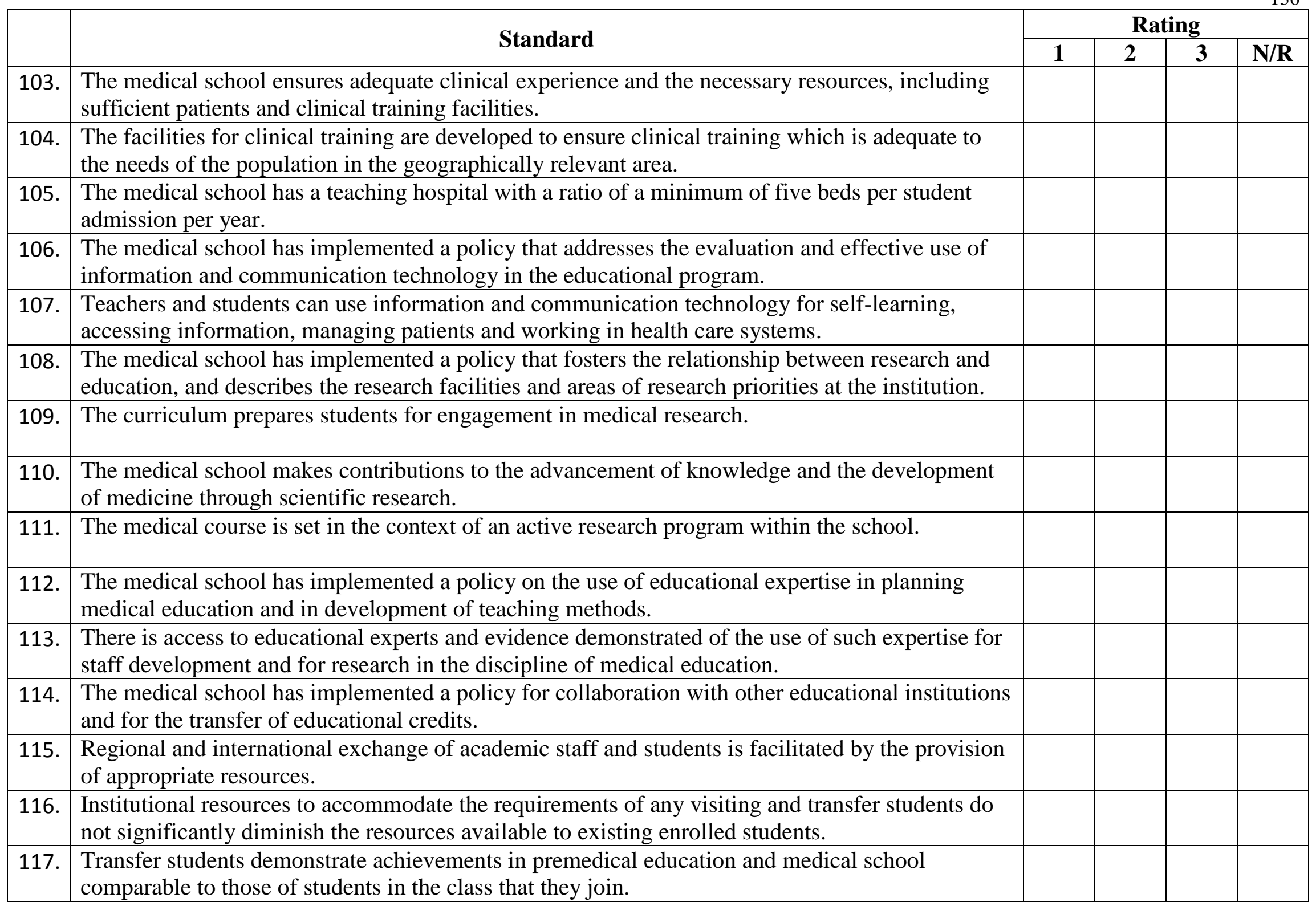




\begin{tabular}{|c|c|c|c|c|c|}
\hline & \multirow{2}{*}{ Standard } & \multicolumn{4}{|c|}{ Rating } \\
\hline & & 1 & 2 & 3 & $\mathbf{N} / \mathbf{R}$ \\
\hline 118. & $\begin{array}{l}\text { Prior coursework taken by students who are accepted for transfer or admission to advanced } \\
\text { standing is compatible with the program to be entered. }\end{array}$ & & & & \\
\hline 119. & $\begin{array}{l}\text { Transfer students are not accepted into the final year of the program except under rare } \\
\text { circumstances. }\end{array}$ & & & & \\
\hline 120. & $\begin{array}{l}\text { The accepting school verifies the credentials of visiting students, formally registers and maintains } \\
\text { a complete roster of such students, approves their assignments, and provides evaluations to their } \\
\text { parent schools. }\end{array}$ & & & & \\
\hline 121. & $\begin{array}{l}\text { Students visiting from other schools for clinical clerkships and electives possess qualifications } \\
\text { equivalent to students they will join in these experiences. }\end{array}$ & & & & \\
\hline 122. & $\begin{array}{l}\text { If students are permitted to take electives at other institutions, there is a system centralized in the } \\
\text { dean's office to review students' proposed extramural programs prior to approval and to ensure } \\
\text { the return of a performance appraisal by the host program. }\end{array}$ & & & & \\
\hline 123. & $\begin{array}{l}\text { The medical school establishes a mechanism for program evaluation that monitors the curriculum } \\
\text { and student progress, and ensures that concerns are identified and addressed. }\end{array}$ & & & & \\
\hline 124. & $\begin{array}{l}\text { Program evaluation addresses the context of the educational process, the specific components of } \\
\text { the curriculum and the general outcome. }\end{array}$ & & & & \\
\hline 125. & Both teacher and student feedback is systematically sought, analyzed and responded to. & & & & \\
\hline 126. & $\begin{array}{l}\text { Teachers and students are actively involved in planning program evaluation and in using its } \\
\text { results for program development. }\end{array}$ & & & & \\
\hline 127. & $\begin{array}{l}\text { Student performance is analyzed in relation to the curriculum and the mission and objectives of } \\
\text { the medical school. }\end{array}$ & & & & \\
\hline 128. & $\begin{array}{l}\text { Student performance is analyzed in relation to student background, conditions and entrance } \\
\text { qualifications, and is used to provide feedback to the committees responsible for student } \\
\text { selection, curriculum planning and student counseling. }\end{array}$ & & & & \\
\hline 129. & $\begin{array}{l}\text { Program evaluation involves the governance and administration of the medical school, the } \\
\text { academic staff and the students. }\end{array}$ & & & & \\
\hline 130. & $\begin{array}{l}\text { A wide range of stakeholders have access to results of course and program evaluations, and their } \\
\text { views on the relevance and development of the curriculum are considered (stakeholders include } \\
\text { the community, education and healthcare authorities, professional organizations, postgraduate } \\
\text { educators.) }\end{array}$ & & & & \\
\hline
\end{tabular}




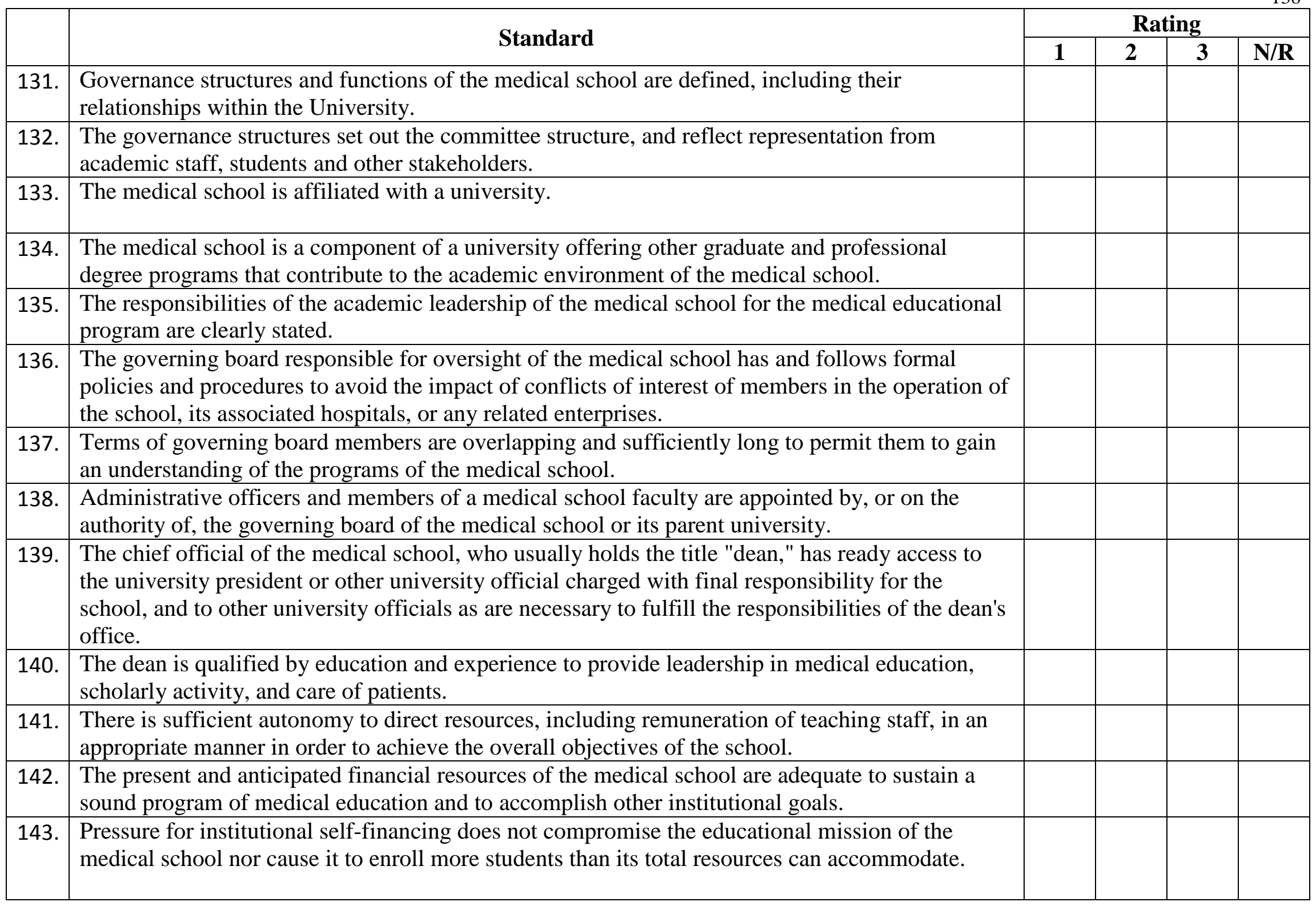




\begin{tabular}{|c|c|c|c|c|c|}
\hline & \multirow{2}{*}{ Standard } & \multicolumn{4}{|c|}{ Rating } \\
\hline & & 1 & 2 & 3 & $\mathbf{N} / \mathbf{R}$ \\
\hline 144. & $\begin{array}{l}\text { The administrative staff of the medical school is appropriate to support the implementation of the } \\
\text { school's educational program and other activities and to ensure good management and } \\
\text { deployment of its resources. }\end{array}$ & & & & \\
\hline 145. & $\begin{array}{l}\text { The management includes a program of quality assurance and the management submits itself to } \\
\text { regular review. }\end{array}$ & & & & \\
\hline 146. & $\begin{array}{l}\text { The medical school has a constructive interaction with the health and health-related sectors of } \\
\text { society and government. }\end{array}$ & & & & \\
\hline 147. & Collaborations with partners of the health sector are formalized. & & & & \\
\hline 148. & $\begin{array}{l}\text { The medical school as a dynamic institution initiates procedures for regular reviewing and } \\
\text { updating of its structure and functions and rectifies documented deficiencies. }\end{array}$ & & & & \\
\hline 149. & $\begin{array}{l}\text { The process of renewal is based on prospective studies and analyses and leads to the revisions of } \\
\text { the policies and practices of the medical school in accordance with past experience, present } \\
\text { activities and future perspectives. }\end{array}$ & & & & \\
\hline 150. & $\begin{array}{l}\text { The medical school recognizes the need for continuing medical and health education for health } \\
\text { professionals and the community. Regular symposiums, workshops and conferences are } \\
\text { organized to fill this need. }\end{array}$ & & & & \\
\hline
\end{tabular}

Please list on a separate page any additional essential standards that are not included in this survey but which you believe are important to the quality of Undergraduate Medical Education.

Thank you for your response!

Please return the completed survey in the enclosed envelope. 
APPENDIX C

ESSENTIAL STANDARDS USED BY ACCREDITING AGENCIES 
Table 8: Essential Standards Used by Accrediting Agencies

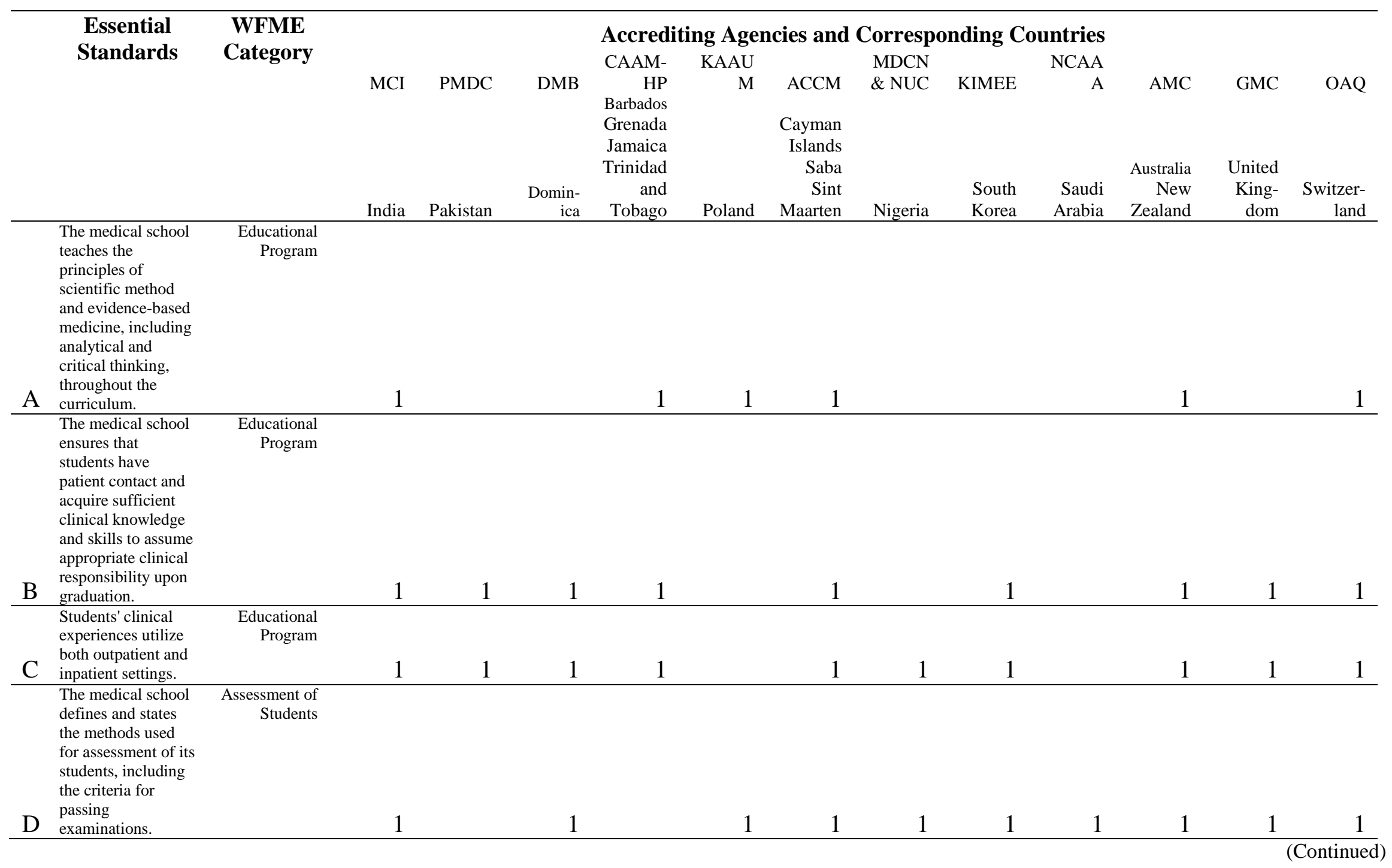


Table 8. (Continued)

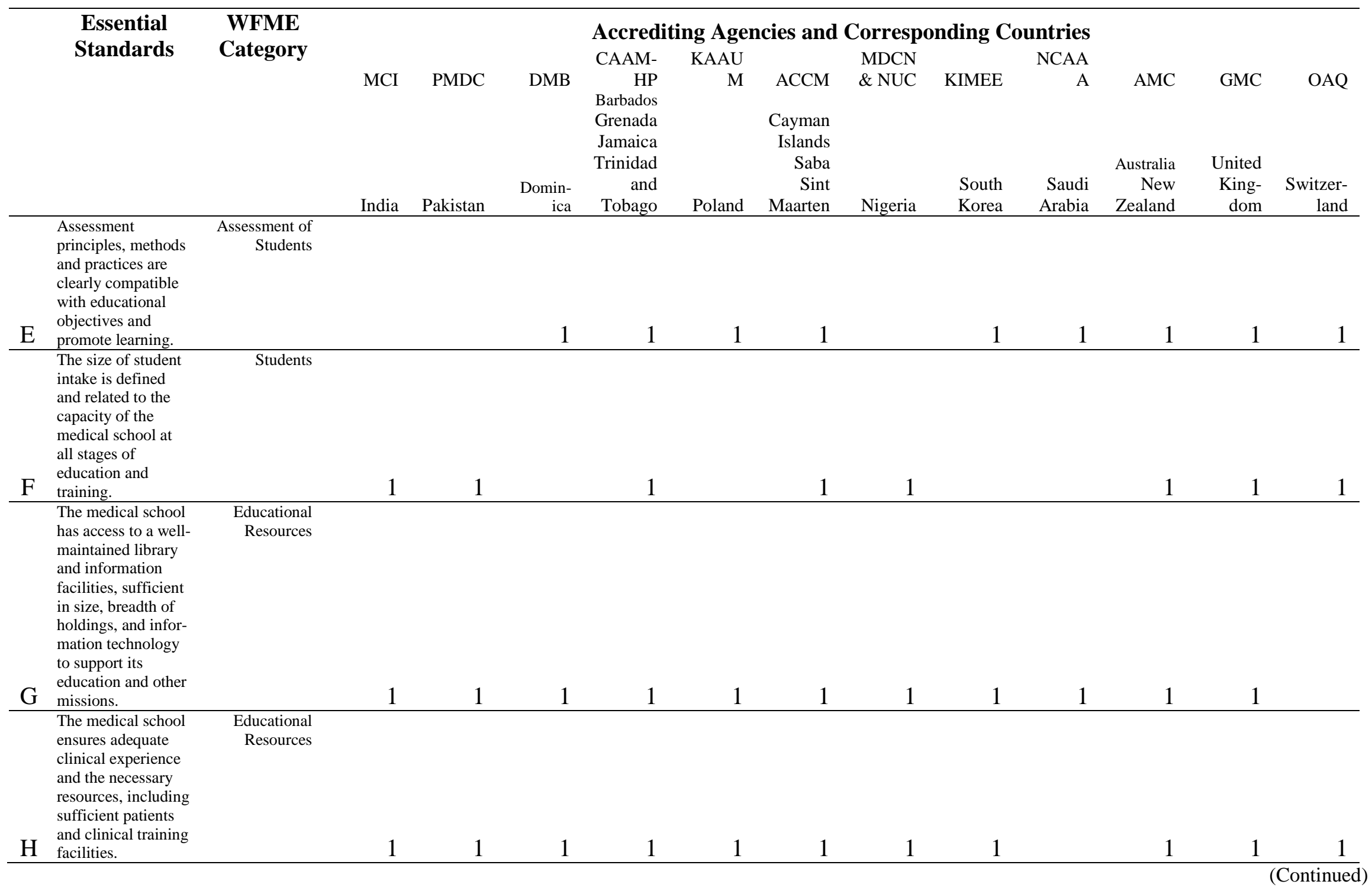


Table 8. (Continued)

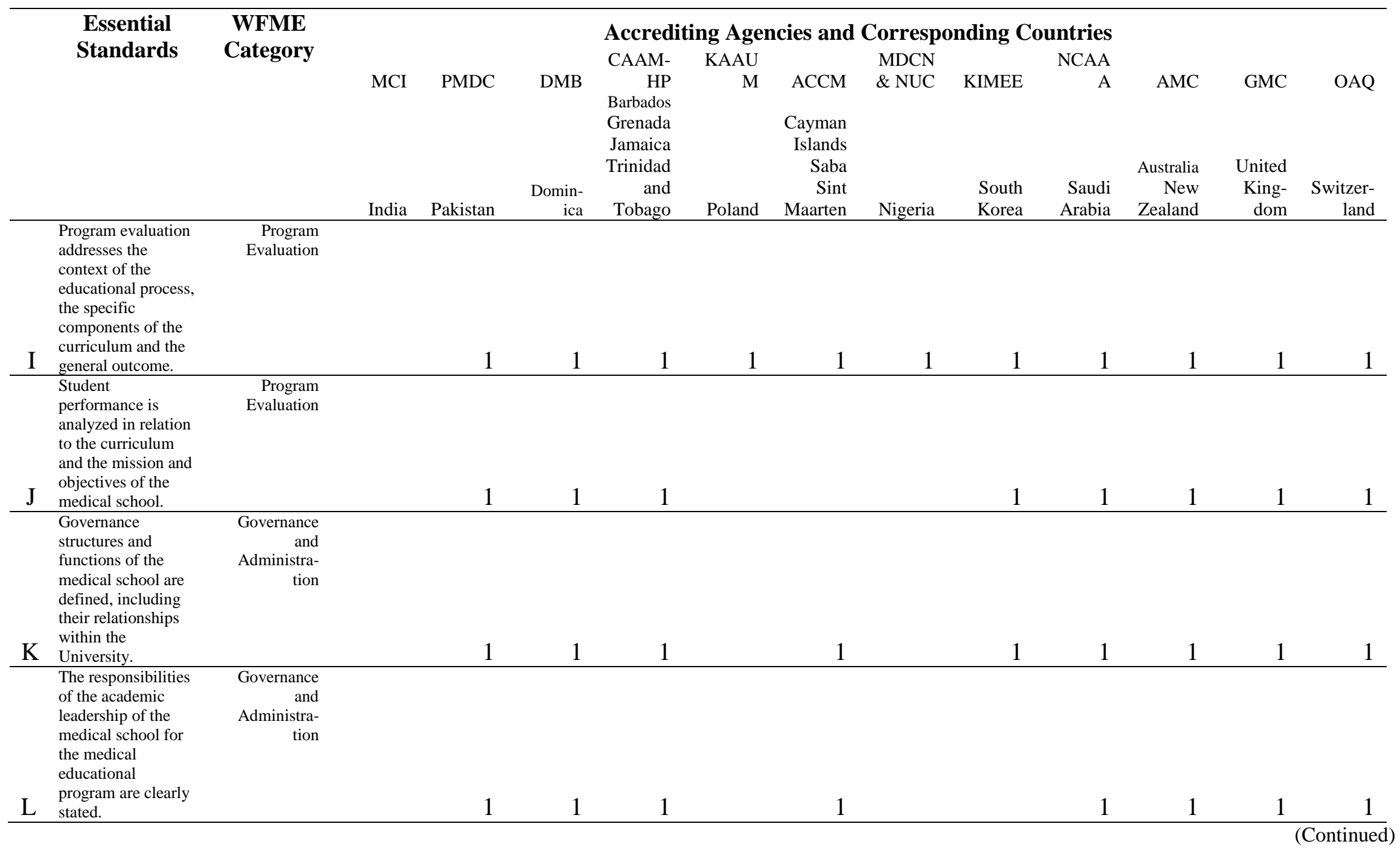


Table 8. (Continued)

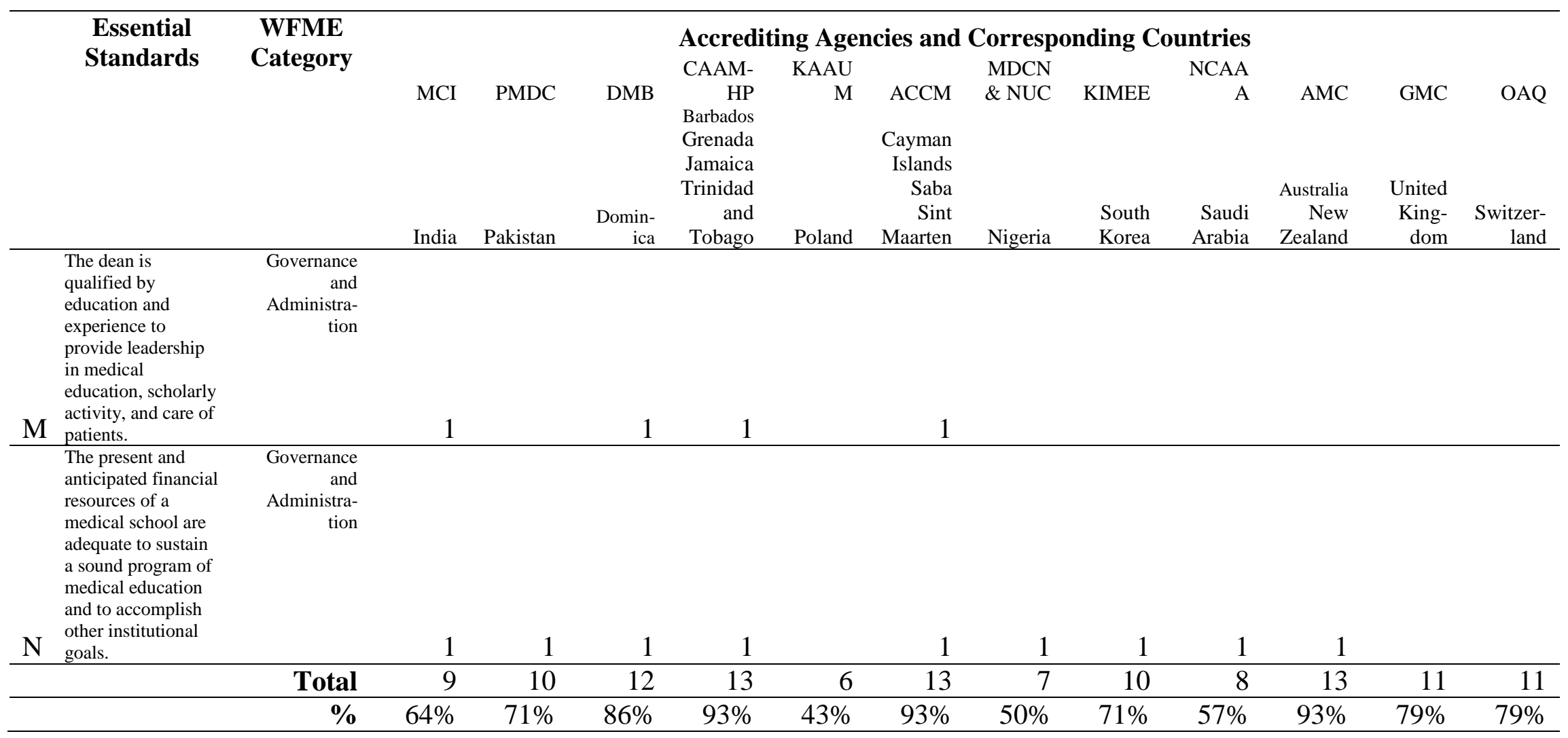

MCI: Medical and Dental Council

PMDC: Pakistan Medical and Dental Council

DMB: Dominican Medial Board

CAAM-HP: Caribbean Accreditation Authority for Education in Medicine and Other Health Professions

KAAUM: Accreditation Committee for Polish University Medical Schools

ACCM: Accreditation Commission on Colleges of Medicine

MDCN \& NUC: Medical and Dental Council of Nigeria \& National Universities Commission

KIMEE: Korean Institute of Medical Education and Evaluation 
NCAAA: National Commission for Academic Accreditation and Assessment

AMC: Australian Medical Council

GMC: General Medical Council

OAQ: Center of Accreditation and Quality Assurance of the Swiss Universities 